\title{
Numerical simulation of a load-based microindentation technique for nde on thermal barrier coating systems
}

Kwangsoon Lee

West Virginia University

Follow this and additional works at: https://researchrepository.wvu.edu/etd

\section{Recommended Citation}

Lee, Kwangsoon, "Numerical simulation of a load-based microindentation technique for nde on thermal barrier coating systems" (2011). Graduate Theses, Dissertations, and Problem Reports. 3075.

https://researchrepository.wvu.edu/etd/3075

This Dissertation is protected by copyright and/or related rights. It has been brought to you by the The Research Repository @ WVU with permission from the rights-holder(s). You are free to use this Dissertation in any way that is permitted by the copyright and related rights legislation that applies to your use. For other uses you must obtain permission from the rights-holder(s) directly, unless additional rights are indicated by a Creative Commons license in the record and/ or on the work itself. This Dissertation has been accepted for inclusion in WVU Graduate Theses, Dissertations, and Problem Reports collection by an authorized administrator of The Research Repository @ WVU.

For more information, please contact researchrepository@mail.wvu.edu. 


\title{
NUMERICAL SIMULATION OF A LOAD-BASED MICRO- INDENTATION TECHNIQUE FOR NDE ON THERMAL BARRIER COATING SYSTEMS
}

\author{
Kwangsoon Lee \\ Dissertation submitted to the \\ College of Engineering and Mineral Resources at West Virginia University \\ in partial fulfillment of the requirements for the degree of \\ Doctor of Philosophy \\ in \\ Mechanical Engineering \\ Bruce S. Kang, Ph. D., Chair \\ Jacky C. Prucz, Ph. D. \\ Victor H. Mucino, Ph. D. \\ Nick Wu, Ph. D. \\ Hota V. Gangarao, Ph. D.
}

Department of Mechanical and Aerospace Engineering

Morgantown, West Virginia

2011 


\title{
Abstract \\ NUMERICAL SIMULATION OF A LOAD-BASED MICRO-INDENTATION TECHNIQUE FOR NDE ON THERMAL BARRIER COATING SYSTEMS
}

\author{
Kwangsoon Lee
}

The durability and life-cycle of thermal barrier coatings (TBC) applied to gas turbine blades and combustor components limits the maximum temperature and subsequent efficiency at which gas turbine engines operate. The development of new materials, coating technologies and evaluation techniques is required if enhanced efficiency is to be achieved. Of the current ceramic materials used in turbines, Yttria stabilized zirconia (YSZ) is widely used for TBCs are most prevalent, due to its low thermal conductivity, high thermal expansion coefficient and superior mechanical strength. However, thermally grown oxide (TGO) and thermal expansion coefficient mismatch are the major causes of large residual stress and will cause interfacial rumpling instability leading to large scale spallation failure. Through finite element simulations, it is shown that the residual stresses generated within the thermally grown oxide (TGO), bond coat (BC), YSZ and their interfaces create slight variations in indentation unloading surface stiffness response prior to spallation failure.

In this research, a load-based micro-indentation method for NDE of TBCs exposed to thermal loads is investigated. The surface stiffness response is measured to assess damage accumulation and identify macroscopic debonding failure sites. Finite element analyses indicate that high YSZ/BC interfacial rumpling leads to the development of both in-plane and out-of-plane residual stresses upon cooling. Additional rumpling of this interface as a result of non-uniform TGO growth leads to enhanced residual stresses. Finite element analyses of YSZ/TGO/BC interfacial stresses generated upon cooling provide an explanation for the experimentally observed micro-cracking and failure patterns. The associated coating degradation is evaluated using a non-destructive load based multiple partial unloading micro-indentation procedure. The results show that the proposed micro-indentation evaluation technique can be an effective and specimen independent TBC-failure-prediction tool capable of determining the location of initial spallation failure prior to its actual occurrence. 


\section{TABLE OF CONTENTS}

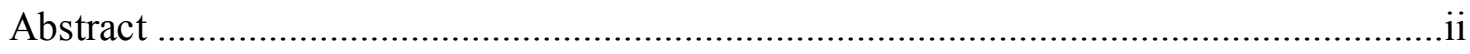

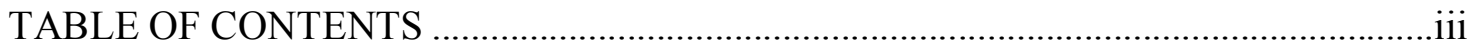

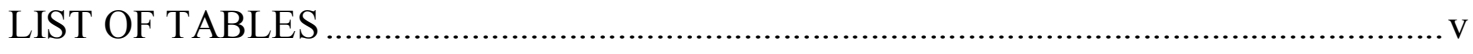

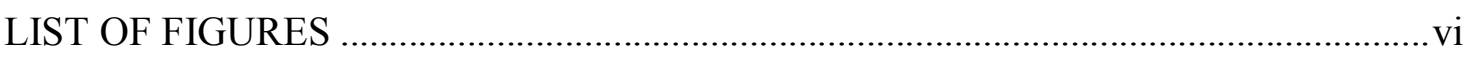

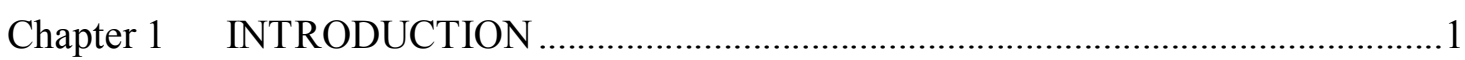

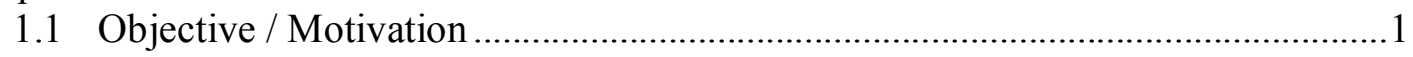

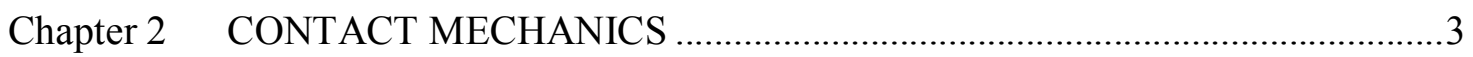

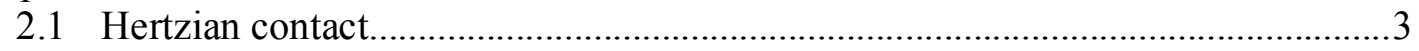

2.2 Field and Swain method ..................................................................................

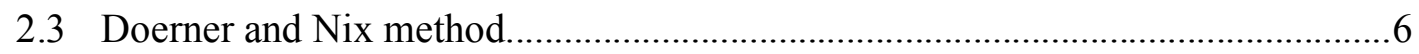

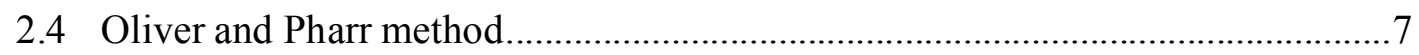

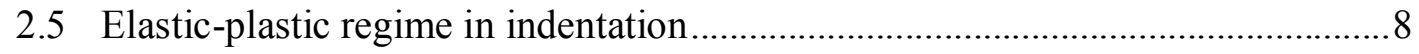

2.5.1 Spherical indentation in elastic-plastic regime ........................................ 9

2.6 Determination of elastic-plastic material properties ..........................................11

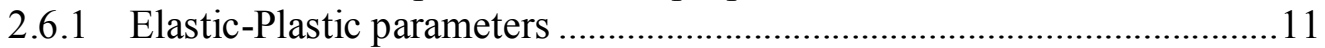

Chapter 3 A LOAD-BASED MULTIPLE PARTIAL UNLOADING

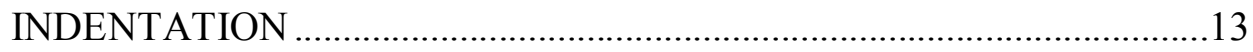

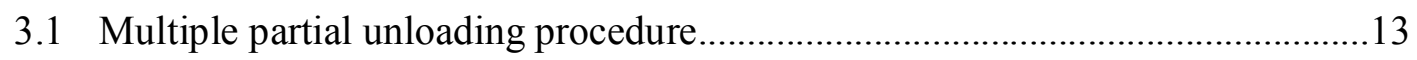

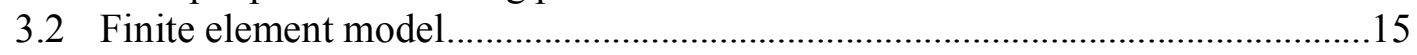

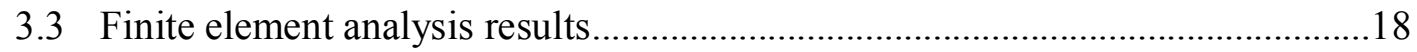

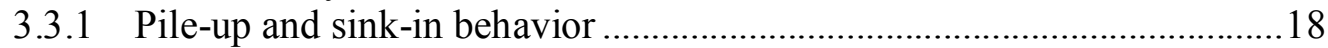

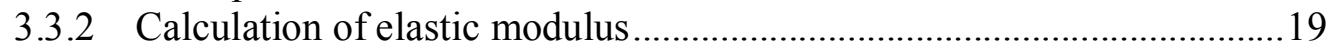

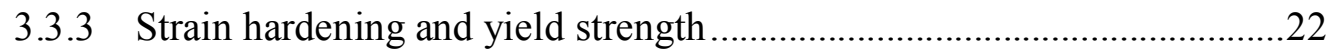

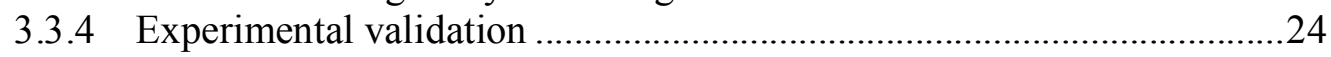

Chapter 4 THERMAL BARRIER COATING SYSTEMS............................................29

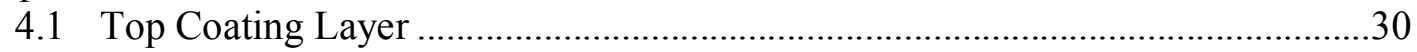

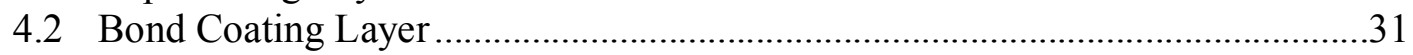

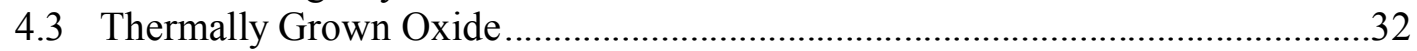

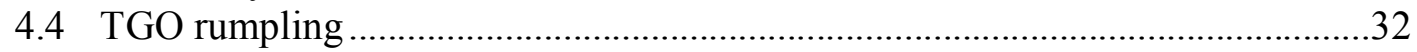

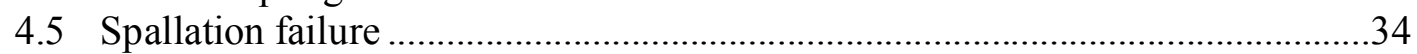

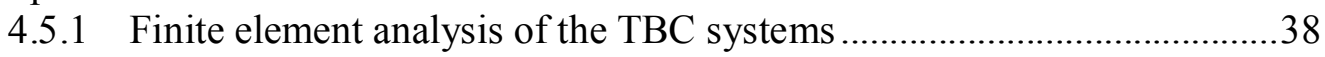

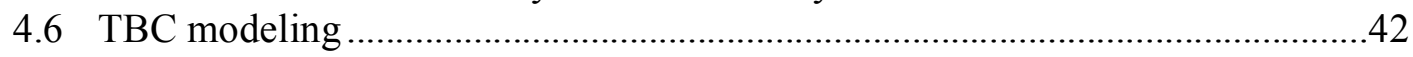

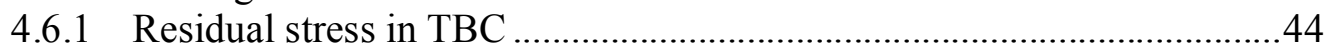

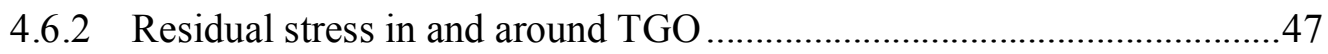

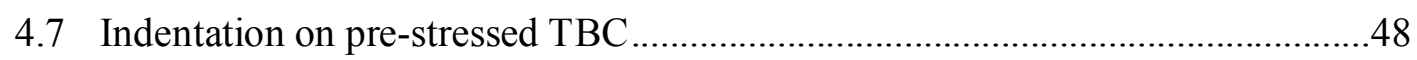

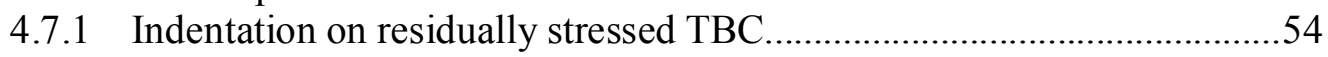




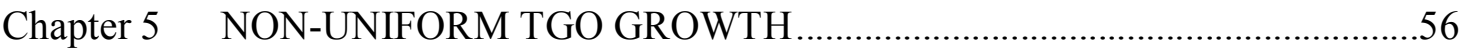

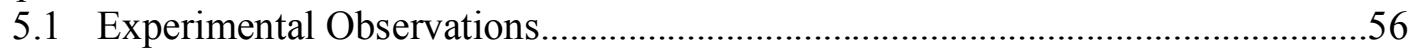

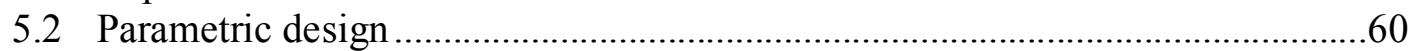

5.2.1 Finite element model for uniform and non-uniform TGO growth ..........60

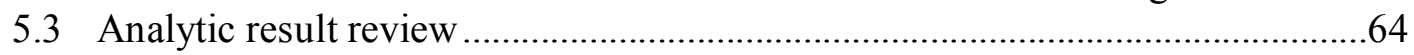

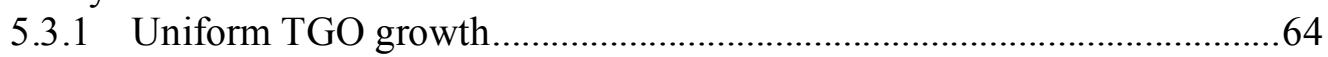

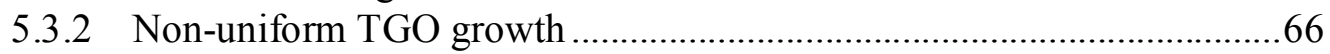

Chapter 6 SURFACE STIFFNESS RESPONSE FOR THE PROGRESSION

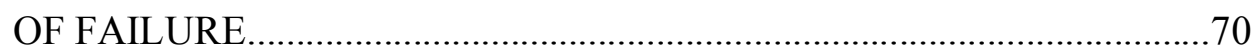

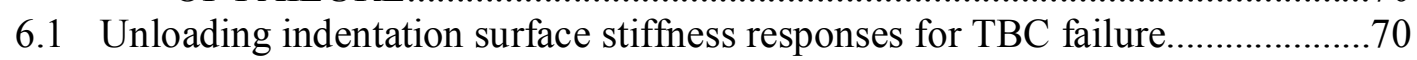

6.1.1 Finite element model for the progression of TBC failure .......................71

6.1.2 Surface stiffness responses for the progression of TBC failure................74

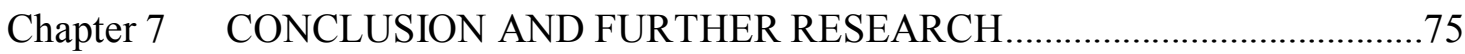

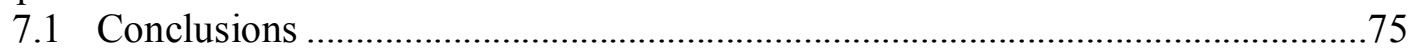

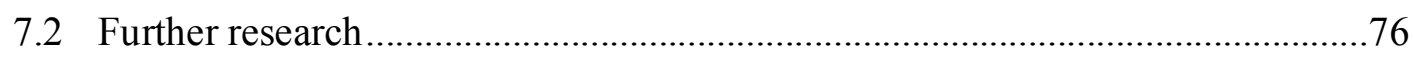

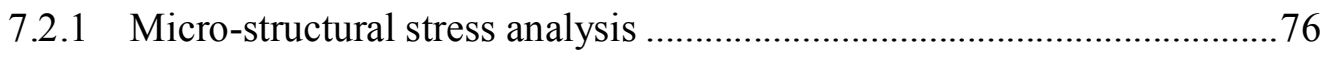

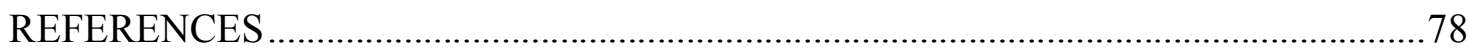




\section{LIST OF TABLES}

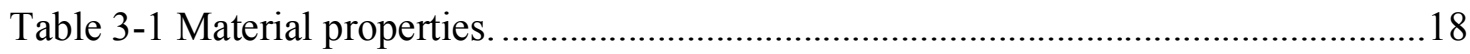

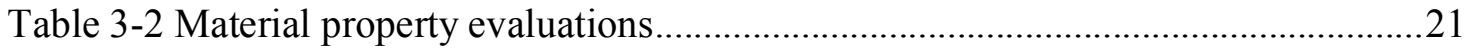

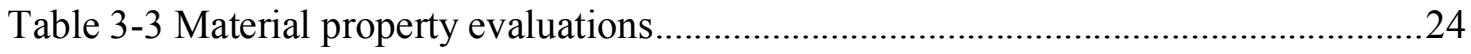

Table 3-4 load based indentation material properties........................................................2

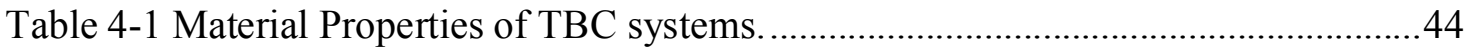

Table 4-2 Result of indentation on residually stressed model..............................................55

Table 5-1 Numerical uniform TGO model design parameters...........................................61

Table 5-2 Numerical TGO model design parameters. .......................................................62

Table 6-1 Design parameters for variable TGO evolution................................................. 72 


\section{LIST OF FIGURES}

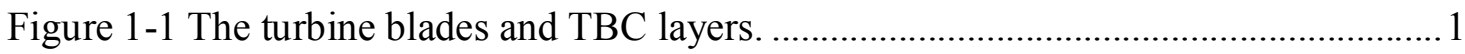

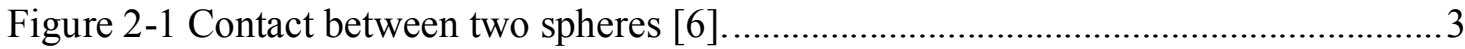

Figure 2-2 Geometry of impression by indentation [7] ................................................

Figure 2-3 Load-depth curve by spherical indentation [7] .............................................. 6

Figure 2-4 Schematic of contact behavior [18] ........................................................... 7

Figure 3-1 Load-depth curve of multiple partial unloading. ............................................. 14

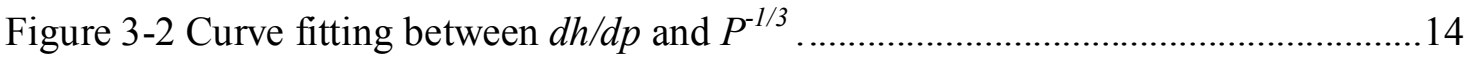

Figure 3-3 Finite element analysis boundary conditions................................................ 15

Figure 3-4 Finite element mesh and elements............................................................. 16

Figure 3-5 Contact pair between the indenter and substrate .............................................16

Figure 3-6 Mesh pattern between the indenter and substrate............................................17

Figure 3-7 Stress-strain plots of the materials used throughout the study..........................17

Figure 3-8 Pile-up behavior around the contact area........................................................ 19

Figure 3-9 Sink-in behavior around the contact area......................................................... 19

Figure 3-10 Von-Mises stress contour of material 4-3 ....................................................20

Figure 3-11 Curve fitting between $d h / d P$ and $P^{-1 / 3}$ of material 4-3 .................................21

Figure 3-12 Curve fitting and elastic modulus calculation percent error. ..........................22

Figure 3-13 Linear relationship between $\ln \left(P / \pi R^{2} E\right)$ and $\ln \left(h_{d} / R\right)$ of material 4-3 ...........22

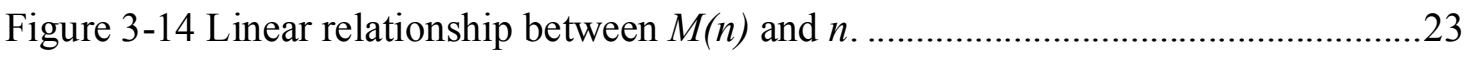

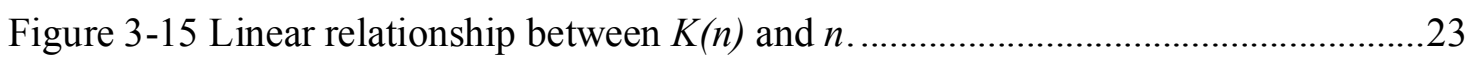

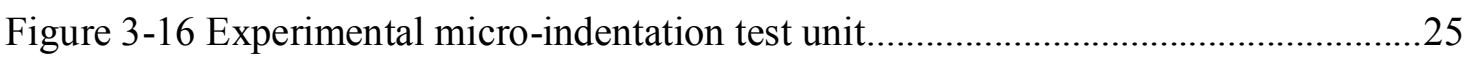

Figure 3-17 Load-displacement curve of UNS C1 1000, H04 ..........................................26

Figure 3-18 Curve fitting between unloading slope and $\mathrm{P}^{(-1 / 3)}$ of UNS C11000, H04......27

Figure 4-1 Cross sectional view of TBC systems by EB-PVD [51] .................................. 30

Figure 4-2 Cross sectional view of TBC systems by APS [49] ........................................30

Figure 4-3 Cross sectional images of TBC before and after thermal exposure. .................31

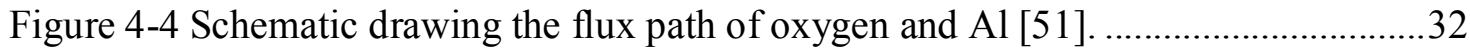


Figure 4-5 Cross sectional views of crack nucleation and extension [52].

Figure 4-6 Schematic diagram of the TBC with a rumpling by compression [57]. .34

Figure 4-7 The interaction of TBC cracks, crack coalescence and transverse strength [49].

Figure 4-8 (A) Schematic diagram showing the four different cracking mechanisms in APS TBC. (B) Cross-sectional view of a failed APS TBC [67]................36

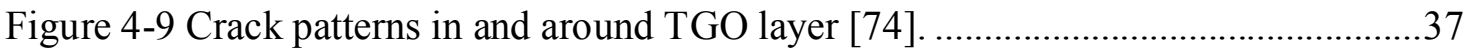

Figure 4-10 Crack pattern and TGO morphology along with thermal cycles [75] ............37

Figure 4-11 Plot of interfacial toughness vs. normalized radial distance [76] ...................38

Figure 4-12 Finite element model of the TBC system [82]................................................39

Figure 4-13 Residual stress on TBC-Top Coat interface [82] ........................................... 39

Figure 4-14 Residual stress on TBC-Top Coat interface [82] .........................................40

Figure 4-15 A schematic drawing showing the material flow by the stress field [83] .....40

Figure 4-16 (a) the competition between buckle initiation and interface crack extension, (b) the corresponding locations for energy release rate curves and for study of the competition between buckling and delamination propagation [84].

Figure 4-17 Stress vs. time in the oxide layer by thermal loading cycle [86].

Figure 4-18 The comparison between the numerical simulation and experimental observation after 24 thermal cycles [88] .................................................42

Figure 4-19 TBC model and boundary conditions..........................................................43

Figure 4-20 TGO rumpling shape and design parameters.............................................4

Figure 4-21 Uniform TGO model and finite element mesh. ..............................................44

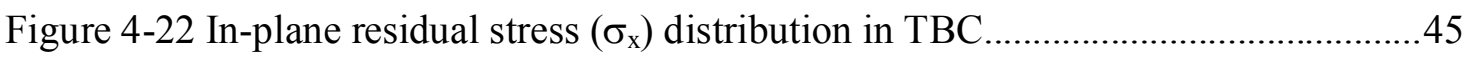

Figure 4-23 Out-of-plane residual stress $\left(\sigma_{\mathrm{y}}\right)$ distribution in TBC...................................45

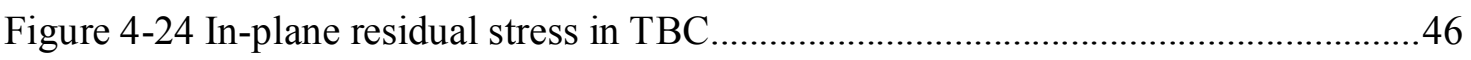

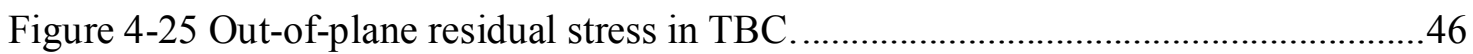

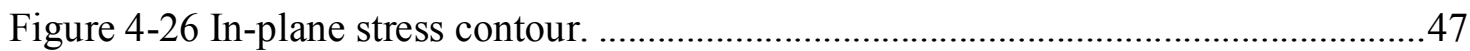

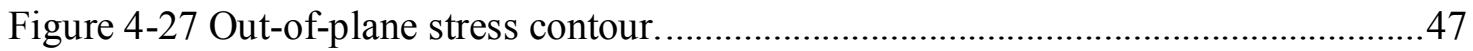

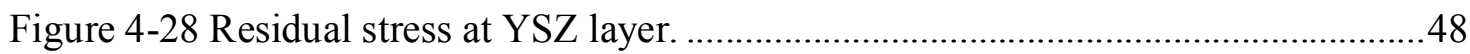

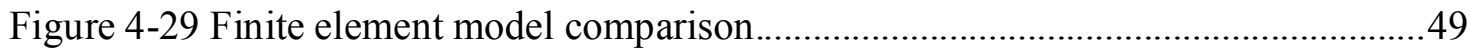

Figure 4-30 Stress-strain data used for indentation simulation [90] ..................................50

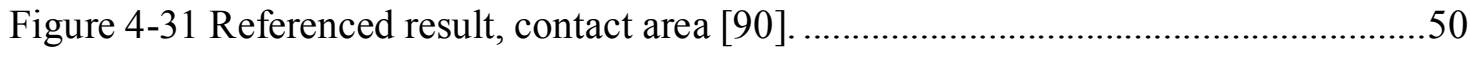

Figure 4-32 Referenced results, elastic modulus [90] ....................................................51 
Figure 4-33 Measured contact area.

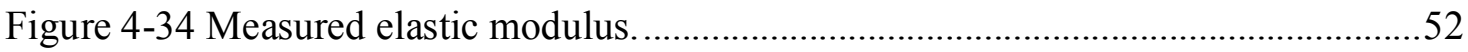

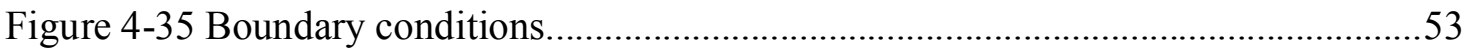

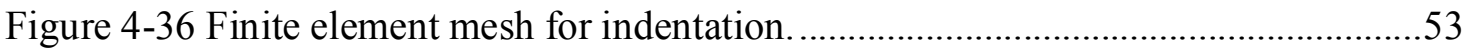

Figure 4-37 Surface stiffness responses to increase residual stress. .................................54

Figure 4-38 Measured elastic modulus with increase residual stress.................................54

Figure 4-39 Schematic of indentation at the center on residual stressed TBC...................55

Figure 4-40 Schematic of indentation at the edge on residual stressed TBC....................55

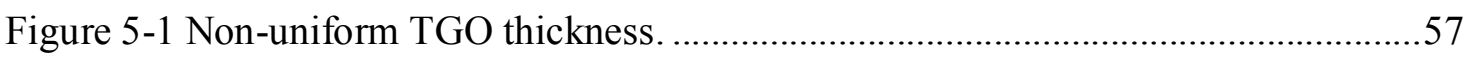

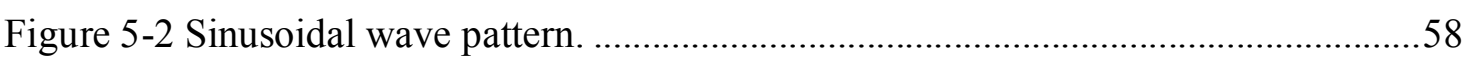

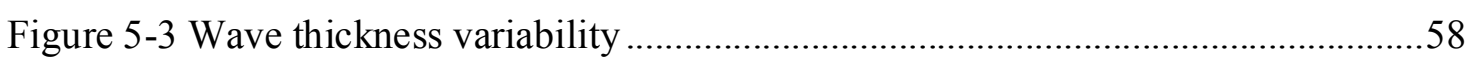

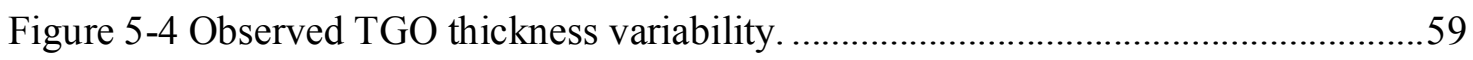

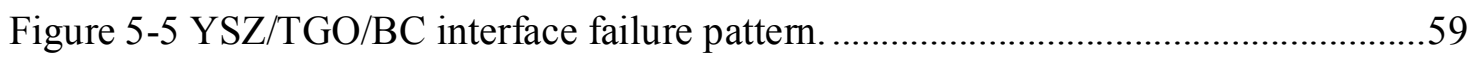

Figure 5-6 Thermally grown oxide modeling parameters.................................................61

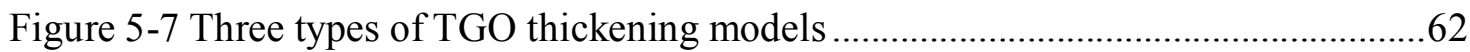

Figure 5-8 Boundary conditions applied to the numerical TBC model.............................63

Figure 5-9 Finite element mesh resolution around YSZ/TGO/BC interface. ....................63

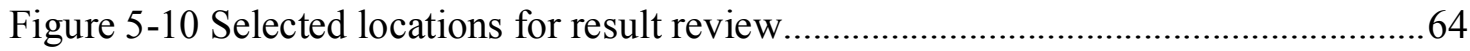

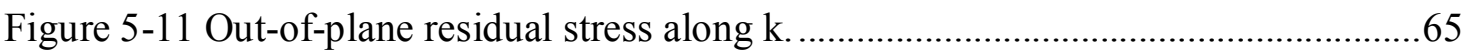

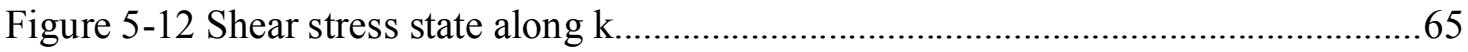

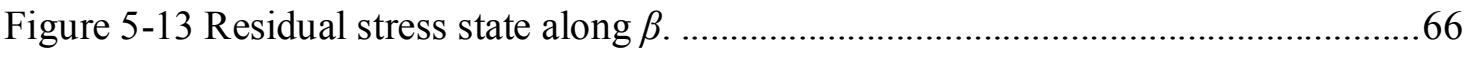

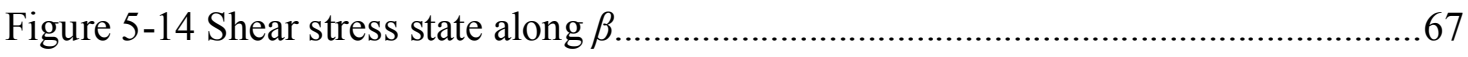

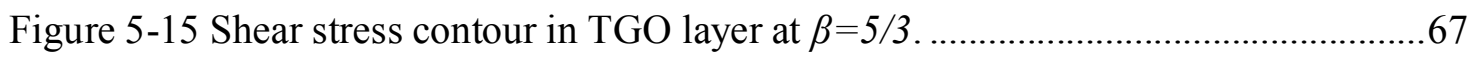

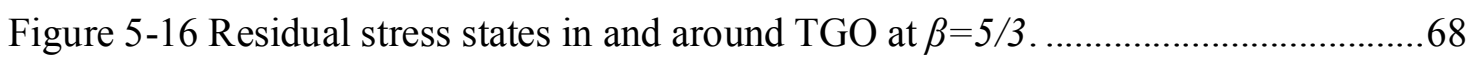

Figure 5-17 Non-uniform TGO growth and interfacial crack path [102].........................68

Figure 5-18 Cracking sequence by the stresses due to variable TGO growth. .................69

Figure 6-1 Variable TGO model of phase I and finite element mesh.................................72

Figure 6-2 TGO micro-structural evolution and micro-cracking pattern [102] .................73

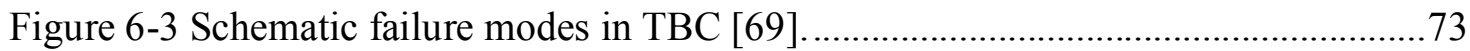

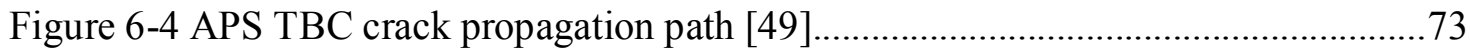

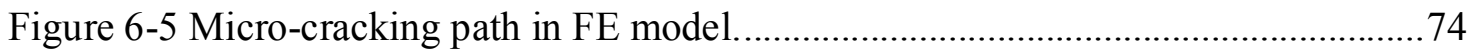

Figure 6-6 Indentation stiffness responses along with spallation failure. .........................74

Figure 7-1 Micro-structural model and the calculated residual stress [53].......................76 


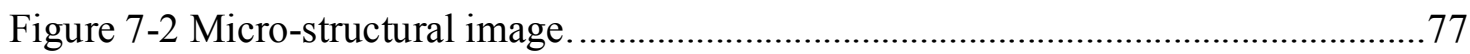

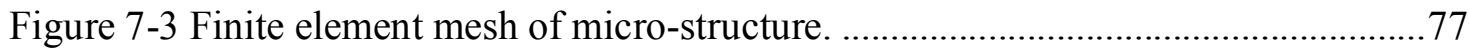

Figure 7-4 Residual stress contour in and around TGO................................................. 


\section{Chapter $1 \quad$ INTRODUCTION}

\section{$1.1 \quad$ Objective / Motivation}

Thermal barrier coating (TBC) used in gas turbine engines is a ceramic material with low thermal conductivity and the implementation of TBC is a very efficient way to protect the turbine blade and component substrates from damage induced by high temperature exposure. The importance of $\mathrm{TBC}$ is increasing as raising ignition temperatures are needed to maximize operational efficiency of land based gas turbine engines. Air Plasma Sprayed (APS) and Electron Beam-Physical Vapor Deposition (EBPVD) 6-8 weight \% Yttria stabilized zirconia (YSZ) TBCs have facilitated the use of superalloys at temperatures $100 \sim 300^{\circ} \mathrm{C}$ higher than that of conventional operation, thus increasing efficiency [1,2]. As shown in Figure 1-1, composed of multiple layers, the top coat, also protecting the system from oxidation is deposited with a metallic layer residing between it and the superalloy substrate, this layer is referred to as the bond coat (BC). The $\mathrm{BC}$ is generally comprised of Nickel (Ni), Cobalt $(\mathrm{Co})$ and Chromium $(\mathrm{Cr})$ with sufficient concentrations of Aluminum (Al) ensuring the later occurring $\mathrm{TGO}$ is predominantly composed of stable $\alpha-\mathrm{Al}_{2} \mathrm{O}_{3}$. The TGO, a major contributor to the interfacial thermo mechanical resistance of the coating, although mainly composed of $\alpha$ $\mathrm{Al}_{2} \mathrm{O}_{3}$, entertains spinel oxides $\left(\mathrm{NiAl}_{2} \mathrm{O}_{4}\right)$ and other impurities such as yttrium and zirconia oxides as well.

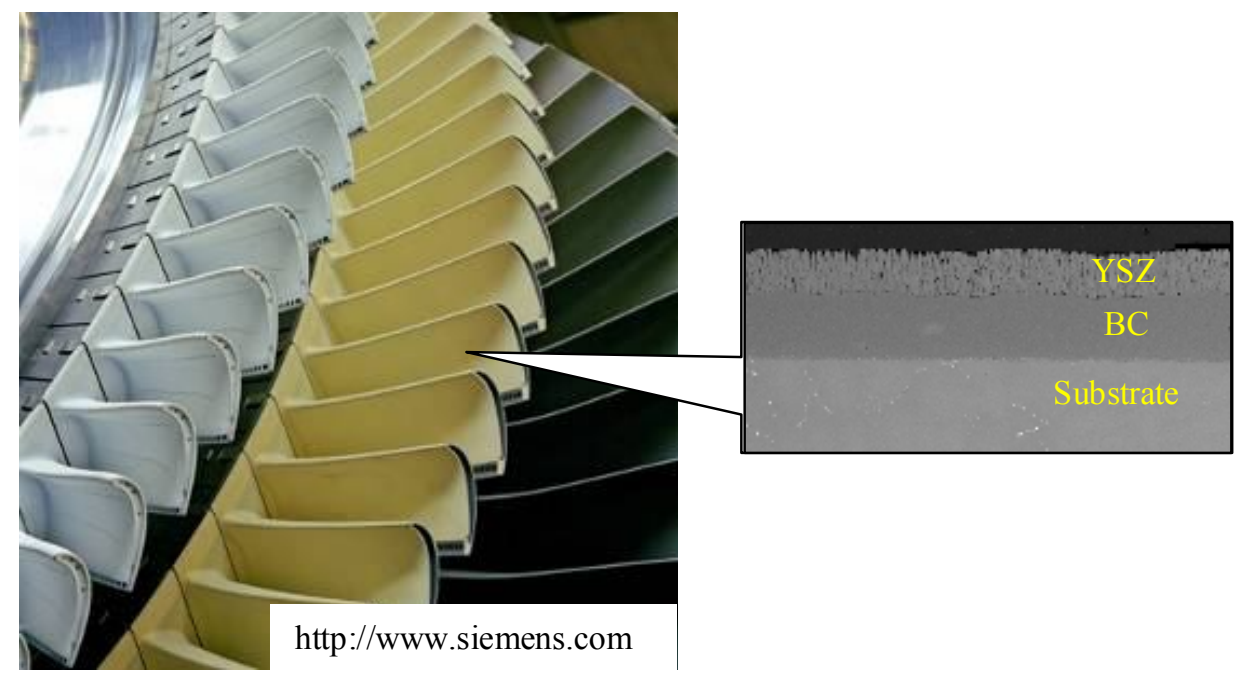

Figure 1-1 The turbine blades and TBC layers. 
The developing residual stresses caused by thermal expansion mismatches within the TBC system and unstable TGO are considered the primary causes for its premature and erratic spallation failure. The residual stresses are enlarged between YSZ/TGO/BC interfaces due to the growth of TGO. Further increasing of these stresses produce microcracks in and around TGO. The first goal of this research is to improve the understanding of residual stress development along with TGO growth. In addition, realistic numerical TGO models are required to figure out the detailed explanation of the relationship between spallation failure patterns and residual stresses, yet no successful failure model has been developed. In this research, various TGO geometries are suggested based on experimentally obtained cross sectional scanning electron micrographs. Moreover, as a result of non-uniform TGO growth is found to lead the development of additional geometrical imperfections. Through a detailed analysis of the out-of-plane tensile stresses produced upon cooling, a complete spallation failure prediction path has been developed.

Many current TBC researches are utilizing indentation methods to measure residual stresses and material degradation. However, there are some inconveniences of cost and limited accuracy. Recently a load-based multiple partial unloading method has been developed aiming to enhance experimental convenience [3]. Subsequently, the loadbased micro-indentation technique has been proposed as a non-destructive evaluation for TBC damage detection [4]. In the current study, finite element simulation demonstrates a load-based micro-indentation technique to evaluate residual stress variation and locate having higher residual stresses, consequently predicting spallation failure. However, a relationship between the indentation stiffness response and spallation failure has not been clearly investigated yet due to the complex nature of TBC failure mechanism. In the result of finite element simulations, the progression of spallation failure within the interface is observed to have a profound effect on indentation surface stiffness responses. In this manner, the progression of spallation failure is proven to be successfully evaluated using a load-based multiple partial unloading micro-indentation procedure. Exploiting these relationships, refinement and expansion on the actual measurement system not only able to detect the spallation failure location but do so prior to its occurrence, is able to show promise as an analytic approach.

Classical contact mechanics and a new analytical micro-indentation approach for determining the elastic modulus, yield stress and strain hardening exponent are presented in Chapter 2. This newly developed indentation technique is reviewed with numerical and experimental validations in Chapter 3 . Chapter 4 investigates about TBC systems and define the relationship between the indentation surface stiffness response and residual stress. The spallation failure pattern is analyzed using numerical analysis of variety TGO scales via experimental observations in Chapter 5. In Chapter 6, the variation of surface stiffness responses are proved to be correlated with propagation of spallation failure. Finally a complete results of this research and further study are discussed in Chapter 7. 


\section{Chapter 2 CONTACT MECHANICS}

\subsection{Hertzian contact}

The initial concept of elastic contact mechanics developed in 1880s by Hertz [5]. This contact mechanism has been expanded by many researchers for material mechanical property evaluation. Hertz suggested contact solution between two elastic bodies. The Hertzian solution shows unique expressions for contact radius, pressure and rigid body motion. This achievement is useful for an analytic approach of contact model. In case of contact between two spheres of radius $R_{1}$ and $R_{2}$, Figure 2-1, the area of an applied load is defined by an applied load, indenter radius and reduced modulus as show the contact radius, Equation (2.1), $a$ is the contact radius, $P$ the applied load, $R$ the indenter radius and $E_{R}$ the reduced modulus.

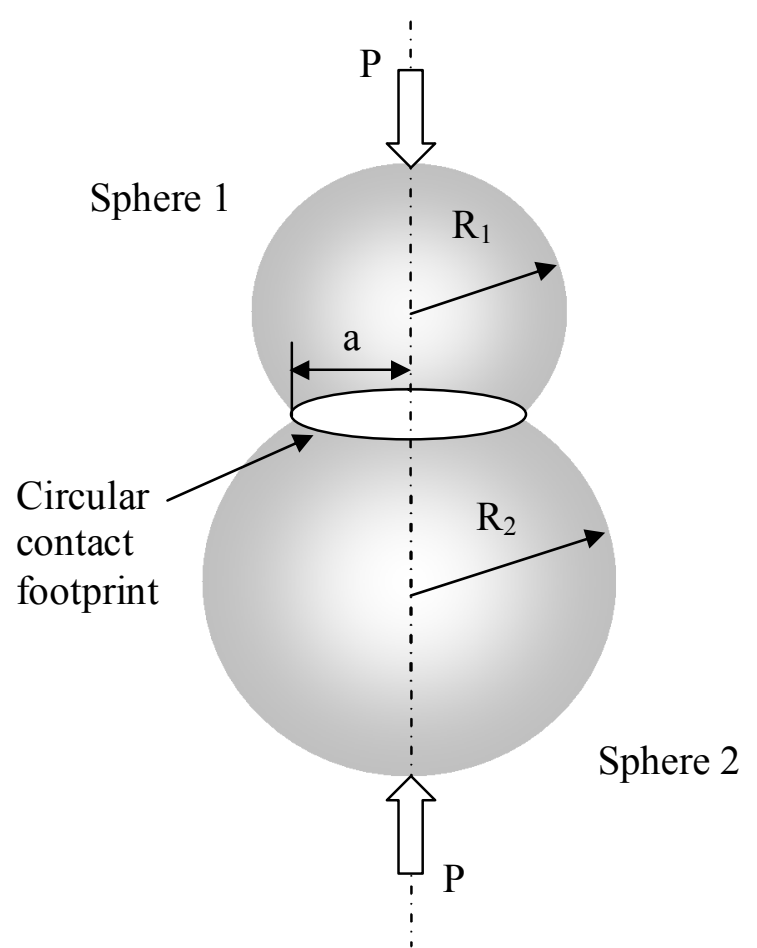

Figure 2-1 Contact between two spheres [6].

$$
a^{3}=\frac{3}{4} \frac{P R}{E_{R}}
$$


Where reduced modulus is defined by the elastic modulus and Poisson's ratio of two bodies. Thus reduced modulus is expressed by Equation (2.2). $R$ in Equation (2.1) is relative radius and defined as shown in Equation (2.3).

$$
\begin{gathered}
\frac{1}{E_{R}}=\frac{\left(1-v_{1}^{2}\right)}{E_{1}}+\frac{\left(1-v_{2}^{2}\right)}{E_{2}} \\
\frac{1}{R}=\frac{1}{R_{1}}+\frac{1}{R_{2}}
\end{gathered}
$$

The contact pressure distribution is defined as Equation (2.4) where $r$ is the radial distance from the axis of symmetry and $P_{c}$ the maximum contact pressure, also $r \leq a$. The pressure distribution, maximum contact pressure and applied load are related as shown in Equation (2.5).

$$
\begin{gathered}
P(r)=P_{c}\left(1-\frac{R^{2}}{a^{2}}\right)^{1 / 2} \\
P=\int_{0}^{a} P(r) 2 \pi r d r=\frac{2}{3} P_{c} \pi a^{2}
\end{gathered}
$$

Thus, maximum contact pressure, $P_{c}$ at the center of the circular contact area is defined by an applied load, reduced modulus and indenter radius, Equation (2.6).

$$
P_{c}^{3}=\frac{6 P E_{R}^{2}}{\pi^{3} R^{2}}
$$

Hertzian contact solution and theories are reviewed elsewhere [7]. Furthermore, Hertzian contact solutions have been reviewed in the damage mechanics point of view of brittle materials. Hertzian cone cracks and diffusion subsurface damage zones were investigated by Brian R. Lawn [8]. Indentation tests offer load-depth data, Figure 2-4 shows a schematic of indentation of this relationship. Indentation processes are complex and related not only to elastic but elastic-plastic material behavior as well. Thus many researchers have investigated the exact analytic relation occurring during this process. Hertz proposed governing contact mechanics equations and they have since been applied in various indentation research initiatives. For the elastic deformation, the total indentation depth is employed and the rigid body motion is reformulated as Equation (2.7), where $h_{e}$ is elastic indentation depth. This equation (2.7) presents a clear relationship between applied load and elastic indentation depth, thus this is used as a basic equation for elastic indentation. 


$$
P=\frac{4}{3} E_{R} R^{\frac{1}{2}} h_{e}^{\frac{3}{2}}
$$

\subsection{Field and Swain method}

Much of which has been aimed at developing an exact analytic relationship for both the loading and unloading process, taking into account not only the elastic but elastic-plastic material properties as well. Many early models included only elastic behavior under the assumption that unloading is a purely elastic process. Field and Swain [9] suggested an indentation method using single partial unloading. Hertz showed the contact area, Equation (2.1) and substituted into Equation (2.7). The relationship between contact radius and elastic indentation depth can be defined as Equation (2.8). Equation (2.8) is translated in terms of contact radius, thus Hertz's elastic contact solution is defined as shown in Equation (2.9). The relationship between total depth and contact depth is shown in Figure 2-2.

$$
\begin{gathered}
a^{2}=R h_{e} \\
P=\frac{4}{3} E_{R} a h_{e}
\end{gathered}
$$

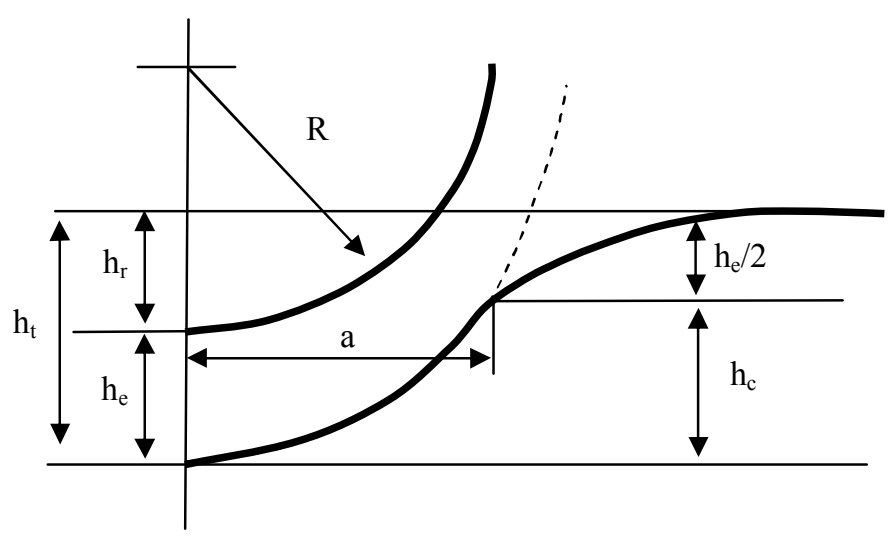

Figure 2-2 Geometry of impression by indentation [7].

Since the contact depth is arranged by the total depth and elastic depth, it is calculated by the total depth and residual depth, Equation (2.10) and Equation (2.11).

$$
\begin{gathered}
h_{e}=h_{t}-h_{r} \\
h_{c}=h_{t}-\frac{h_{e}}{2}
\end{gathered}
$$




\subsection{Doerner and Nix method}

Doerner and Nix [10] figured out through an experimental review that unloading procedure is initiated contact radius remains constant until a plastic regime is reached. Due to this, initial unloading slopes within the load-depth curve were found to be linear. Utilizing this phenomenon, a relationship between elastic indentation depth maximum load, unloading slope and indenter geometry were established by Sneddon [11]. It has already been observed in cylindrical punch indentation that unloading slope is linear until full unloading and the contact radius is quite same. Thus Doerner and Nix used cylindrical punch method to determine the contact depth and contact area. Since an easy way to determine contact depth is developed, the contact depth has been determined by extrapolation from initial unloading slope to zero load as shown in Figure 2-3. Finally the contact area is rearranged with adding coefficient as Equation (2.12) thus reduced modulus is calculated simply by rearranging unloading slope and contact area, Equation (2.13).

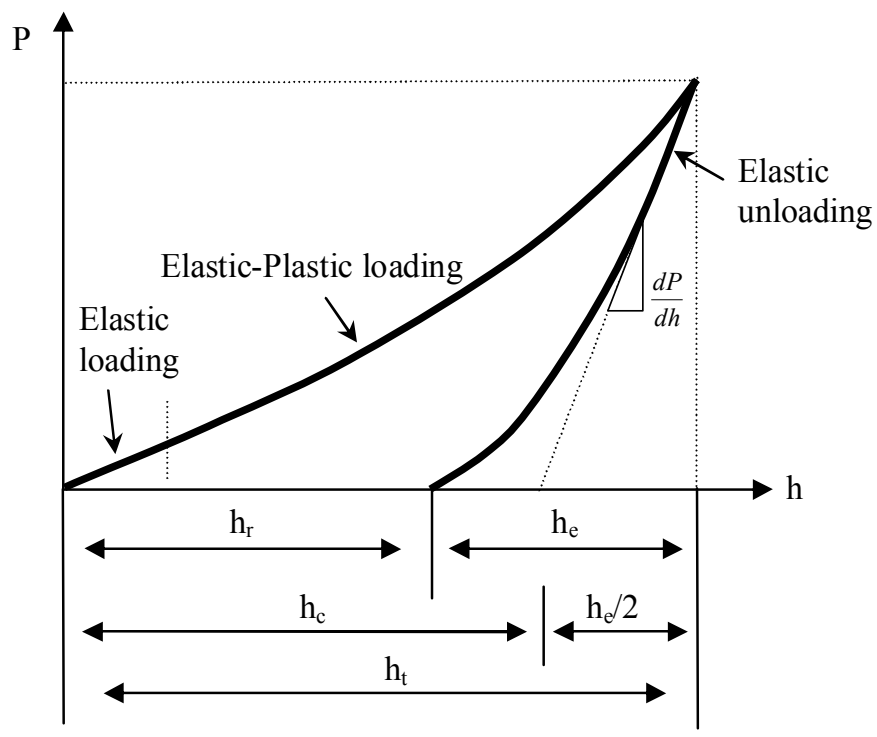

Figure 2-3 Load-depth curve by spherical indentation [7].

$$
\begin{gathered}
A=24.5 h_{c}^{2} \\
\frac{d P}{d h}=2 h_{c} E_{R} \sqrt{\frac{24.5}{\pi}}
\end{gathered}
$$




\subsection{Oliver and Pharr method}

Hertz mostly analyzed spherical type indentation. Contact radius, total depth and contact depth are rearranged in case of spherical indentation. Contact radius is approximately related to contact depth and the indenter radius, Equation (2.14). Where $h_{c}$ is contact depth caused by plastic deformation. Also, the extended form of the Hertzian formula is used to present the contact properties for the presence of a coating [12].

$$
a=\sqrt{2 h_{c} R-h_{c}^{2}} \approx \sqrt{2 h_{c} R}
$$

The Hertzian contact solution has been adapted for measurement of the strength and flaw density distribution for a transparent brittle material [13]. Figure 2-4 shows the two contact deformation, sink in and pile up and contact parameters are indicated.

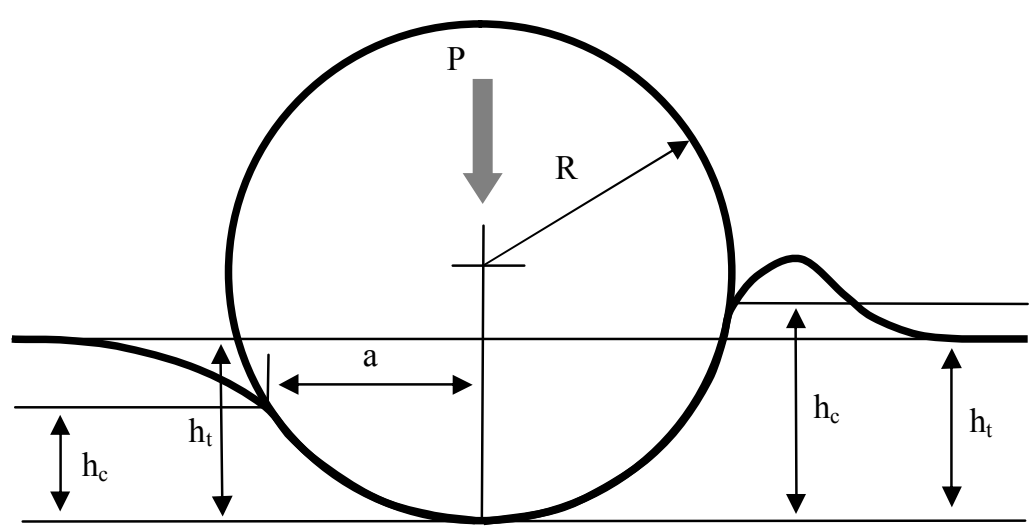

Figure 2-4 Schematic of contact behavior [18].

Later expansion of previous model to incorporate elastic-plastic deformation in and round the indented region resulted in the development of a relationship between total indentation depth and indenter contact area [14]. Sneddon suggested elastic depth for an elastic indentation solution, Equation (2.15).

$$
h_{e}=\varepsilon \frac{P_{\max }}{\left(\frac{d P}{d h}\right)}
$$

In order to expand to elastic-plastic regime, Oliver and Pharr [15] used Sneddon's elastic solution in order to represent contact depth with total indentation depth. $\varepsilon$ is a coefficient for indenter shape. $\varepsilon$ is found from experimental results that 0.75 and it is related to material behavior, Equation (2.16). 


$$
h_{c}=h_{t}-\varepsilon \frac{P_{\max }}{\left(\frac{d P}{d h}\right)}
$$

Oliver and Pharr showed that the contact stiffness can be evaluated by power law equation with fitting the unloading data. $C, m$ and $h_{r}$ are determined by least-square fitting, Equation (2.17).

$$
P=C\left(h-h_{r}\right)^{m}
$$

Aside from defining the relationship between unloading slope and elastic modulus, contact area $A$ is another focused problem. Doerner and Nix defined contact area with function of contact depth. Oliver and Pharr rearranged contact area, Equation (2.18).

$$
A=\pi a^{2}=2 \pi h_{c} R
$$

This contact area calculation has been shown pretty high accuracy for determination of elastic modulus and used for usual indentation measurement. In the case of adhesive contact by a rigid punch also examined [16]. Thus reduced modulus can be calculated by using unloading slope and contact area, Equation (2.19). Where $\beta$ is and depends on indenter geometry and is 1 for a conical indenter.

$$
E_{R}=\frac{\sqrt{\pi}}{2 \beta \sqrt{A}} \frac{d P}{d h}
$$

Since the Sneddon solution was implemented for the Oliver-Pharr method, the effects of the indenter angle and the Poisson's ratio of the sample were examined [17]. Although some consideration for elastic-plastic behavior has been entertained, these analytical models are derived under the basic assumption that the unloading process is purely elastic and tested against homogeneous isotropic material. Further elastic contact mechanics and indentation theories are reviewed elsewhere $[18,19]$.

\subsection{Elastic-plastic regime in indentation}

Elastic-plastic material behavior in indentation is very complex to describe exactly. Due to the complex nature of indentation based elastic-plastic material behavior finite element methods have been widely employed in its study. Different strain hardening exponents are able to be assumed in order to consider a variety plastic behavior in finite element solutions. D. J. Strange et al. conducted finite element analysis with two separate work hardening models and verified their accuracy by comparing experimental data [20]. Exploiting these techniques, refinement and expansion on classical theories have proven useful although incomplete. Especially specific and reliable studies of strain hardening effect have not been carried out completely. I. S. Choi et al. conducted 
parametric finite element analysis studies of indentation for non-linear plastic materials by building a general methodology for quantitative interpretations of depth sensing techniques [21]. Also this research was expanded to nano-indentation as well, where the pile-up/sink-in behavior during indentation is known to be a function of the strain/work hardening exponent and ratio of yield stress to elastic modulus [22]. Continuously indentation research for elastic plastic regime has been developed with efforts that try to extract other material properties through the indentation test. Initial attempts to extract stress-strain data by Tabor were progressive but were later stymied [23]. Soon thereafter, researchers tried to define stress and plastic strain as a function of indentation parameters. Taljat [24] published in 1998 about finite element simulation of spherical indention. In this research, a new analytic approach is suggested to calculated stress-strain relation. Taljat analyzed indentation parameters and successfully defined stress and plastic strain as a function of contact radius, the indentation depth and indenter radius within range of $0.3<\varepsilon_{p}<1.6$. This research showed promise as a novel numerical approach for the extraction of elastic-plastic material properties, yet a more generalized form is needed for convenience and application. Experimental procedures carried out using metallic glass materials reviewed the possibility of establishing some relationship between pop-in events occurring during the indentation process and elastic-plastic properties [25]. More recently, an algorithm for yield strength and strain hardening exponent using finite element analysis was suggested by H. Lee and J. H. Lee et al. [26]. Through finite element analysis and curve fitting for various combined material properties, they finally suggested an effective algorithm. Moreover, a relationship between material properties and indentation parameters has been developed for which elastic-plastic properties were found without the use of contact radius measurements. Manhong Zhao and Nagahisa Ogasawara et al. [27] showed a way to extract elastic-plastic properties with defining non-dimensional indentation equation. They built a relationship between indentation parameters and material properties using numerical analysis. This non-dimensional indentation equation shows high accuracy. Later attempts to rebuild the Hertzian contact mechanics equations as a function of stress and elastic modulus have also been successfully performed by S. Basu et al. [28]. In this research, plastic behavior is taken into account through a definition that the contact area is a function of the calibrated area. Investigations of stress-strain features using high load indentation have established the presence of a linear relationship between strain and maximum load [29]. Also invented contact modeling of two rough surfaces is investigated to predict the real contact area and subsurface stresses affecting friction and wear of an interface [30].

\subsubsection{Spherical indentation in elastic-plastic regime}

As the previous review, a lot of effort and research have been conducted to explore elastic-plastic material behavior in indentation test and property measurement. Recent attempts have aimed to extract the stress-strain relation in terms of yield stress, the strain hardening exponent and elastic modulus have been carried out to define the relationships between load-depth curve and elastic-plastic properties [31]. The relationship between the permanent penetration depth and indentation load was examined with continual loading-unloading procedures [32,33]. Also finite element simulations have been extensively used to examine indentation characters in the elastic-plastic regime. The ratio of mean pressure to flow stress along penetration depth with various yield stress 
and work hardening is investigated by Y.J. Park et al. [34]. In this research elastic and elastic-plastic dominant ranges are examined with finite element simulation and shown with schematic graphs. Sinisa Dj. et al. [35] performed significant elastic plastic research using finite element simulation. At the research, indentation map is introduced and it shows the trend in indentation deformation with increasing contact size for yield strain. This map contains five distinct regimes that Hertzian elastic indentation, elastic-plastic indentation, rigid-plastic similarity regime, finite-deformation plasticity and finitedeformation elasticity. Elastic-plastic deformation, strain hardening exponent, yield strength and friction effects are examined, results indicate the following. "The region of validity of the plastic similarity solution is severely limited by elastic effects for small contacts and, by finite-deformation effects for large contacts." "The boundaries of the indentation regimes are relatively insensitive to the degree of strain hardening and to the level of interfacial friction." "Extraction of material parameters, such as the hardening exponent and the characteristic strength is feasible from load versus indent depth measurements, but may require more sophisticated indentation measurements than those currently practiced." [35]. Finally, a relationship explaining finite element elastic-plastic behavior around spherical indentation is developed, where $P$ is applied load, $\varepsilon_{o}$ the yield strain, $\sigma_{o}$ the yield stress, $R$ the indenter radius, $n$ the strain hardening exponent and $h_{c}$ the indentation contact depth, Equation (2.20).

$$
\frac{P \varepsilon_{0}^{n}}{\pi R^{2} \sigma_{0}}=K(n)\left(\frac{h_{c}}{R}\right)^{\left(\frac{n}{2}+1\right)}
$$

The development of this relationship and those by other researchers [36] although substantial, are not completely defined and difficult to apply. Furthermore, the accuracy of such functions is not consistent across materials of all stress-strain forms. As a result, the motivation exists to develop a more practical and fundamental relationship among load, indentation depth, yield strength, strain hardening exponent and elastic modulus that does not require system calibration or the use of high precision depth sensors. S. Kucharski et al. [36] suggested a more practical methodology of extracting elastic-plastic properties where in a power-law relationship between mean stress and contact radius, Equation (2.22). Where $\alpha$ and $\beta$ are constants found to be 3.07 and 0.32 respectively, $D$ the spherical indenter diameter. These values are fitted parameters and based on a multitude of simulation data. The elastic strain is able to be neglected when a rigid-plastic material model is considered thus the plastic strain is represented as a function of stress, where $\sigma$ is stress, $\varepsilon_{p}$ the plastic strain and $k$ the material parameter, Equation (2.21). For this identical relation, similar solution can be derived, Equation (2.22). The parameter $c^{2}$ is defined with contact radius, contact depth and spherical indenter diameter, Equation (2.23).

$$
\begin{gathered}
\sigma=k \varepsilon_{p}^{n} \\
\frac{P}{\pi a^{2}}=\alpha \beta^{n} k\left(\frac{a}{D}\right)^{n}
\end{gathered}
$$




$$
c^{2}=\frac{a^{2}}{h_{c} D}=1.41 e^{-0.97 n}
$$

Rebuild Equation (2.22) to be a function of indentation load and indentation depth, it becomes as Equation (2.24).

$$
P=\pi \alpha k \beta^{n} c^{2+n} D^{2}\left(\frac{h_{c}}{D}\right)^{\frac{n}{2}+1}
$$

Parameters have approximately fitted with the various simulation results thus yield strength and strain hardening exponent can be evaluated reversely. As reviewed, many researches have tried to get material properties inelastic and elastic-plastic regime and expand in a more complex area. For example, nano scale surface material response is being examined by an indentation method using atomic force microscope (AFM) and Raman spectroscopy [37-39]. Also, porous material's properties are investigated by the indentation test [40]. Furthermore, M. L. Oyen et al. built a viscous-elastic-plastic indentation model for thin film systems [41].

\subsection{Determination of elastic-plastic material properties}

In a general indentation test, load and depth are continuously monitored. Material evaluation is carried out by analysis of this load-depth data. The slope of this load-depth curve varies along elastic plastic behavior. As previously mentioned, material recovery in the unloading procedure is considered to be a purely elastic process, thus elastic modulus can be extracted from the unloading slope. Also, it is known that initial indentation is elastic as well and can be described using Hertzian contact mechanics; however, as indentation depth increases the material beneath the indenter becomes gradually more elastic-plastic. This elastic-plastic behavior is a function of strain hardening exponent and follows a power-law form. By this method, elastic-plastic material properties are able to be extracted, where properties are divided into elastic and elastic-plastic regimes.

\subsubsection{Elastic-Plastic parameters}

Post yielding material properties such as yield stress and the strain hardening exponent are difficult to obtain using standard indentation techniques. Yet these properties dictate the relationship between load and displacement throughout the indentation process. Due to this, a mathematical relationship containing these parameters should be able to predict such a trend. As previously mentioned, elastic-plastic material behavior can be expressed in a power law form found in Equation (2.20), however this function is difficult to apply. Thus with the application of Hooke's law [42], yield stress and yield strain may be combined to form elastic modulus $(E)$, Equation (2.25). Furthermore, rearranging Equation (2.20) and redefining $n / 2+1$ as the function $M(n)$, a 
new relationship for indentation load, indenter radius, contact depth, yield stress and strain hardening exponent is developed, Equation (2.26).

$$
\begin{gathered}
E=\frac{\sigma_{0}}{\varepsilon_{0}} \\
\frac{P}{\pi R^{2} E}=K(n)\left(\frac{h_{c}}{R}\right)^{M(n)}\left(\frac{\sigma_{0}}{E}\right)^{1-n}
\end{gathered}
$$

This modification of Mesarovic and Fleck's original function although simplified is not easily applied and remains incomplete. However, taking the natural log of this equation yields a function which is considered to be linear $(y=a x+b)$, Equation (2.27). Through this procedure, $y$ becomes $\ln \left(P / \pi R^{2} E\right), x$ is then defined as $\ln \left(h_{d} / R\right), a$ is equal to $M(n)$ and $b$ is found to be $\ln (K(n))+(1-n) \ln \left(\sigma_{o} / E\right)$. Although now in a rearranged linear form, the equation remains incomplete as the functions $M(n)$ and $K(n)$ are unknown. Variables of strain hardening exponent, parameters $M(n)$ and $K(n)$ must be generated not experimentally but rather using numerical finite element methods to ensure proper coefficient prediction where variations of strain hardening exponent may exist across the surface of a single sample. As a result of this, in the following sections equations for both parameters will be generated and this newly developed elastic-plastic indentation equation will be verified numerically across a large assortment of materials. Additionally, although easily measured in numerical analyses, experimental acquisition of indentation contact depth is extremely difficult, thus Equation (2.16) has been utilized for its calculation where $\varepsilon$ is a geometrical parameter ( 0.75 for spherical indenters) and $h_{\max }$ the total indentation depth [43].

$$
\ln \left(\frac{P}{\pi R^{2} E}\right)=M(n) \ln \left(\frac{h_{c}}{R}\right)+\ln (k(n))+(1-n) \ln \left(\frac{\sigma_{o}}{E}\right)
$$




\section{Chapter 3 A LOAD-BASED MULTIPLE PARTIAL UNLOADING INDENTATION}

In this research, a load based multiple partial unloading method is hired and Hill's elastic-plastic contact equation is modified to evaluate elastic-plastic mechanical material properties. Using finite element analysis, a load-based multiple partial unloading indentation methodology is verified and calculated elastic-plastic material properties are compared to literature values.

\subsection{Multiple partial unloading procedure}

A load-based multiple partial unloading method has been developed aiming to enhance experimental convenience and reduce analytic errors. Many current indentation methods require the use of high precision sensors or sophisticated optical techniques to measure indentation depth and contact area. These requirements have limited accuracy, are difficult to use and are often expensive. A load-based multiple partial unloading method does not require the use of such devices, Figure 3-1. Derived using a classical Hertzian contact mechanics, the derivation of this equation with respect to indentation depth yields Equation (3.1), where $E_{R}$ is the reduced modulus [3]. This form is able to be regarded as a linear equation as $y=C x$, where y is $d h / d P$ and constant term $C$ is equal to $\left(6 R E_{R}^{2}\right)^{-1 / 3}$. Contact depth and contact area are not shown in this equation thus indentation load can be defined by unloading slope, indenter radius and reduced modulus. This now linear relationship can be further reduced to a function needing only the indenter radius and slope $(C)$ to obtain elastic modulus, thus removing the need for any indentation depth measurement, Equation (3.2). Previous indentation methods using only single point unloading are incapable of obtaining this slope, thus require contact area or indentation depth measurements. Also, conventional indentation methods develop errors in the elastic modulus measurement along the applied load. That is, if a large applied load is used the resulting elastic modulus will be large too. This is also true for a small applied load, small applied load results in an underestimation of the true elastic modulus. The multiple partial unloading method on the other hand eliminates this loading influence. This technique allows for unloading slope stiffness responses at various loads to be monitored effectively. Unloading slopes from the multiple partial unloading show a good linear trend with $P^{-1 / 3}$. Then $C$ is simply calculated by linear curve fitting. Figure 3-2 shows a linear relationship between $d h / d P$ and $P^{-1 / 3}$. This trend displays clear. 


$$
\begin{gathered}
\frac{d h}{d P}=\left(6 R E_{R}^{2}\right)^{\frac{-1}{3}} P^{\frac{-1}{3}}=C P^{\frac{-1}{3}} \\
E_{R}=\left(6 R C^{3}\right)^{\frac{-1}{2}}
\end{gathered}
$$

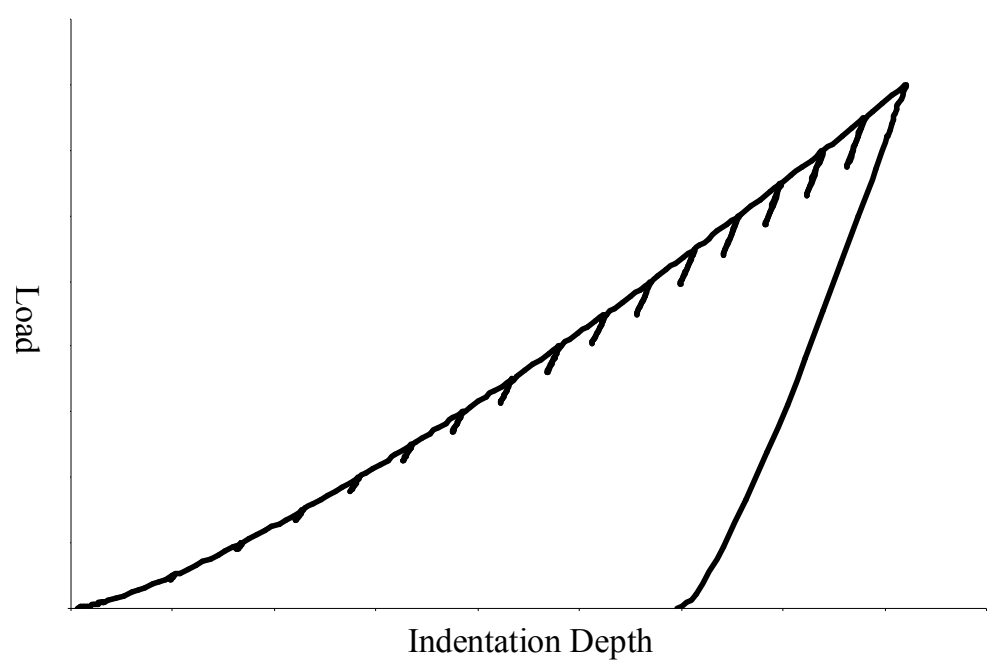

Figure 3-1 Load-depth curve of multiple partial unloading.

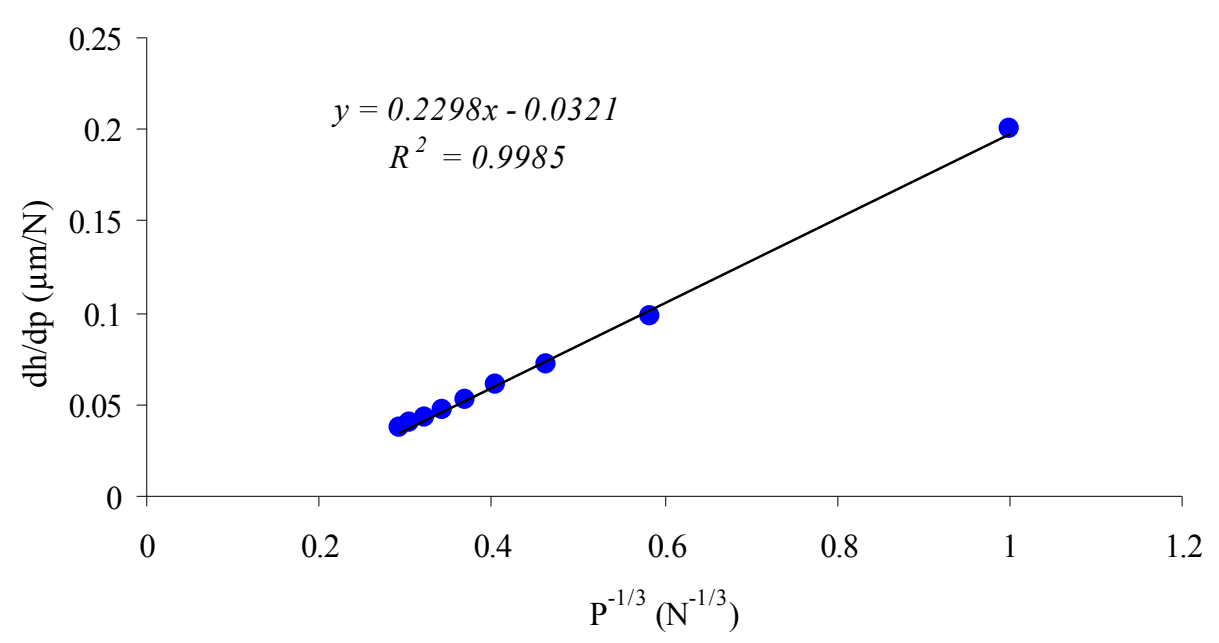

Figure 3-2 Curve fitting between $d h / d p$ and $P^{-1 / 3}$. 


\subsection{Finite element model}

Finite element analysis is employed throughout the course of this research ensuring proper validation of the newly developed approach for material property evaluation. All simulations are assumed to be axis-symmetric and applied about the yaxis in ANSYS ${ }^{\mathrm{TM}}$ v11.0, Figure 3-3. The boundary conditions applied to the model are as follows:

a) The base of the model is constrained about the y-axis but free to move along the $\mathrm{x}$-axis.

b) Overall model size is $2 \mathrm{~mm}$ (width) by $3.5 \mathrm{~mm}$ (height).

c) A rigid body indenter having a radius of $793.5 \mu \mathrm{m}$. The geometry and boundary conditions are shown in Figure 3-3.

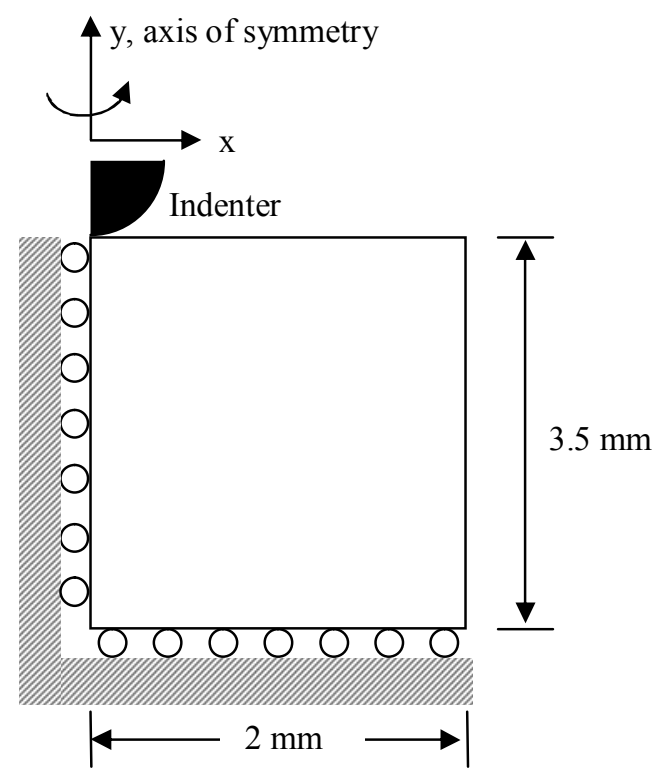

Figure 3-3 Finite element analysis boundary conditions.

In an attempt to reduce the number of elements required, the indenter is generated by first locating a central mass element (Mass21) after which nodes are generated about this point using the previously defined indenter radius. Finally, the central mass and outer nodes are linked with a rigid element (MPC184), Figure 3-4. The nodes located along the radius of the indenter, as well as those along the surface of the substrate, are linked by contact elements (Target69, Contact172) shown in Figure 3-5. Where in the friction is assumed to be zero. This design resulted in a total of 30312 elements and 29971 nodes being used for the finite element model. 


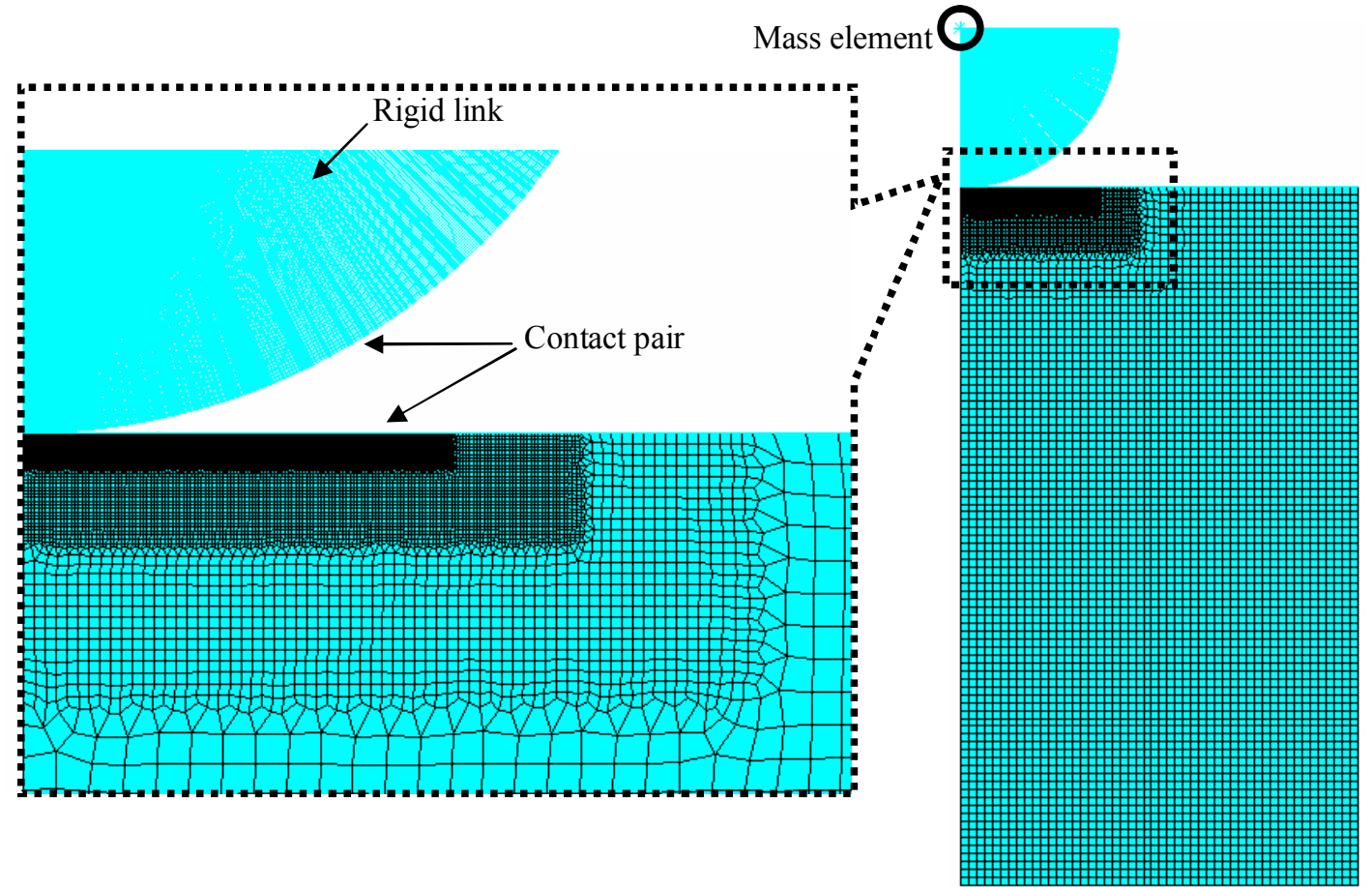

Figure 3-4 Finite element mesh and elements.

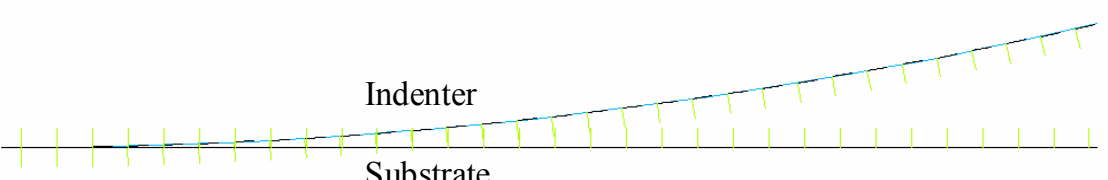

Figure 3-5 Contact pair between the indenter and substrate.

Assuring accurate results, a plane element (Plane182) having a minimum size of $1 \mu \mathrm{m}$ is used within the contact area. This element size is then gradually increased to $40 \mu \mathrm{m}$ along with distance from the point of contact. Thus contact behavior is caused stable and gradually at the initial contact area and nearby. Previously mentioned, the nodes along the radius of the indenter and surface nodes of the substrate are facing one by one, Figure 3-6. This arrangement of nodes is effective to lead a good converged solution for nonlinear analysis. Also the accurate elastic-plastic solution can be performed because the contact pressure is calculated sensitively. 


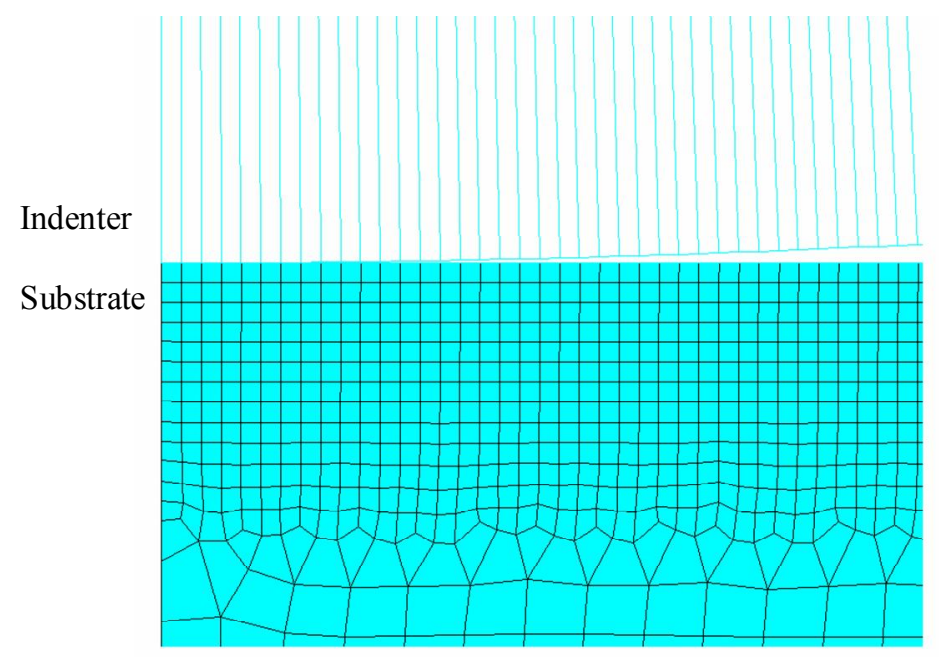

Figure 3-6 Mesh pattern between the indenter and substrate.

In an attempt to simplify and design a parametric study, the material properties used will follow a basic piecewise linear/power-law form. This allows the elastic region of the stress-strain curve to remain constant about a given material. Yet the plastic region varies, Equation (3.3), wherein $n$ is equal to 1 for a perfectly elastic material and zero for a perfectly plastic material. Four strain hardening exponents are chosen for use in this study, 0.1, 0.2, 0.3 and 0.4, the stress-strain curves of which are found in Figure 3-7.

$$
\varepsilon=\frac{\sigma_{o}}{E}\left(\frac{\sigma}{\sigma_{o}}\right)^{\frac{1}{n}} \text {, where } \sigma>\sigma_{\mathrm{o}}
$$

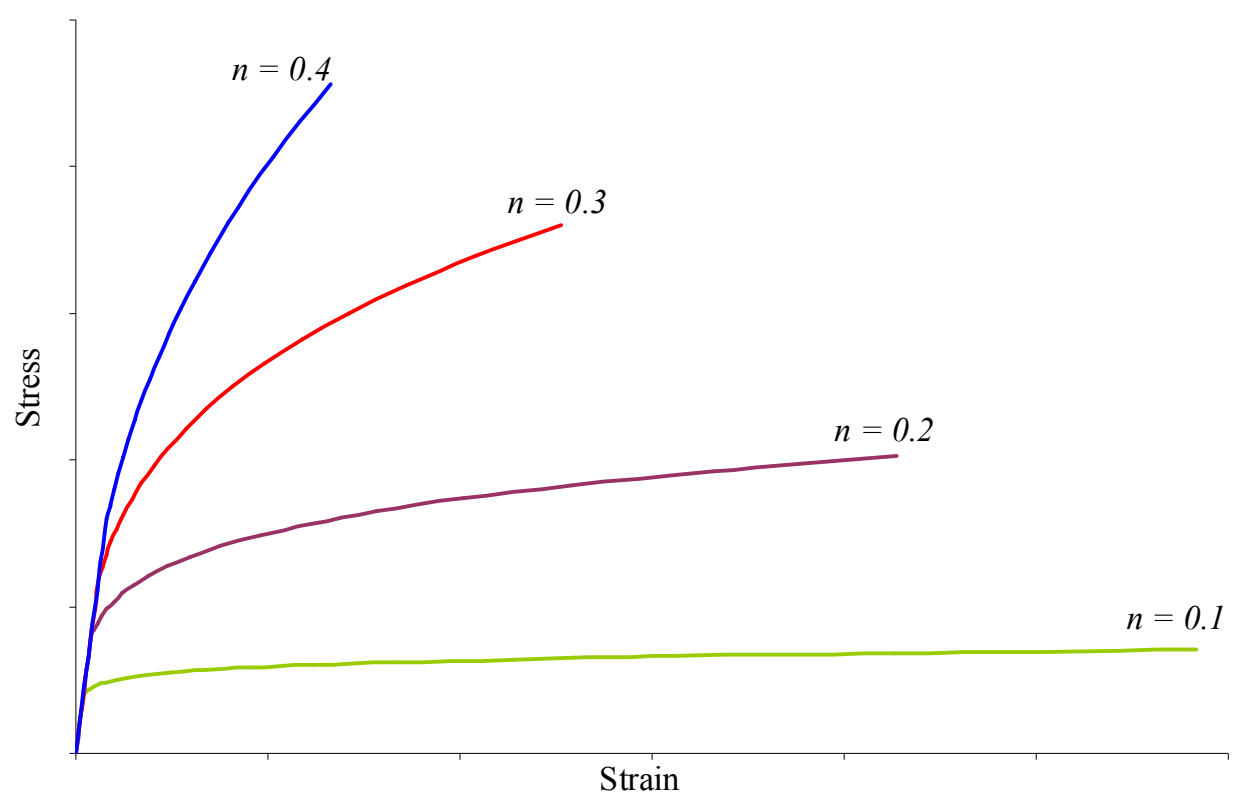

Figure 3-7 Stress-strain plots of the materials used throughout the study. 
As an isotropic strain hardening rule is assumed, thus a multi-linear isotropic hardening material model is employed. In this model the stress-curve is input manually and defined in 500 for sub-steps. Additionally each material is further varied using both yield stress and the four strain hardening exponents previously mentioned. Yield stress is defined using the ratio $\sigma_{o} / E$, and is set to the values of $0.001,0.002,0.003$ and 0.004 , Table $3-1$. Poisson's ratio across all materials and simulations remained at a constant of 0.3 .

Table 3-1 Material properties.

\begin{tabular}{|c|c|c|c|c|}
\hline Material Number & Elastic Modulus (GPa) & Poisson's Ratio & Yield Stress (MPa) & Strain Hardening \\
\hline $1-1$ & 50 & 0.3 & 50 & 0.1 \\
\hline $1-2$ & 50 & 0.3 & 100 & 0.2 \\
\hline $1-3$ & 50 & 0.3 & 150 & 0.3 \\
\hline $1-4$ & 50 & 0.3 & 200 & 0.4 \\
\hline $2-1$ & 100 & 0.3 & 100 & 0.1 \\
\hline $2-2$ & 100 & 0.3 & 200 & 0.2 \\
\hline $2-3$ & 100 & 0.3 & 300 & 0.3 \\
\hline $2-4$ & 100 & 0.3 & 400 & 0.4 \\
\hline $3-1$ & 150 & 0.3 & 150 & 0.1 \\
\hline $3-2$ & 150 & 0.3 & 300 & 0.2 \\
\hline $3-3$ & 150 & 0.3 & 450 & 0.3 \\
\hline $3-4$ & 150 & 0.3 & 600 & 0.4 \\
\hline $4-1$ & 200 & 0.3 & 200 & 0.1 \\
\hline $4-2$ & 200 & 0.3 & 400 & 0.2 \\
\hline $4-3$ & 200 & 0.3 & 600 & 0.3 \\
\hline $4-4$ & 200 & 0.3 & 800 & 0.4 \\
\hline $5-1$ & 250 & 0.3 & 250 & 0.1 \\
\hline $5-2$ & 250 & 0.3 & 500 & 0.2 \\
\hline $5-3$ & 250 & 0.3 & 750 & 0.3 \\
\hline $5-4$ & 250 & 0.3 & 1000 & 0.4 \\
\hline
\end{tabular}

\subsection{Finite element analysis results}

\subsubsection{Pile-up and sink-in behavior}

Once the finite element simulation is carried out through the material properties from 1-1 to 5-4, pile-up and sink-in behavior is observed as the material properties vary. The material around the contact area shows elastic-plastic deformation. In the finite element analysis result, the materials with a low yield stress to elastic modulus $\left(\sigma_{o} / E\right)$ and low strain hardening value $(n)$, the substrate material is found to pile-up and increase contact area, Figure 3-8. In the materials with high ratio of $\left(\sigma_{d} / E\right)$ show sink-in around contact area and contact area is reduced, Figure 3-9. Both of pile-up and sink-in behavior 
cause difficulty to measure accurate contact area. These elastic-plastic material behavior around the contact area is depend on material properties and strain hardening exponents. Also, it is dependent on ductile and brittle material behavior.

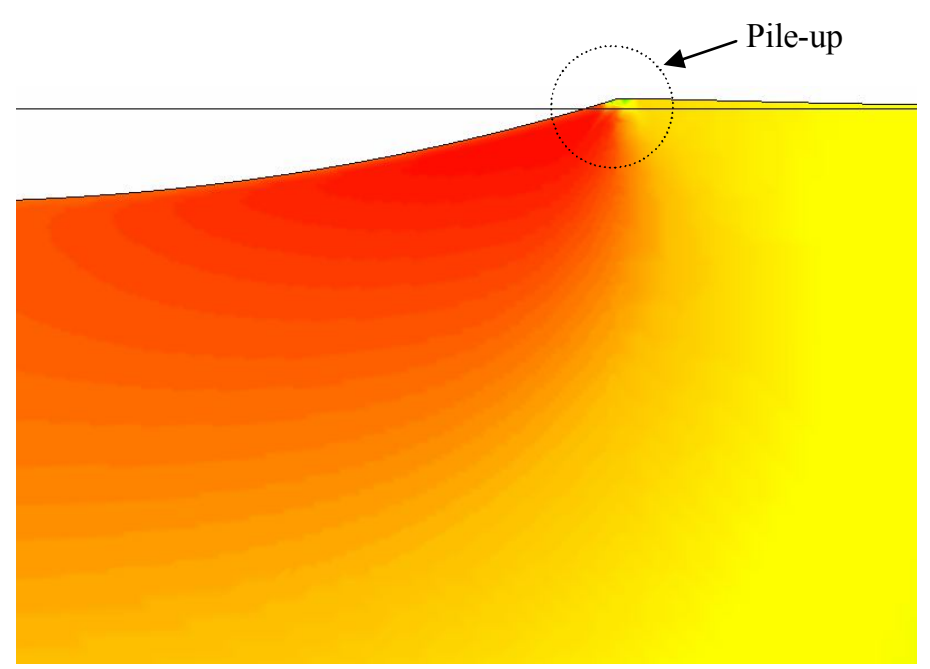

Figure 3-8 Pile-up behavior around the contact area.

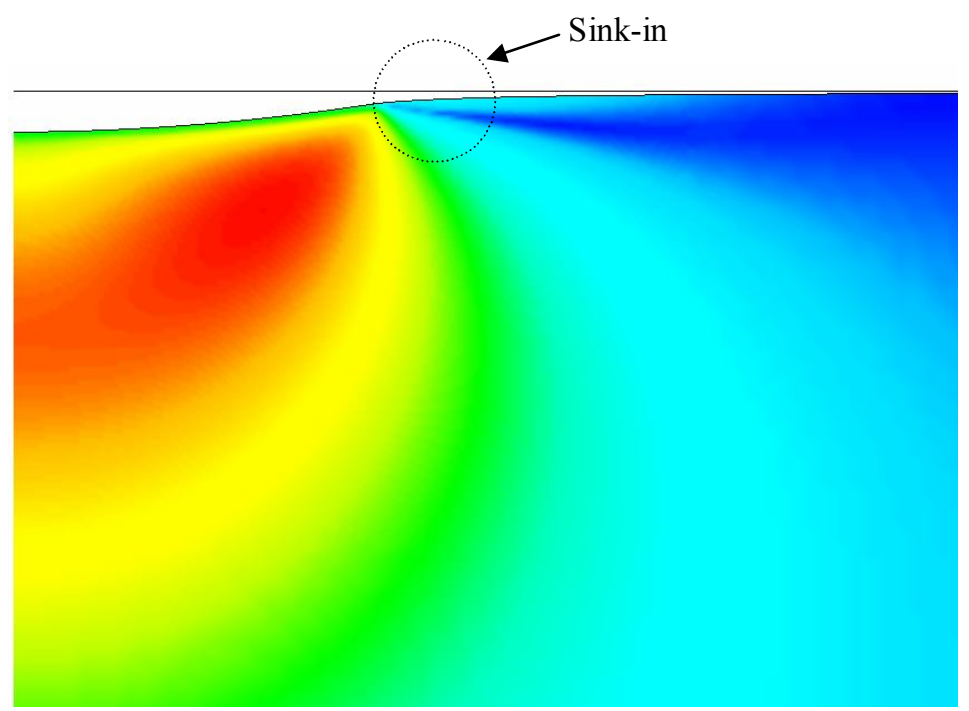

Figure 3-9 Sink-in behavior around the contact area.

\subsubsection{Calculation of elastic modulus}

Throughout the multiple partial unloading indentation testing process, a predefined load or displacement is applied to the rigid indenter. During which both load and depth data are acquired from the radial node along the y-axis ensuring proper evaluation. The stresses occurring in and around this area of contact are both elastic and plastic, where in any stress occurring above the yield is defined as plastic, Figure 3-10. All elastic modulus calculations carried out utilizing the multiple partial unloading procedures are performed using five partial unloadings at $1,5,10,15$ and $20 \mathrm{~N}$, all of 
which are unloaded $10 \%$. This loading and unloading range are found to generate the clearest and most linear trends, Figure 3-11. These results indicate that this indentation methodology is capable of extracting accurate elastic modulus of unknown materials to within $6 \%$ of their actual values, Table 3-2. Material 1-1 is found to have the greatest percentage of error. This is most likely due to the relatively low elastic modulus, yield stress and strain hardening of the materials employed to generate functions $C(n)$ when compared to that of the other materials. A similar concern must be placed on materials having either a strain hardening exponent or yield stress ratio outside the range of 0.1 0.4 and $0.001 \sim 0.004$ respectively. Although this may slightly limit the materials for which this relationship holds true, additional research efforts may lead to a more general and accurate algorithm. The results of the error percentage of both the calculated elastic modulus and coefficient $C$ decrease as the true yield stress, strain hardening exponent and elastic modulus increase, Figure 3-12. This indicates that materials having a larger yield stress and strain hardening rate develop a more accurate and linear relationship among $d h / d P$ and $P^{-1 / 3}$. This does not however diminish the added benefits of a load-based indentation procedure, where in no high precision displacement sensors or contact area measurements are required. The removal of these constraints has led to the development of a portable device capable on onsite, in-situ material mechanical property evaluation [3]. Furthermore, this multiple-partial unloading procedure has been employed in the construction of a high temperature indentation system, capable of material mechanical property evaluation up to $1200^{\circ} \mathrm{C}$ [44].

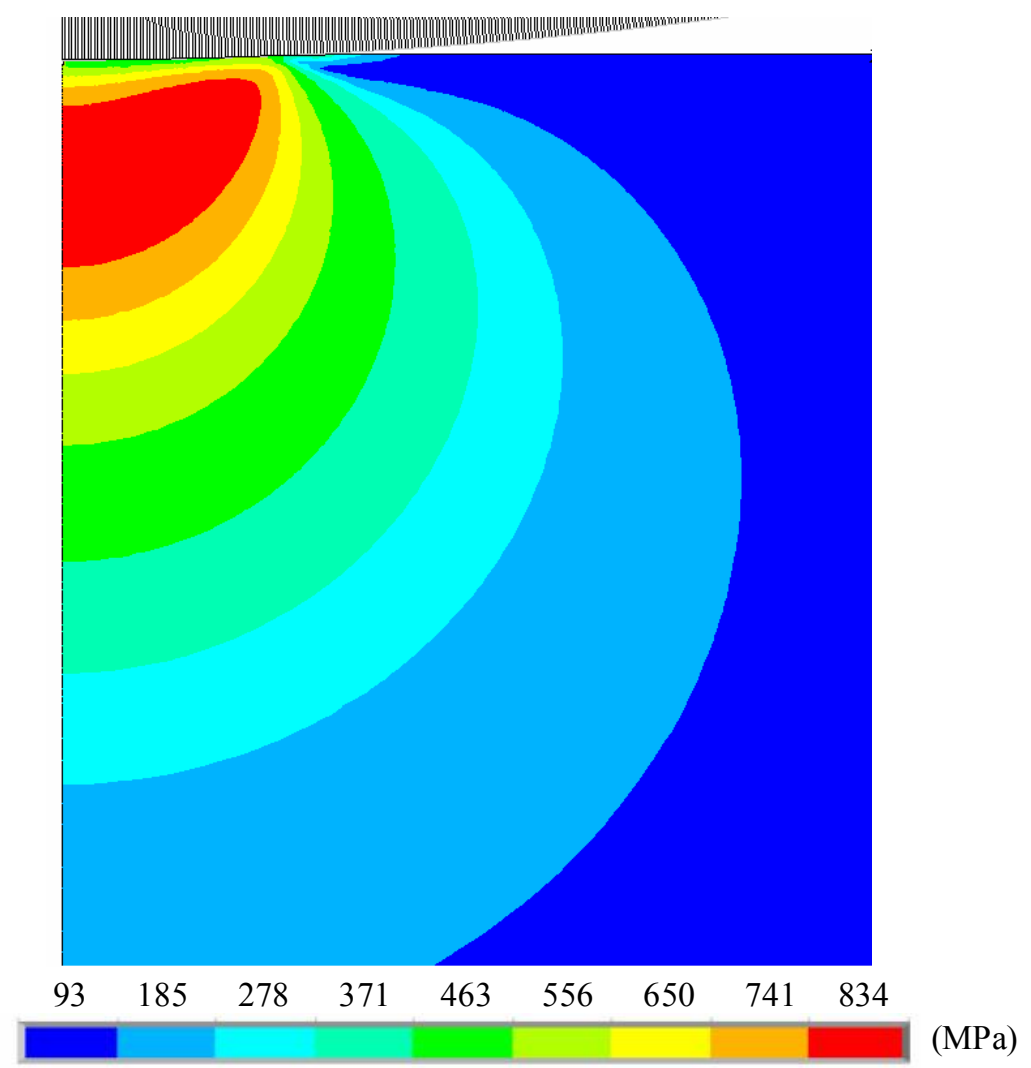

Figure 3-10 Von-Mises stress contour of material 4-3. 


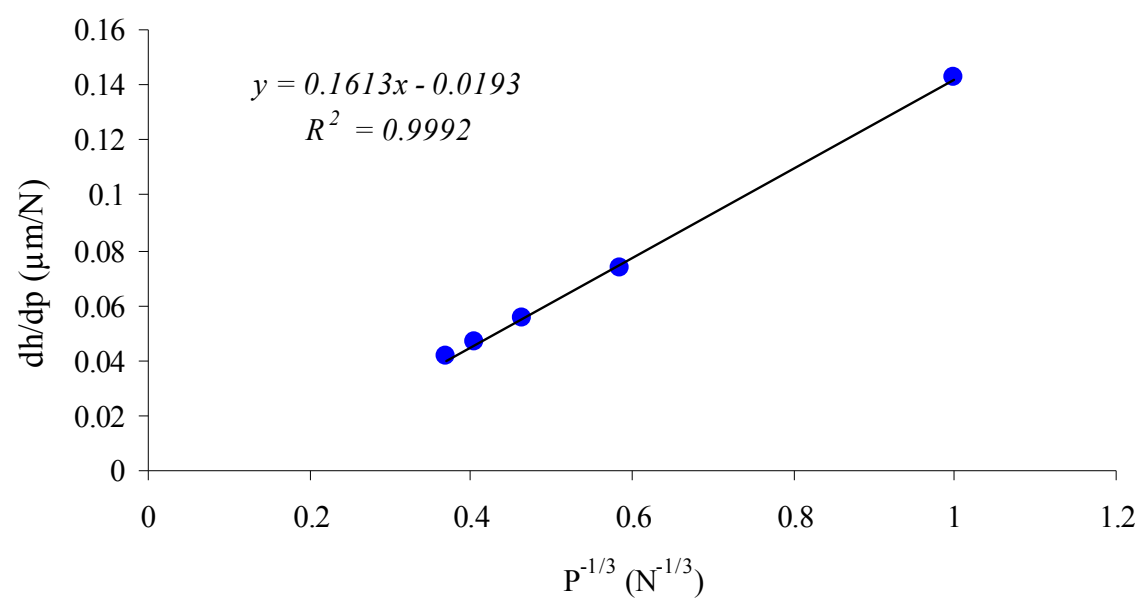

Figure 3-11 Curve fitting between $d h / d P$ and $P^{-1 / 3}$ of material 4-3.

Table 3-2 Material property evaluations.

\begin{tabular}{|c|c|c|c|}
\hline Material number & Error $(\mathrm{C}) \%$ & Elastic modulus $(\mathrm{GPa})$ & Error (E) \% \\
\hline $1-1$ & 3.49 & 53 & 5.27 \\
\hline $1-2$ & 3.18 & 48 & 4.59 \\
\hline $1-3$ & 2.91 & 52 & 4.53 \\
\hline $1-4$ & 2.53 & 48 & 3.68 \\
\hline 2-1 & 3.12 & 105 & 4.72 \\
\hline $2-2$ & 2.58 & 104 & 3.89 \\
\hline $2-3$ & 2.52 & 96 & 3.76 \\
\hline $2-4$ & 2.20 & 97 & 3.29 \\
\hline $3-1$ & 3.00 & 143 & 4.46 \\
\hline $3-2$ & 2.27 & 145 & 3.38 \\
\hline $3-3$ & 2.13 & 145 & 3.17 \\
\hline $3-4$ & 2.09 & 145 & 3.11 \\
\hline 4-1 & 2.64 & 192 & 3.93 \\
\hline $4-2$ & 1.69 & 195 & 2.53 \\
\hline $4-3$ & 1.43 & 196 & 2.13 \\
\hline $4-4$ & 1.13 & 197 & 1.69 \\
\hline $5-1$ & 2.41 & 259 & 3.63 \\
\hline $5-2$ & 1.65 & 244 & 2.46 \\
\hline $5-3$ & 1.11 & 254 & 1.66 \\
\hline $5-4$ & 0.95 & 245 & 1.43 \\
\hline
\end{tabular}




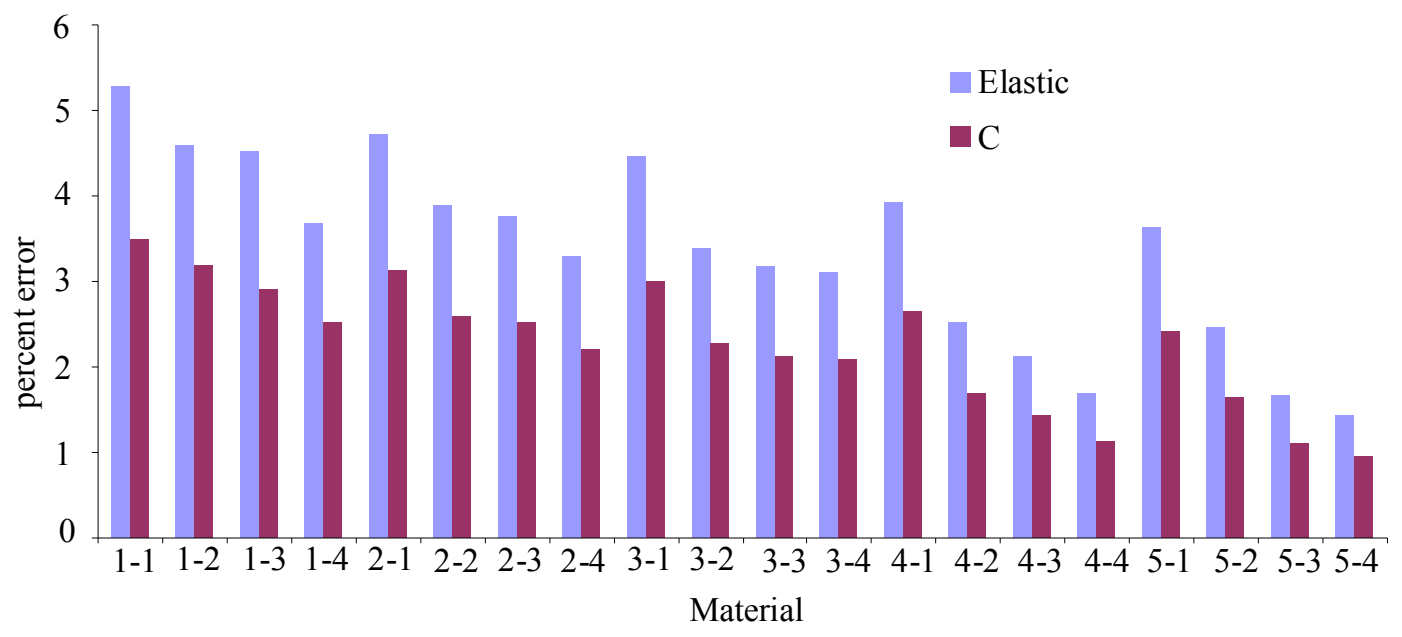

Figure 3-12 Curve fitting and elastic modulus calculation percent error.

\subsubsection{Strain hardening and yield strength}

Finite element analysis has been employed throughout the course of this study to ensure proper validation of the newly developed approach for material property evaluation. In addition for elastic modulus calculation, the multiple partial unloading indentation data has been used to generate functions for the unknown parameters $M(n)$ and $K(n)$. Yet prior to extraction of these parameters a linear relationship between $\ln \left(P / \pi R^{2} E\right)$ and $\ln \left(h_{c} / R\right)$ must first be established, where the slope of this line is equal to $M(n)$ and the intercept $\ln (K(n))+(1-n) \ln \left(\sigma_{\delta} / E\right)$, a typical example of which is found in Figure 3-13.

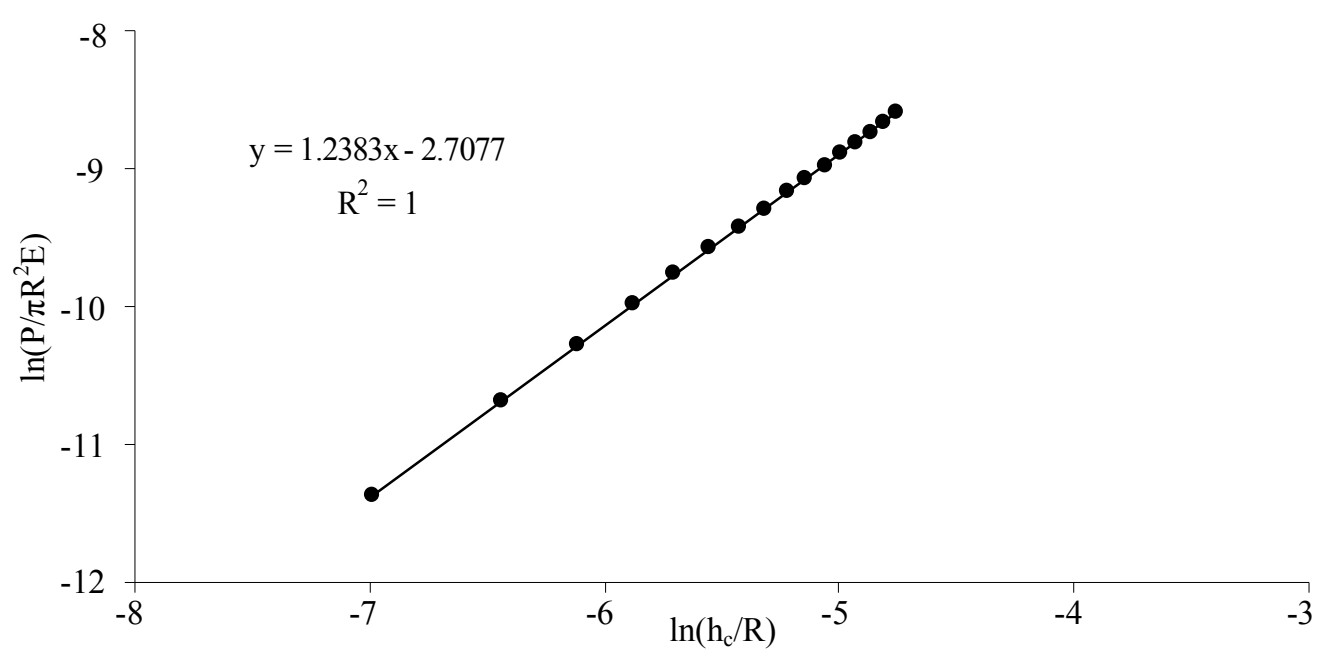

Figure 3-13 Linear relationship between $\ln \left(P / \pi R^{2} E\right)$ and $\ln \left(h_{c} / R\right)$ of material 4-3.

Repeating this procedure across all materials with known elastic moduli, yield stress, load and contact depth leads to the development of functions for both for both $M(n)$ and $K(n)$ 
along strain hardening exponent (n), Figure 3-14 and Figure 3-15. Found to be linear, functions for both coefficients were generated and shown in Equations (3.4) and (3.5).

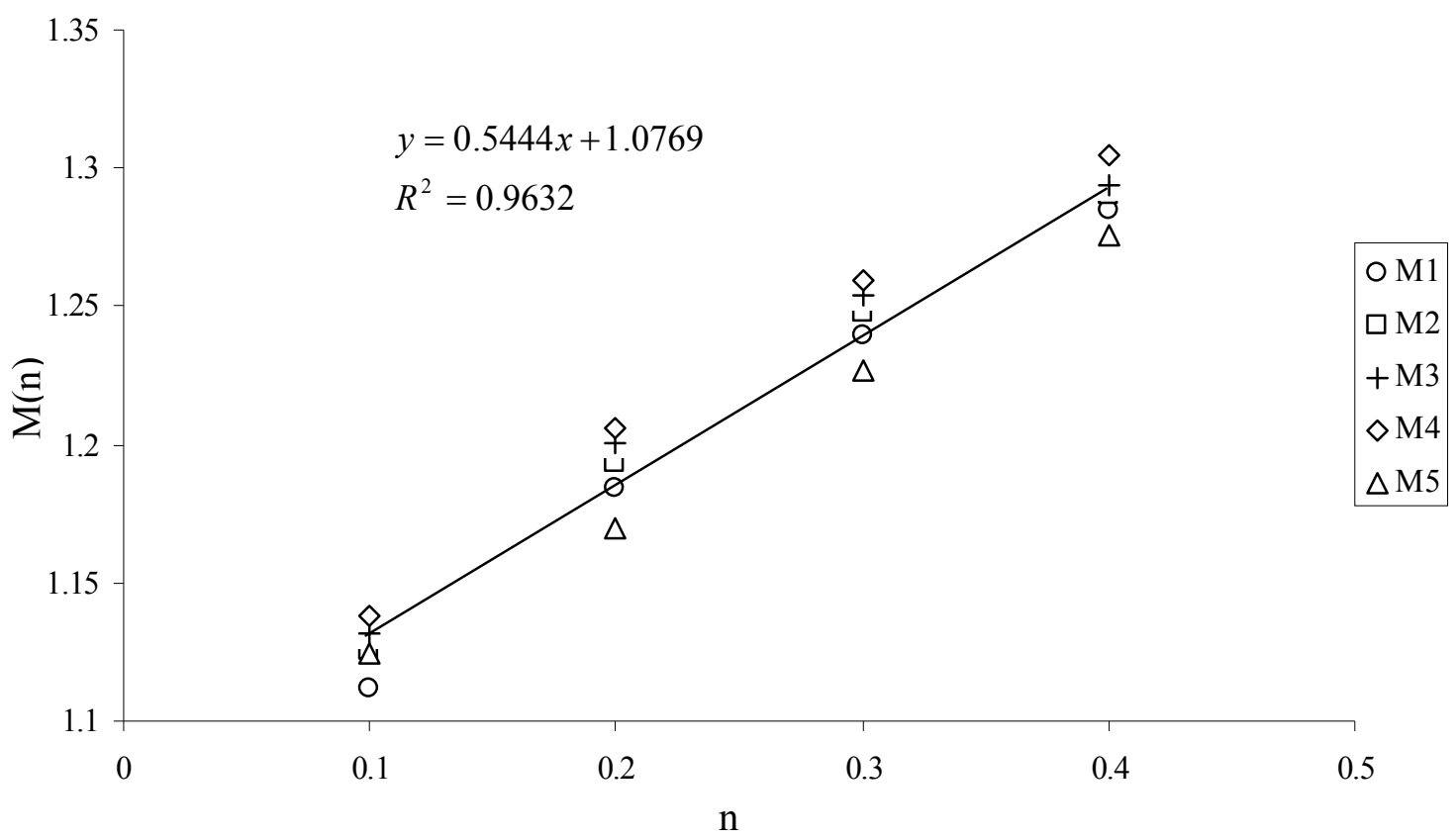

Figure 3-14 Linear relationship between $M(n)$ and $n$.

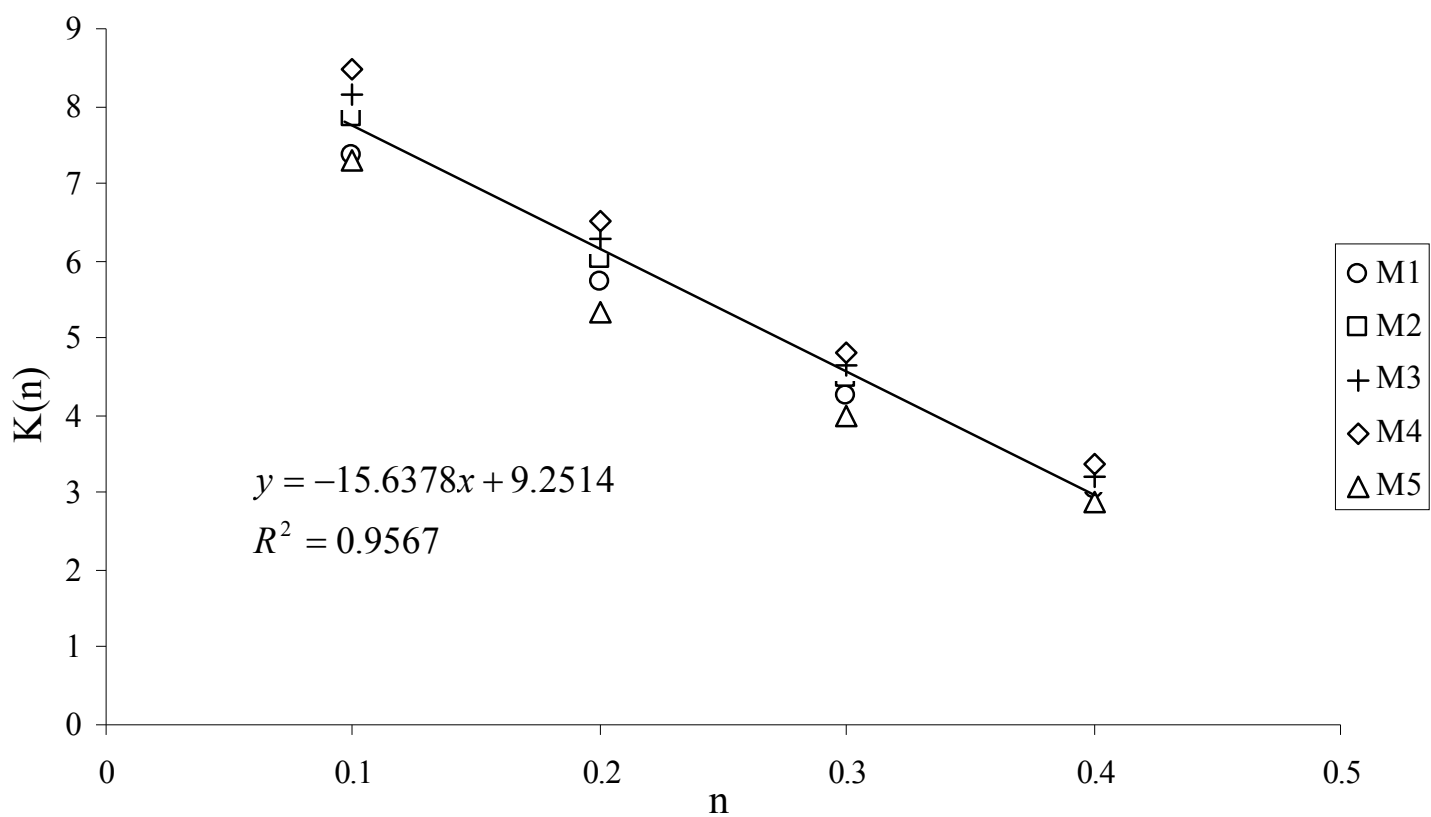

Figure 3-15 Linear relationship between $K(n)$ and $n$.

$$
M(n)=0.5444 n+1.0769
$$




$$
K(n)=-15.638 n+9.2514
$$

Once found, the slope of this linear model will now represent $M(n)$, whereas the yintercept is indicative of $\ln (k(n))+(1-n) \ln \left(\sigma_{d} / E\right)$ and $K(n)$. Using this procedure, all materials are evaluated. Once again fitting these values using the standard linear modeling procedure, functions for both coefficients are defined, Equation (3.6).

$$
\frac{P}{\pi R^{2} E}=(-15.64 n+9.25)\left(\frac{\sigma_{o}}{E}\right)^{1-n}\left(\frac{h_{c}}{R}\right)^{(0.54 n+1.077)}
$$

Finally to establish the validity of this newly defined elastic-plastic load-depth equation, several materials are evaluated assuming no prior knowledge of their mechanical properties; zirconia, aluminum, steel and copper (UNS C11000, H04). Loaddisplacement results indicate that this relationship is capable of extracting elastic-plastic mechanical properties of unknown materials to within $10 \%$ of their true values, Table 3-3. Aluminum is found to have the greatest percentage of error, yet this is most likely due to the relatively large elastic modulus of the materials employed to generate functions $M(n)$ and $K(n)$ when compared to that of aluminum. Also, a similar concern must be placed on materials having either strain hardening exponents or yield stresses outside the range of $0.1 \sim 0.4$ and $0.001 \sim 0.004$ respectively. Although this may slightly limit the materials for which this relationship holds true, additional research efforts may lead to a more general and accurate algorithm.

Table 3-3 Material property evaluations.

\begin{tabular}{|c|c|c|c|c|c|c|c|c|c|}
\cline { 2 - 10 } \multicolumn{1}{c|}{} & \multicolumn{4}{c|}{ Material Properies } & \multicolumn{6}{c|}{ Computed Properties } \\
\cline { 2 - 10 } \multicolumn{1}{c|}{} & $\mathrm{n}$ & $\sigma_{\mathrm{o}}(\mathrm{MPa})$ & $\mathrm{E}(\mathrm{GPa})$ & $\mathrm{a}$ & $\mathrm{b}$ & $\mathrm{n}$ & Error \% & $\sigma_{\mathrm{o}}$ & Error \% \\
\hline Zirconia & 0.2 & 241 & 99.3 & 1.19 & -3.02 & 0.205 & 2.35 & 236 & 2.09 \\
\hline Aluminum & 0.3 & 320 & 69 & 1.24 & -2.32 & 0.297 & 0.98 & 296 & 7.61 \\
\hline Steel & 0.1 & 690 & 205 & 1.13 & -3.12 & 0.103 & 2.75 & 668 & 3.12 \\
\hline $\begin{array}{c}\text { Copper } \\
\text { (UNS C11000, } \\
\text { H04) }\end{array}$ & 0.15 & 310 & 125 & 1.16 & -3.17 & 0.153 & 1.71 & 306 & 1.44 \\
\hline
\end{tabular}

\subsubsection{Experimental validation}

To validate the proposed indentation test methodology for material elastic modulus, yield strength and strain hardening exponent evaluation, a micro-indentation systems was constructed, as shown in Figure 3-16. Micro-indentation tests were performed on three materials, electrolytic tough pitch copper (UNS C11000, H04), aluminum alloy (UNS AA2036-T4) and stainless steel (UNS S3090). The reported elastic modulus values for these materials are indicated in Table 3-4. Surface preparation of these materials encompassed; a) minor polishing using 600 grit sand papers, followed by b) a brief acetone bath removing any particulate that may have remained. Also, all 
samples were properly constrained prior to any indentation testing. All tests were conducted using a loading/partial-unloading algorithm comprised of ten steps, each of which having a $2 \mu \mathrm{m}$ loading and $1 \mu \mathrm{m}$ unloading displacement.

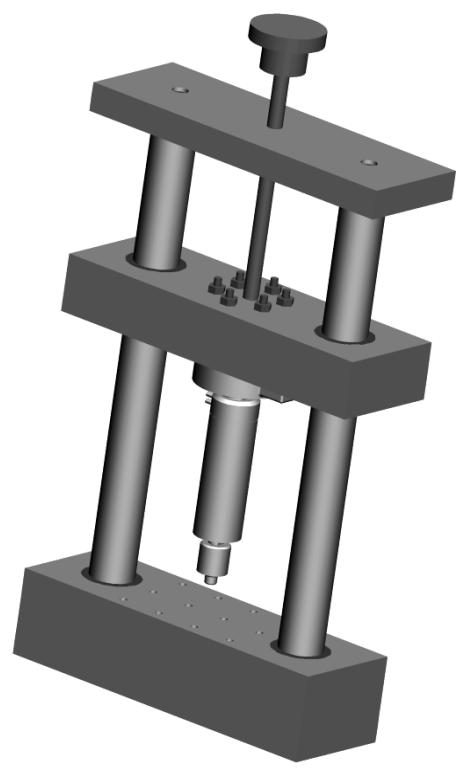

Figure 3-16 Experimental micro-indentation test unit.

During an indentation test, the loading apparatus is also subjected to the indentation load, thus the total actuator displacement $\left(h_{P Z T}\right)$ includes total indentation depth and system deformation, Equation (3.7).

$$
h_{P Z T}=h_{T}+h_{S}
$$

where $h_{T}$ is the total indentation depth, and $h_{s}$ is deformation of the indentation system caused by the indentation load. Taking the derivative on both sides where $d h_{s} / d P$ represents the system compliance, i.e. $d h_{s} / d P=C_{s}$, and it is shown in Equation (3.8) and (3.9).

$$
\begin{gathered}
\frac{d h_{P Z T}}{d P}=\frac{d h_{T}}{d P}+\frac{d h_{s}}{d P} \\
\frac{d h_{P Z T}}{d P}=\left(6 R E_{R}^{2}\right)^{-1 / 3} P^{-1 / 3}+C_{s}=C P^{-1 / 3}+C_{s}
\end{gathered}
$$

The total actuator displacement is relatively easy to obtain experimentally and measurement of the total indentation depth $\left(h_{T}\right)$ is not required. However, determination of the system compliance $\left(C_{s}\right)$ is not easy. For example, as the specimen size varies, the system compliance will also change. Thus, when using Equation (3.9) it is desirable to find an in-situ measurement of the system compliance. This is achieved by using the 
proposed multiple-partial unloading approach [3]. For a spherical indenter at each unloading step, from Equation (3.9), the unloading compliance is defined as shown in Equation (3.10).

$$
\left(\frac{d h_{P Z T}}{d P}\right)_{i}=C \times P_{i}^{-\frac{1}{3}}+C_{s}
$$

Equation (3.10) shows that $\left(d h_{P Z T} / d P\right)_{i}$ and $P_{i}^{-1 / 3}$ have a linear relationship if $C_{s}$ maintains to be a constant during these multiple loading/partial unloading steps, and $C$ is the slope for elastic modulus measurement, Equation (3.9). Validly of the proposed load-based indentation method can be checked via Equation (3.10), i.e. if the system compliance does change during the indentation test, the linear relationship depicted in Equation (3.10) will not be maintained and vice versa. Figure 3-17 shows a load-displacement curve of UNS C11000, H04 with multiple partial unloading. The expectation of a linear relationship between $d h_{P Z T} / d P$ and $P^{-1 / 3}$ was found to hold true during testing of each alloy, as shown in Figure 3-18. Assuming Poisson's ratio value of 0.33 for copper and aluminum and 0.3 for stainless steel. Through the multiple partial unloading indentation tests, elastic modulus values were extracted using Equation (3.10) and calculation of yield stress and strain hardening exponent were conducted using the slope and the intercept of Equation (2.27). The results found to be in good agreement with referenced values, as shown in Table 3-4. To account for test system compliance when calculating load-depth relations two plots must be created to extract $h_{T}$ as shown in Equation (3.11). This is also shown in Figure 3-17.

$$
h_{T}=h_{P Z T}-P C_{s}
$$

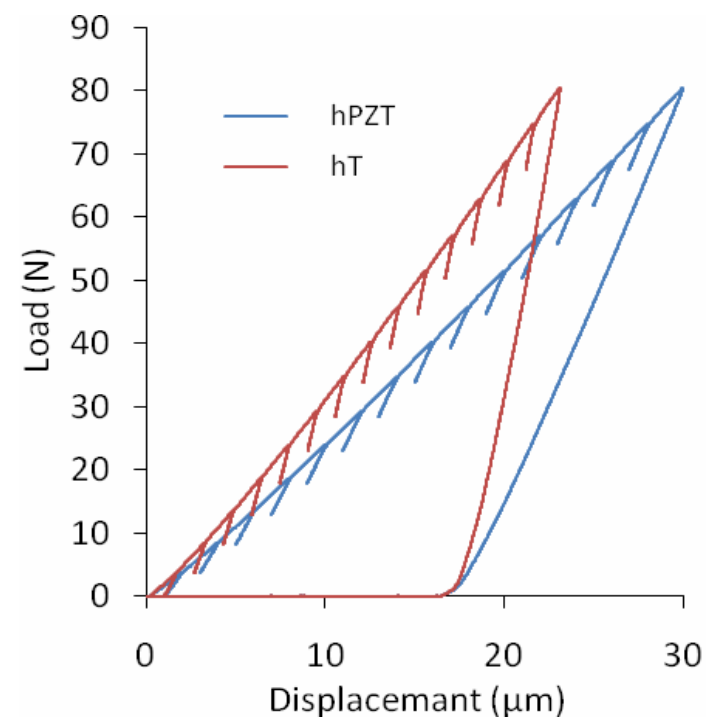

Figure 3-17 Load-displacement curve of UNS C11000, H04. 


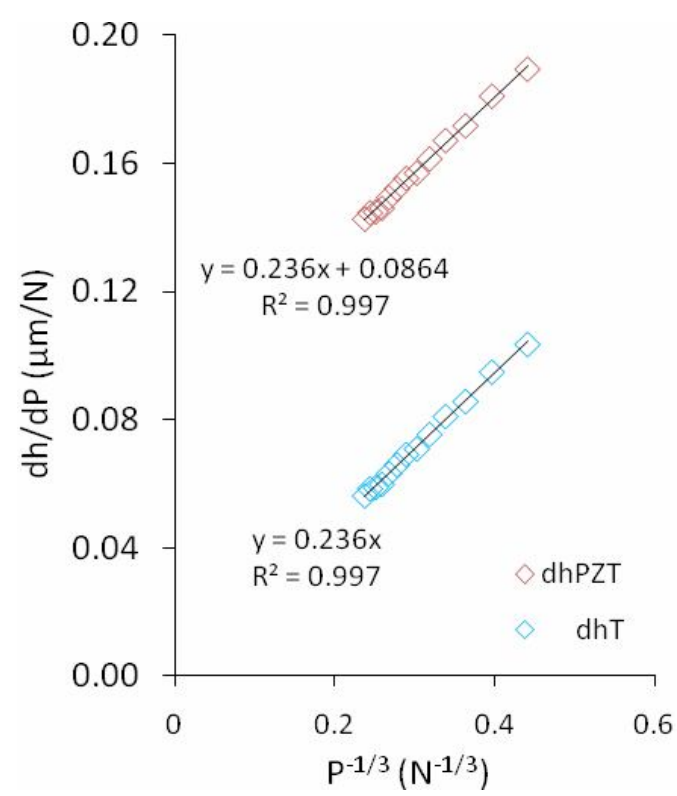

Figure 3-18 Curve fitting between unloading slope and $\mathrm{P}^{(-1 / 3)}$ of UNS C11000, H04.

Table 3-4 load based indentation material properties.

\begin{tabular}{|c|c|c|c|}
\hline \multicolumn{5}{c}{ Electrolytic tough pitch copper, UNS C11000, H04 } \\
\hline Evaluation Number & Elastic Modulus $(\mathrm{GPa})$ & Yield Stress $(\mathrm{MPa})$ & Strain Hardening \\
\hline Literature & $115 \sim 130$ & 310 & $0.1 \sim 0.2$ \\
\hline Test 1 & 129.3 & 305.8 & 0.14 \\
\hline Test 2 & 128.7 & 312.1 & 0.15 \\
\hline Test 3 & 126.2 & 317.4 & 0.18 \\
\hline Test 4 & 125.2 & 310.9 & 0.16 \\
\hline Test 5 & 135.1 & 300.4 & 0.19 \\
\hline Average & 128.9 & 309.3 & 0.17 \\
\hline
\end{tabular}

Aluminum alloy, UNS AA2036-T4

\begin{tabular}{|c|c|c|c|}
\hline Evaluation Number & Elastic Modulus $(\mathrm{GPa})$ & Yield Stress $(\mathrm{MPa})$ & Strain Hardening \\
\hline Literature & 71.0 & 193 & $0.1 \sim 0.3$ \\
\hline Test 1 & 72.0 & 205.3 & 0.28 \\
\hline Test 2 & 73.1 & 208.4 & 0.25 \\
\hline Test 3 & 70.1 & 206.4 & 0.29 \\
\hline Test 4 & 69.5 & 194.8 & 0.19 \\
\hline Test 5 & 72.4 & 204.1 & 0.28 \\
\hline Average & 71.4 & 203.8 & 0.26 \\
\hline
\end{tabular}

Stainless Steel, UNS S3090

\begin{tabular}{|c|c|c|c|}
\hline Evaluation Number & Elastic Modulus $(\mathrm{GPa})$ & Yield Stress $(\mathrm{MPa})$ & Strain Hardening \\
\hline Literature & $200 \sim 210$ & $290 \sim 300$ & $0.1 \sim 0.3$ \\
\hline Test 1 & 205.7 & 314.8 & 0.13 \\
\hline Test 2 & 209.7 & 301.7 & 0.16 \\
\hline Test 3 & 211.6 & 298.8 & 0.12 \\
\hline Test 4 & 214.3 & 307.3 & 0.11
\end{tabular}




\begin{tabular}{|c|c|c|c|}
\hline Test 5 & 199.2 & 304.8 & 0.13 \\
\hline Average & 208.1 & 305.5 & 0.13 \\
\hline
\end{tabular}

This elastic-plastic depth sensing is a new analytical approach for determining the elastic modulus, yield stress and strain hardening exponent. Incorporating both elastic and elastic-plastic material behavior, an innovative load-based multiple partial unloading procedure has been found to yield accurate elastic modulus measurements without the use of contact area measurements or high precision displacement sensors. Also, slight modification of Mesarovic and Fleck's spherical indentation solution [35] has given way to a numerical relationship between strain hardening exponent, yield stress, indentation contact depth, reduced modulus, indenter radius and load. Standard finite element analysis and preliminary experimental test results verifying high accuracy and consistency across a range of materials (zirconia, aluminum, steel and copper). Although reliable, a more extensive analytical study using a larger variety of material properties is expected to yield a more general relationship between these parameters. Furthermore, the effect of loading range of these newly developed procedures has not been treated in detail and requires additional analysis. Finally, the accuracy of these techniques in an experimental application may vary when non-ideal boundary conditions exist and will be examined in further research. 


\section{Chapter 4 THERMAL BARRIER COATING SYSTEMS}

The demand for improved efficiencies in energy conversion systems in recent years has led to the introduction of land-based gas turbines with significantly higher gas inlet temperatures. Handling of such high temperatures requires the use of high strength, directionally solidified and single crystalline nickel-base superalloys. In addition, the components in the turbine's hottest sections are internally cooled and protected by ceramic thermal barrier coatings (TBC) which allow component operation at gas temperatures greater than that of the superalloy's melting point. However, the most critical first stage turbine blades are improved by application of TBC systems for increased firing temperatures [45]. TBC creates a thermal barrier allowing super alloys to be exposed to far harsher thermal environments while maintaining their structural integrity [46]. Facilitating the use of super alloys at temperatures $100 \sim 300{ }^{\circ} \mathrm{C}$ higher than that of conventional operation, Air Plasma Sprayed (APS) 6-8weight\% yttria partially stabilized zirconia (YSZ) not only enhance component life but turbine efficiency as well $[47,48]$. Currently, the TBC effectiveness is limited by its corrosion resistance, structural reliability and unpredictable spallation failure. A multi-layer matrix, a TBC system is composed of three layers. The top coat or thermal barrier of the TBC system is deposited with a metallic bond coating (BC) layer residing between it and the super alloy substrate. This $\mathrm{BC}$ is typically composed of $\mathrm{Ni}, \mathrm{Co}$, and $\mathrm{Cr}$ with sufficient concentrations of Al. The large quantity of aluminum in this layer ensures that oxide scales' developing under thermally energetic conditions are predominantly composed of stable $\alpha-\mathrm{Al}_{2} \mathrm{O}_{3}$. Guaranteeing adequate adhesions of this thermally grown oxide (TGO) rare earth metals such as $\mathrm{Y}$ and $\mathrm{Pt}$ are added in small amounts [49]. The TGO is a major contributor to the TBC systems overall interfacial thermo mechanical resistance and entertains brittle yet unavoidable spinel oxides such as $\mathrm{NiAl}_{2} \mathrm{O}_{4}$ [50]. The growth of TGO provides residual stresses by a thermal expansion mismatch. It results in cracking, buckling and spallation failure of TBC and is related to material degradation. Since combustion components and turbine blades are exposed to severe thermal cycles, it is important to understand the failure mechanisms of TBC in order to design optimum systems. The majority of failure mechanism is residual stress in TGO due to thermal expansion mismatches but it is difficult to measure and not well understood. In this research, a numerical residual stress analysis has been conducted where several variable thicknesses thermally grown oxide (TGO) geometries were imposed. Analysis of the out-of-plane tensile stresses produced upon cooling has provided a detailed explanation of experimentally observed microstructural failure patterns in APS/MCrAlY/RenéN5 TBC systems. 


\subsection{Top Coating Layer}

The top coating layer or thermal barrier coating is a majority to insulate from high temperature. Yittria partially stabilized zirconia is preferred to be used due to its low thermal conductivity. Based on laboratory thermal cycle tests, decent YSZ phase was determined to find superior durability. That was found for $6-8$ weight $\%$ yttria partially stabilized zirconia [51]. There are two ways to deposit YSZ, Electron Beam Physical Vapor Deposition (EB-PVD) and Air Plasma Spray (APS). The YSZ is evaporated from an ingot and deposited onto the preheated surface of the component. The created microstructure is a columnar grain structure with micro-pores that helpful to increase the critical strain and thermal conductivity, Figure 4-1. APS costs less than EB-PVD but the deposition has a significant amount of porosity [52]. The main difference between EBPVD and APS is the surface morphology between BC and YSZ. TGO is created by oxidation in this layer during engine operation.

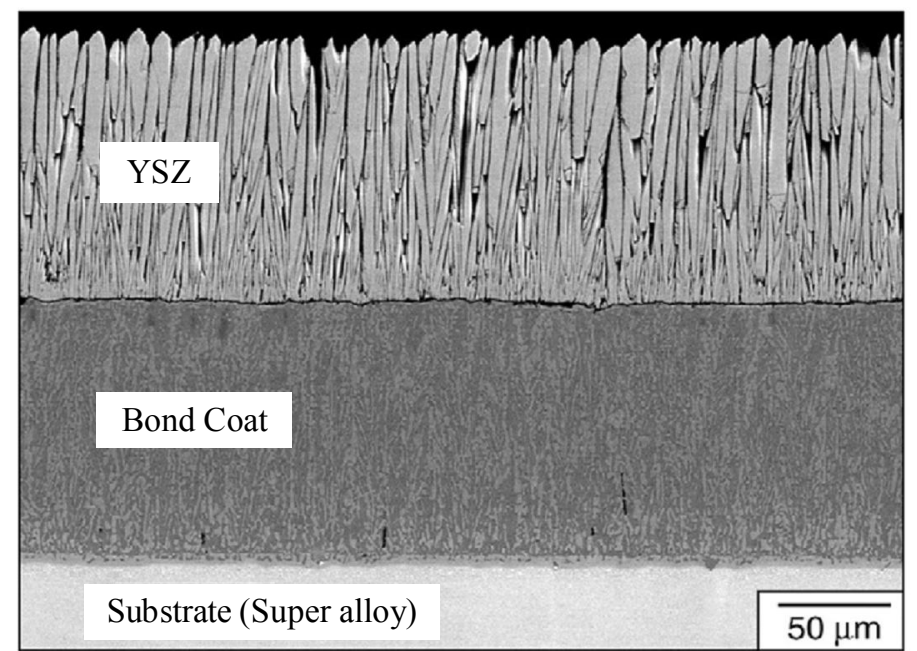

Figure 4-1 Cross sectional view of TBC systems by EB-PVD [51].

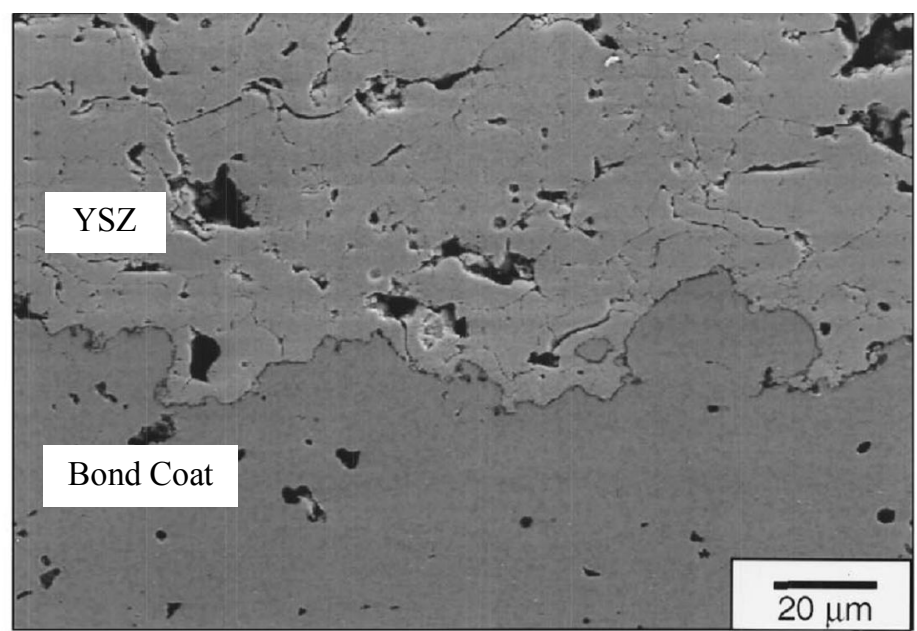

Figure 4-2 Cross sectional view of TBC systems by APS [49]. 


\subsection{Bond Coating Layer}

The bond coat is coated to enhance the adhesion of the YSZ. Its micro-structure and surface morphology affect the TGO creation. BC is usually two-phase, $\beta$ - or $\gamma$ MCrAlY. As TBC has been exposed to high temperature for a long time, the $\beta$-phase is disappeared completely due to $\mathrm{Al}$ diffusion and $\gamma$-phase is left with a twinned microstructure. This $\mathrm{Al}$ diffusion toward to the YSZ and super alloy substrate oxides to form TGO [49].

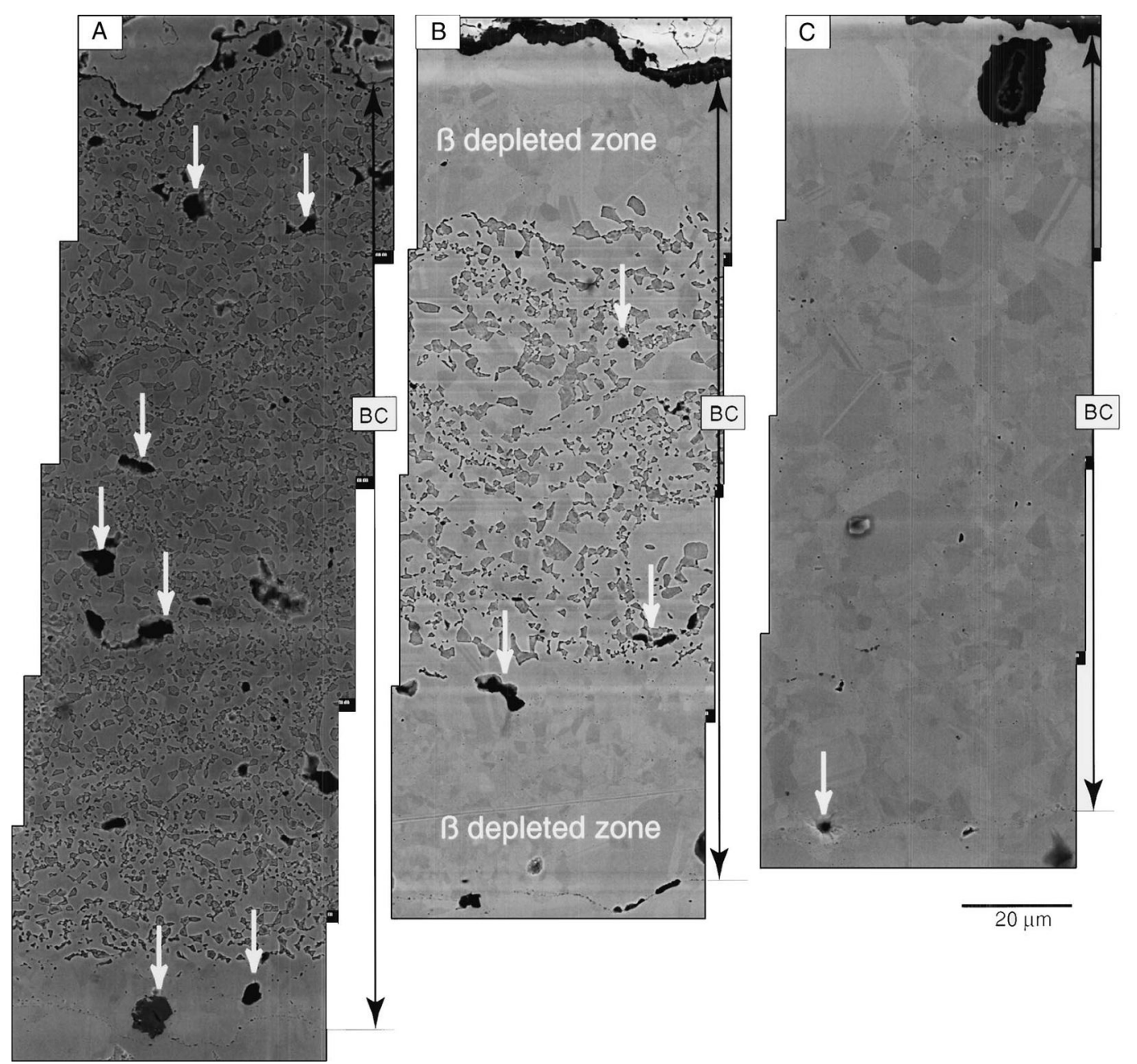

Figure 4-3 cross sectional images of TBC before and after thermal exposure.

(A) The two-phase, $\beta$ - and $\gamma$-MCrAlY shown.

(B) $\beta$-depleted zones are shown, near the substrate and the TGO after $216 \mathrm{~h}$ at $1010^{\circ} \mathrm{C}$.

(C) Only full $\beta$-depleted bond coat is shown after $1944 \mathrm{~h}$ at $1010^{\circ} \mathrm{C}$

The arrows indicate the oxide inclusions and the pores in the bond coat [49]. 


\subsection{Thermally Grown Oxide}

Thermally grown oxide (TGO) is a majority to affect TBCs' durability and its life cycle. The oxygen existed in YSZ diffuses fast by high temperature operation and reacts with the depleted $\mathrm{Al}$ from BC. Thus, TGO $\left(\alpha-\mathrm{Al}_{2} \mathrm{O}_{3}\right)$ is created between YSZ and BC and grown as thermal cycle proceed. The growth of TGO involves counter-diffusion of oxygen and $\mathrm{Al}$ along the $\alpha-\mathrm{Al}_{2} \mathrm{O}_{3}$ grain boundaries under the high temperature, Figure 4-4. Once TGO is formed, its thickening is governed by inward diffusion of oxygen [51].

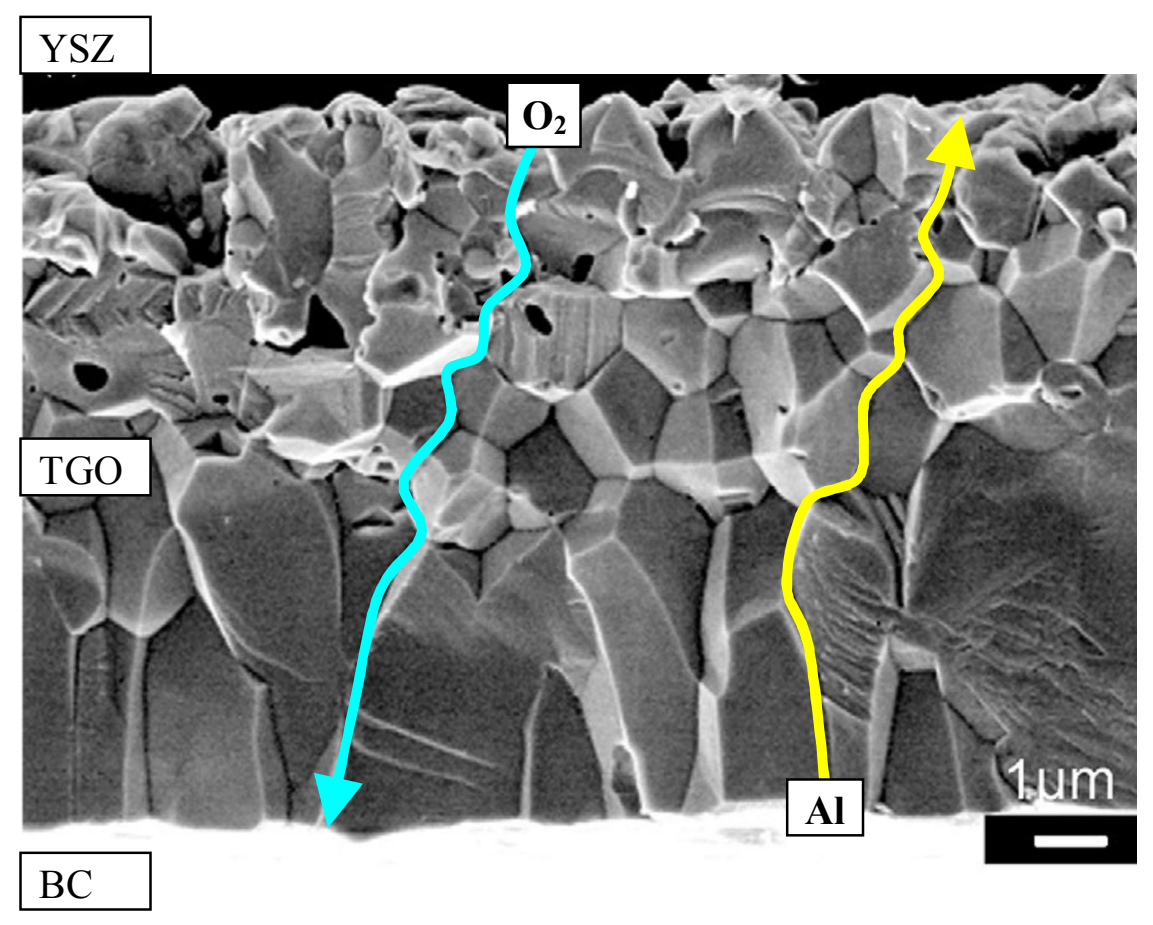

Figure 4-4 Schematic drawing the flux path of oxygen and $\mathrm{Al}[51]$.

As TBC cools to ambient temperature, the large residual compressive stress arises within TGO because of TGO's relatively low thermal expansion coefficient. The compressive induces rumpling and rumpling causes complex non-linear material behavior and interactions between the TGO, YSZ, BC and substrate. The rumpling is strongly influenced by the thermal expansion mismatches. Many researches concluded that large residual stresses developing within the TBC as a result of the unstable TGO growth and coefficients of thermal expansion mismatches generate micro delaminations that ultimately lead to large scale spallation failure but accurate physical investigation is not conducted.

\subsection{TGO rumpling}

The thickness of TGO increases by thermal exposure and micro-cracks are formed in and around interface due to imperfections [49]. The creation and growth of 
micro-crack is associated with the rate of imperfection as the TBC is exposed to thermal cycles. Large compressive stress occurs in TBC on cooling and the TBC is compressed to soothe the stress, Figure 4-6. This phenomenon accelerates the propagation of microcracks to near imperfections. These stresses caused by coefficients of thermal expansion mismatch are responsible for the majority of ratcheting/rumpling that ultimately leads to large scale spallation failure, Figure 4-5 [53-56]. Thus, the durability of the TBC system is dependent on the thermal cycles and the exposure time while the micro-cracks initiate, propagate and link [52].
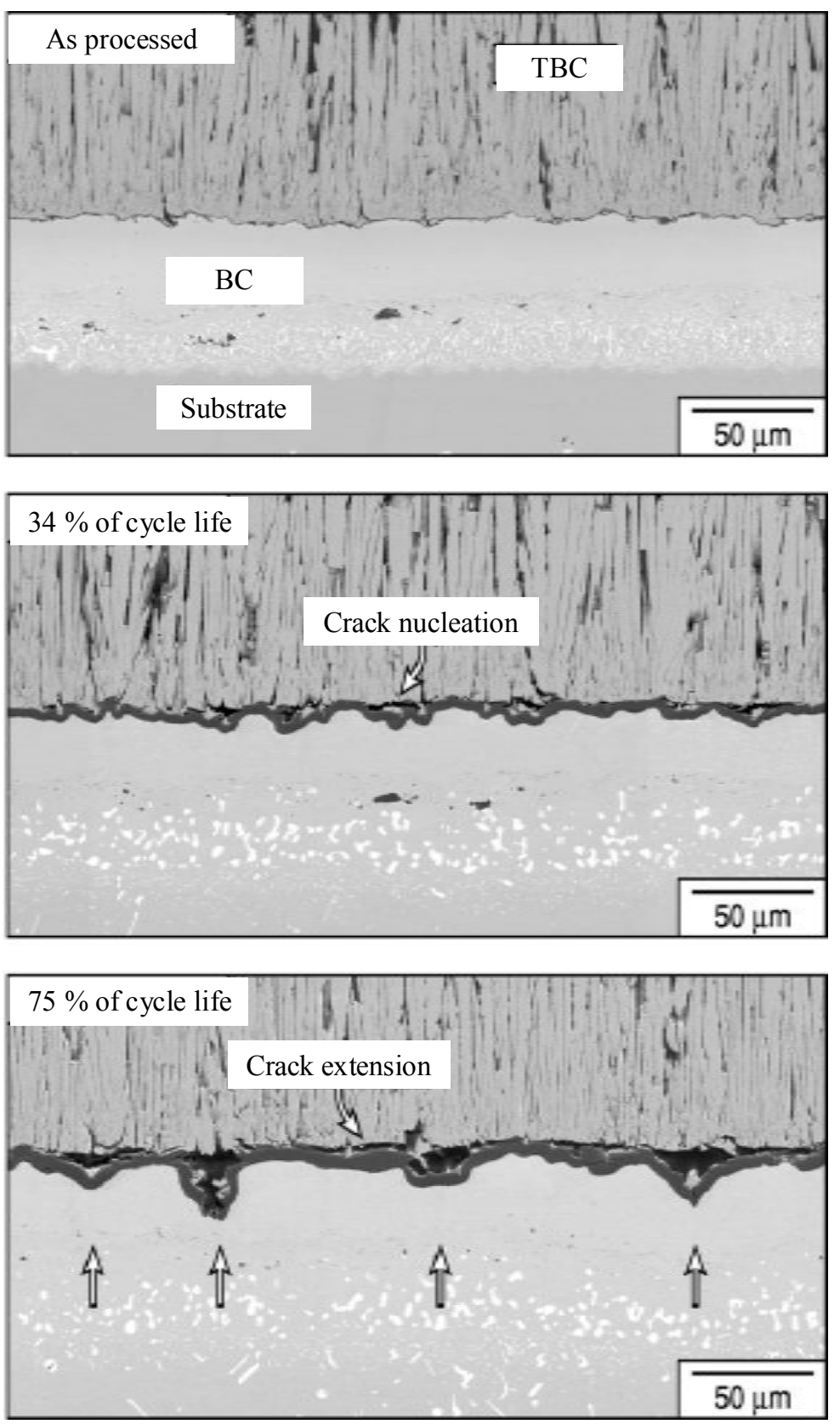

Figure 4-5 Cross sectional views of crack nucleation and extension [52]. 


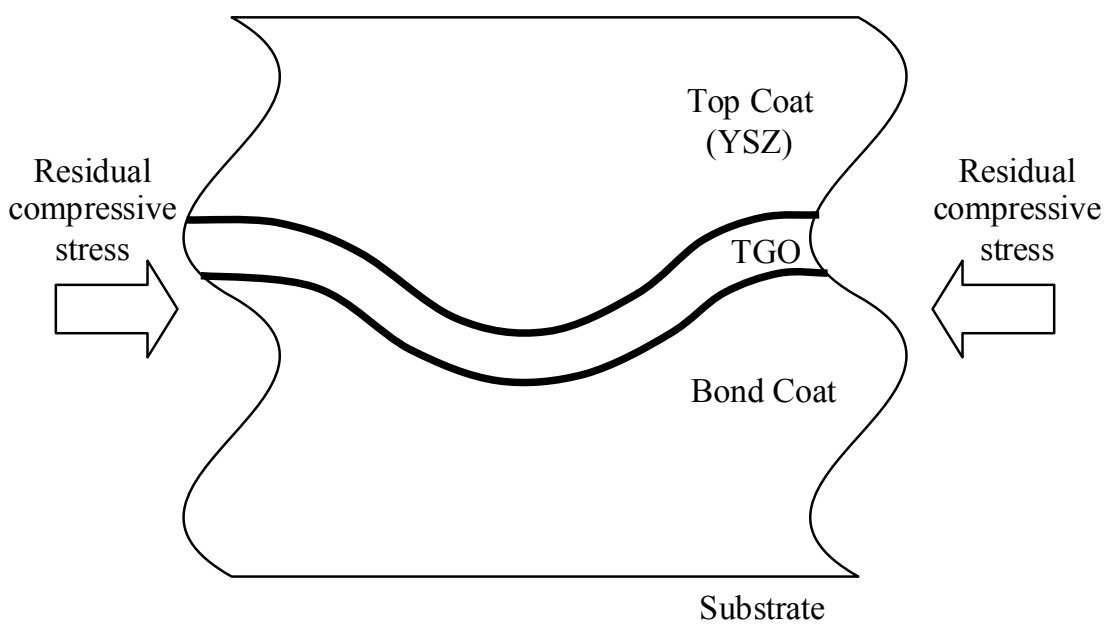

Figure 4-6 Schematic diagram of the TBC with a rumpling by compression [57].

Additional factors including oxidation time, cycle length, surface roughness and phase transformation are explored as well $[54,55]$. More considerable factors such as martensite transformation are included in the TGO rumpling model [58]. D. S. Balint et al. provided an analytical model to examine the residual stress pattern at each layer, TGO thickness effect, heating/cooling rate effect and thermal expansion under the cyclic thermal histories [57]. Morphological imperfection is considered to be a major cause for TGO rumpling on thermal cycle $[59,60]$. Consistent assessment of TGO rumpling studies has previously been conducted [61-63].

\subsection{Spallation failure}

Many TBC spallation failure mechanisms exist, those associated with the growth of TGO are the most prominent and therefore of great concern [64]. Ultimate spallation failure of the TBC system initiating at or near this interface has been observed consistently [65]. TGO growth at this interface is ultimately responsible for the spallation failure of the TBC system. Due to a constrained volume growth, small but significant stresses develop within the TGO. These growth stresses although small at elevated temperatures upon cooling are enlarged due to thermal expansion mismatches between it, the BC and YSZ. Further increasing the out-of-plane stresses produced in this layer, additional roughing or rumpling of the $\mathrm{YSZ} / \mathrm{TGO} / \mathrm{BC}$ interface along thermal exposure creates geometrical imperfections in the $\mathrm{TGO}$, at these locations stresses are found to amplify, Figure 4-7 [49, 53, 51]. Additionally, analysis of the compressive residual stresses within TBC systems has led in the development of a geometry dependent crack prediction model [66]. Following this, analytical models examining the residual stresses were developed as a function of TGO thickness, thermal loading rates and thermal expansion coefficients under simulated cyclic thermal histories [57]. However, it is the undulating YSZ/TGO/BC interface, which produces the out-of-plane residual stresses responsible for in-service failure TBCs. As shown in Figure 4-8, four primary failure modes are illustrated and these spallations are driven when out-of-plane stresses are in 
tension [67]. Researchers using $\mathrm{Cr}^{3+}$ Photoluminescence Piezo-Spectroscopy (CPLPS) have shown TGO compressive residual stresses to be on the order of $1 \sim 3.2 \mathrm{GPa}$ in APS and $2.5 \sim 4.5 \mathrm{GPa}$ in EB-PVD TBC systems [68-71]. Others utilizing Raman and X-Ray Diffraction (XRD) techniques have measured stress values within the YSZ ranging anywhere from $92 \mathrm{MPa}$ on the surface to $660 \mathrm{MPa}$ at the YSZ/TGO interface [72,73].

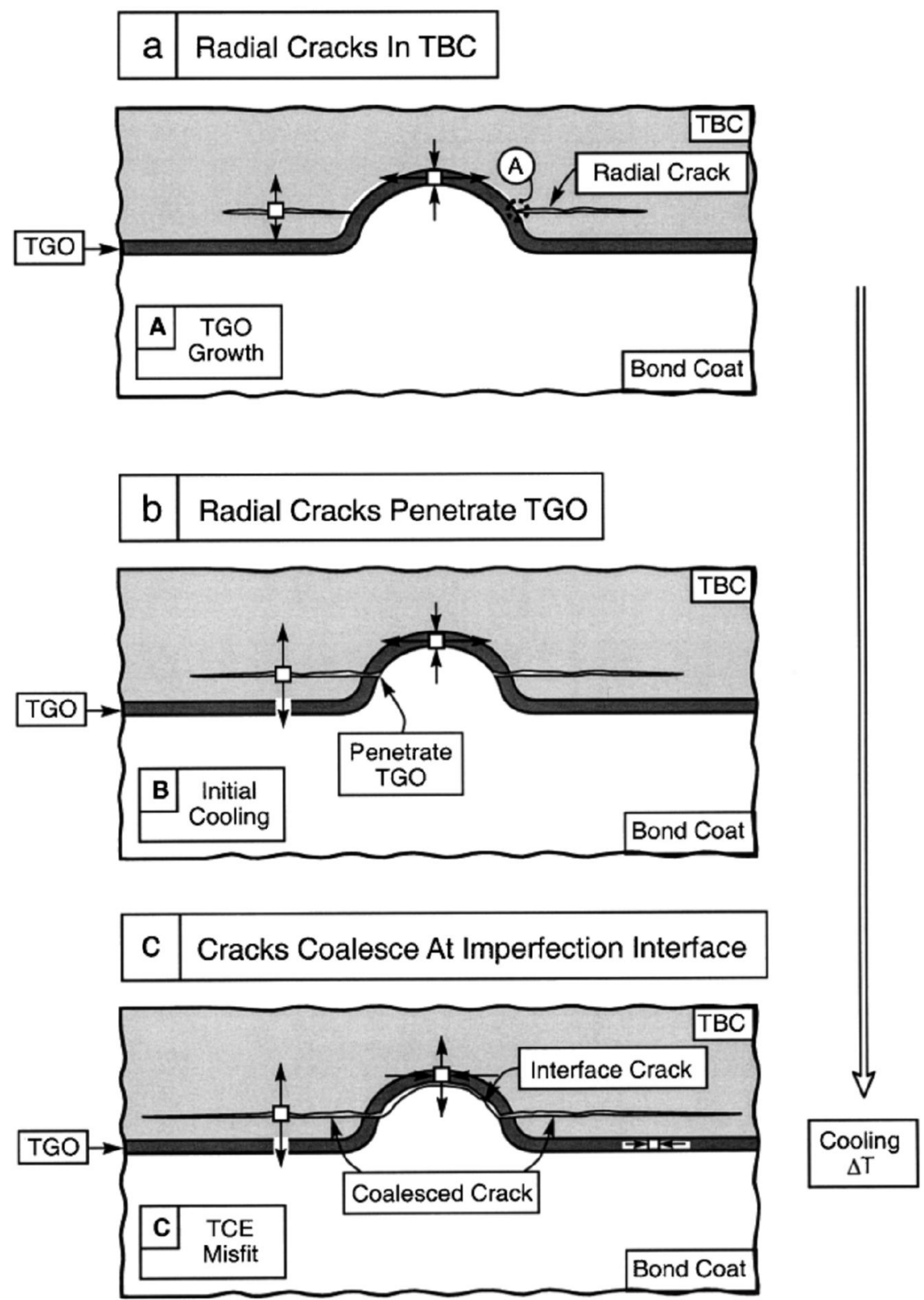

Figure 4-7 The interaction of TBC cracks, crack coalescence and transverse strength [49]. 

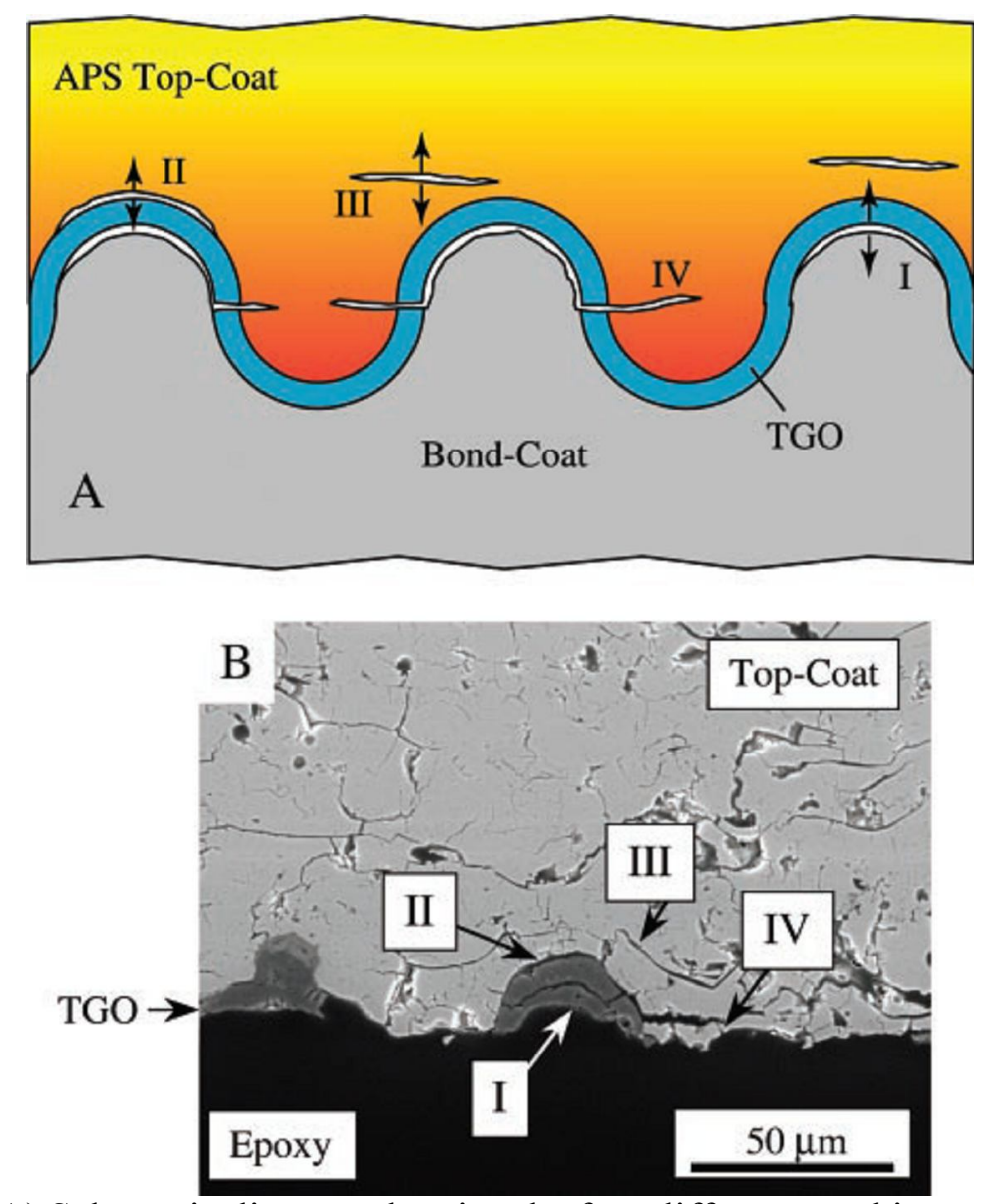

Figure 4-8 (A) Schematic diagram showing the four different cracking mechanisms in APS TBC. (B) Cross-sectional view of a failed APS TBC [67].

T. S. Hille et al. presented another view point to evaluate the failure mechanism in TBC systems. The plastic effect in the BC and anisotropy in the YSZ is important to illustrate the fracture patterns and evolution of crack growth. A four crack patterns are defined through the various combinations of the constitutive models, Figure 4-9 [74]. Also, an effort to predict the main factors which cause the damage has been carried out. Damage at each degree of oxidation is analyzed about predefined interfacial irregularities; this experimental-numerical study investigated the complex interaction between the crack pattern and TGO growth, Figure 4-10 [75]. The interfacial toughness is also considered to be a factor required for accurate spallation prediction. Interfacial toughness is measured by use of an indentation test and directly calculated from delamination radii., Figure 4-11. Interfacial toughness plot is used to indicate the loss of coating adhesion with exposure to high temperatures [76]. M. J. Stinger et al. tried to measure the adherence of the coating with finite element simulation and the indentation is employed to measure toughness along TGO thickness and stress [77]. 


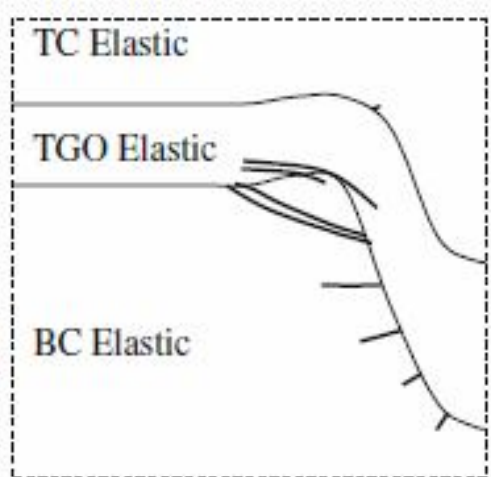

Case 1

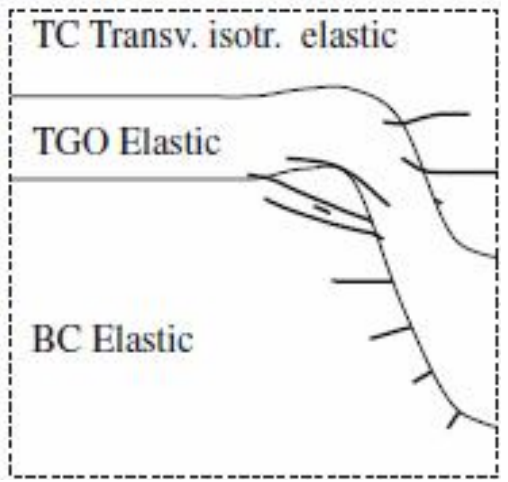

Case 3

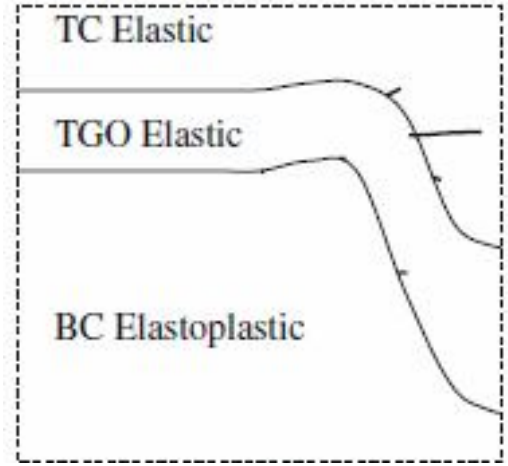

Case 2

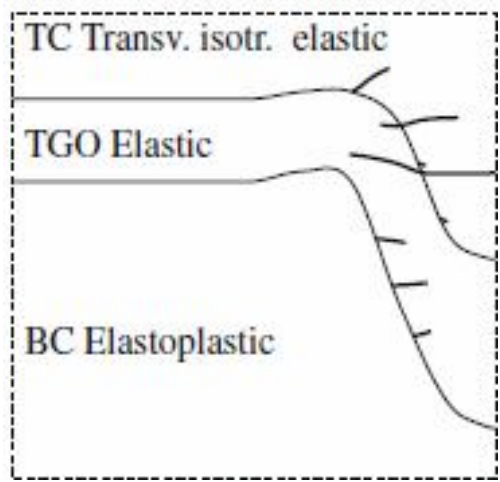

Case 4

Figure 4-9 Crack patterns in and around TGO layer [74].
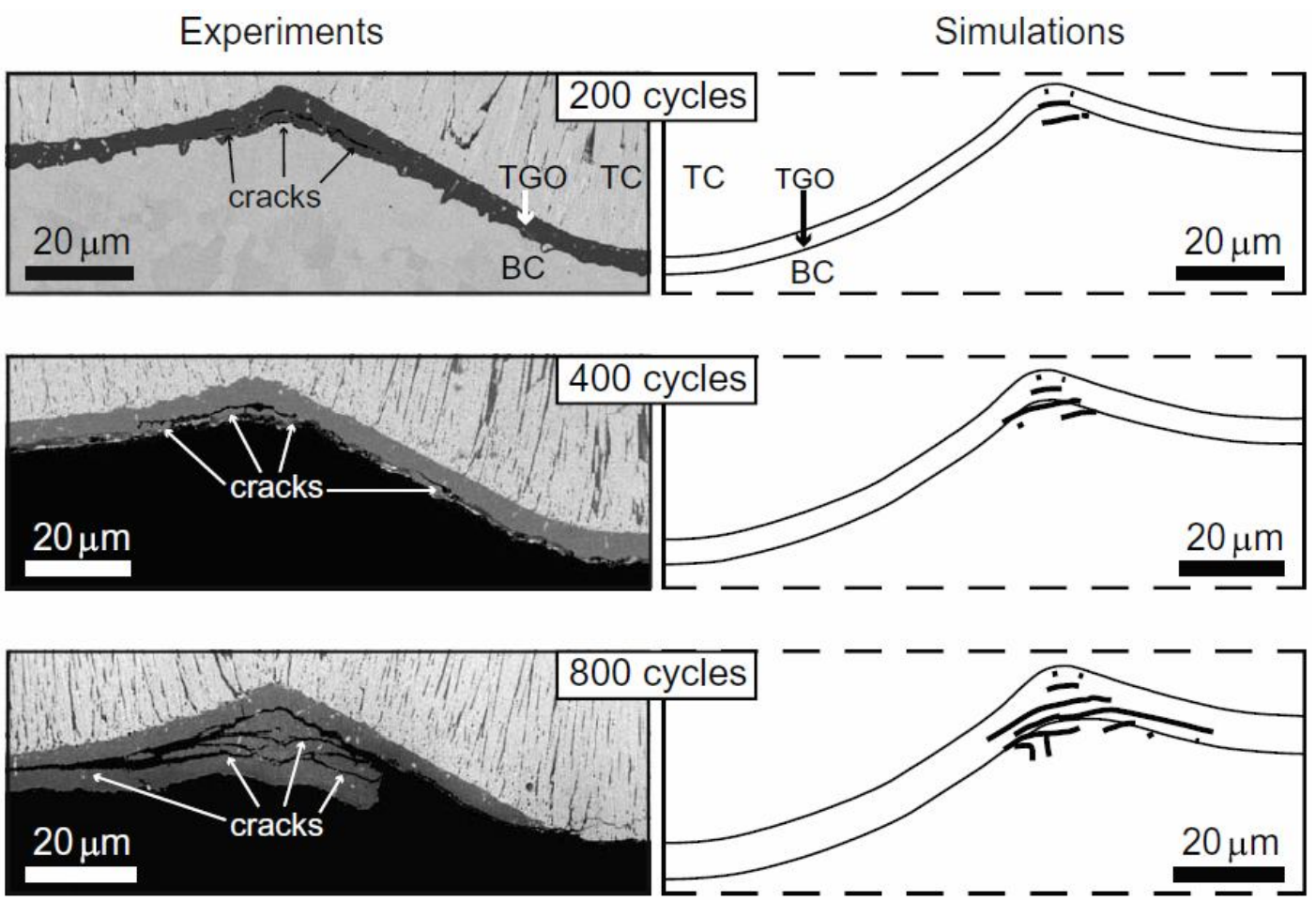

Figure 4-10 Crack pattern and TGO morphology along with thermal cycles [75]. 


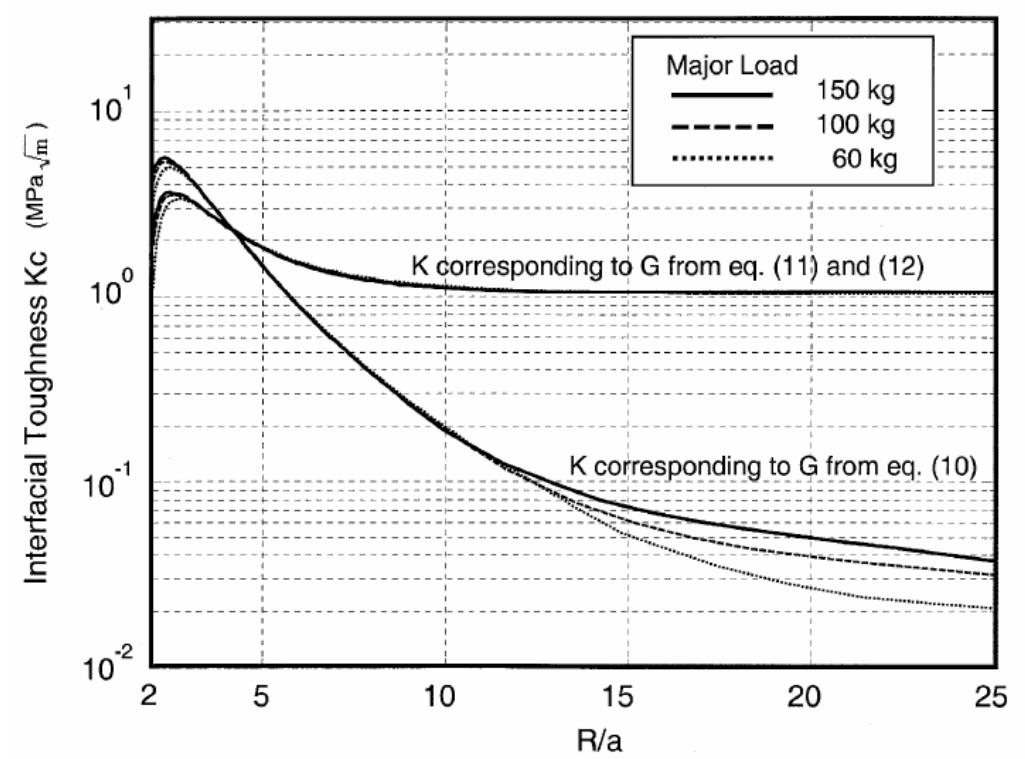

Figure 4-11 Plot of interfacial toughness vs. normalized radial distance [76].

\subsubsection{Finite element analysis of the TBC systems}

It has long been known that residual stresses in TBC systems create variations in behavior, performance and lifetime of the coated components [78], yet macroscopic failure is ultimately the result of a micro-crack coalescence progression $[65,79]$. Furthermore, although experimental stress analysis techniques may be applied to TBC systems, these methods are costly and relatively undefined, thus parametric finite element modeling techniques have been applied to further describe the stress relaxation behavior with various material compositions [80,81]. Through the parametric finite element analysis, Figure 4-12, these primary results are known that "even for smooth undulation and thin TGO thickness the maximum principal stress in TGO is tensile and close or greater than the TGO tensile strength. Since the TGO is a brittle material such stress can break the TGO layer at the beginning of the oxidation, when the TGO layer is very thin" [82]. The other important findings are "1. Thicker TGO layer increases the BC stress, upon cooling to room temperature, until yielding. The subsequent re-heating to maximum peak temperature results in $\mathrm{BC}$ residual stress; this residual stress can be so high to produce reverse yielding in the BC. Cyclic plasticity of BC accumulates plastic strain and cause fatigue cracks to open. 2. The normal stress on TGO-TC interface shown a maximum value near the lower peak of the TGO undulation. The position of the maximum normal stress is consistent with experimental observation that shown crack starting just near the lower peak of the TGO wave. Stresses normal to TC/TGO interface, which are responsible for the TBC delamination, increase with increasing undulation amplitude, at least in a wide range, and above all with increasing TGO thickness, Figure 4-13 and Figure 4-14." [82]. Thermal stress caused by the thermal expansion mismatch is analyzed with a simplified spherical model, thus stress flow around TGO is shown as Figure 4-15 [83]. 


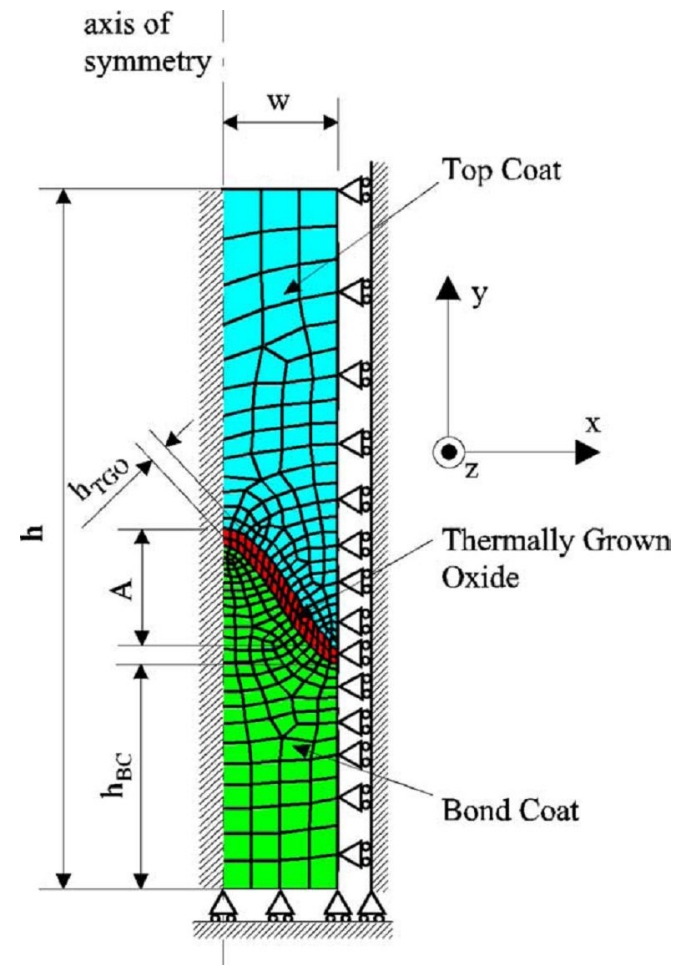

Figure 4-12 Finite element model of the TBC system [82].

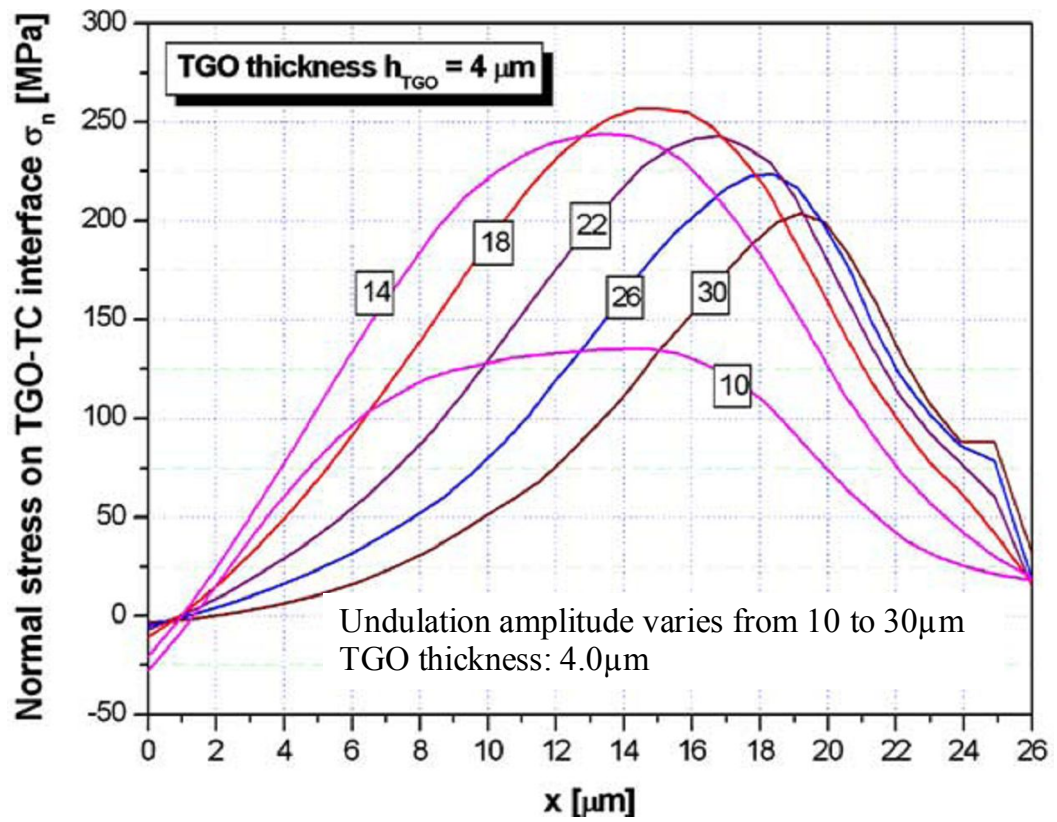

Figure 4-13 Residual stress on TBC-Top Coat interface [82]. 


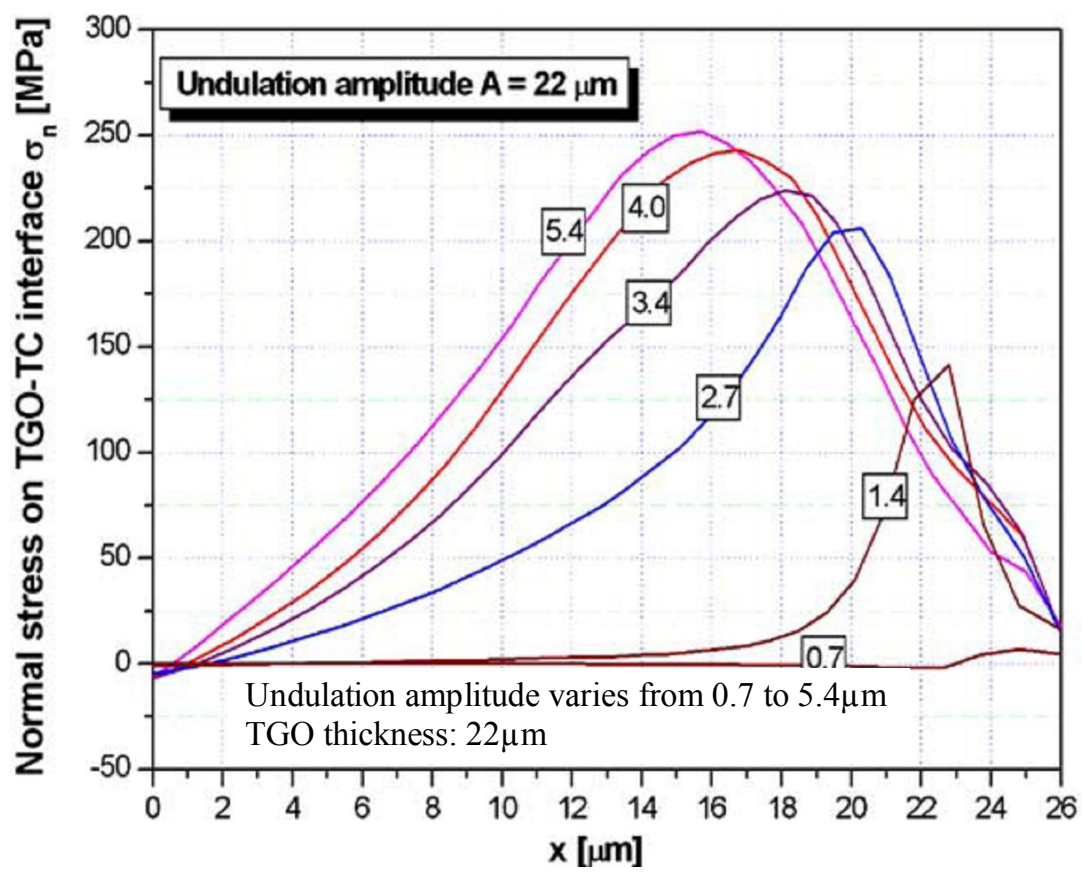

Figure 4-14 Residual stress on TBC-Top Coat interface [82].

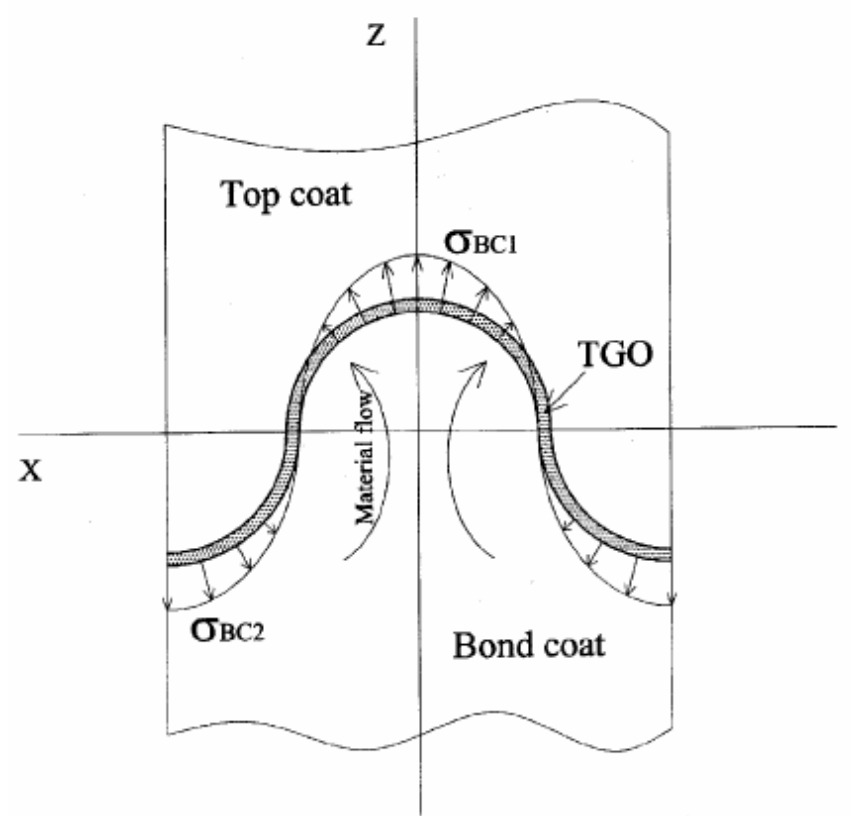

Figure 4-15 A schematic drawing showing the material flow by the stress field [83].

J. Rösler et al. have investigated the stress relaxation behavior of the TBC system for different strengths of the YSZ and TGO with parametric modeling [80,81]. E. Tzimas et al. calculated compressive residual stresses within all layers and predicted cracking to initiate at the specific geometric features [66]. Himanshu Bhatnagar et al. simulated with parametric TGO modeling to review buckling and interface delamination. 
Energy release rate is employed as a significant value to judge delamination growth. Thus "for any given geometric configuration and materials properties, the energy release rate reaches a critical value when the far field stress in the TGO reaches a critical value. The critical stress of TGO varies inversely with TGO thickness and with the delamination size." [84]. As shown in Figure 4-16, the relation between delamination extension and TGO undulation is compared with the energy release rate.

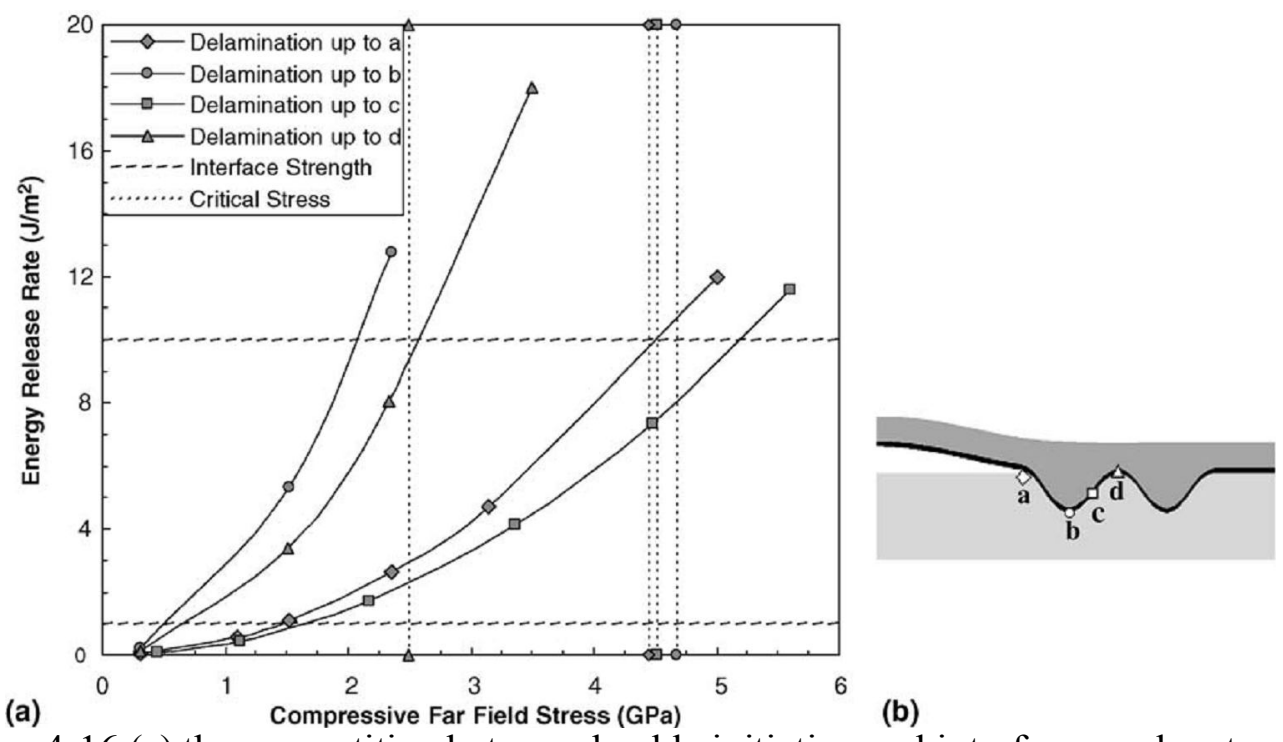

Figure 4-16 (a) the competition between buckle initiation and interface crack extension,

(b) the corresponding locations for energy release rate curves and for study of the competition between buckling and delamination propagation [84].

Also radial stress in each layer is examined by finite element simulation and acknowledged that radial stress in the TGO layer is higher than at the BC layer. This higher radial stress in the TGO layer is ultimately responsible for the micro-cracking that follows. The interface stress pattern follows a trend where, "The large normal interface stresses arise at the peaks, while large shear stresses arise at the mean line of the rough interface" [85]. This radial stress variation along thermal cycles is investigated and compared with spallation mechanisms and micro-crack density, Figure 4-17 [86]. Furthermore, the creep deformation caused in each layer is examined with generated residual stress. This creep effect is significant, whereas it partially dictates residual stress levels [87]. Recently TGO parametric modeling and simulation has been widely used to investigate residual stress and displacement. TGO deformation by thermal cycle is simulated and TGO growth is predicted and compared with experimental results by Jun Ding et al., Figure 4-18 [88]. It is acknowledged that amplitudes of TGO rumpling subjected to cyclic thermal load are affected by BC and substrate thickness by Tolpygo et al. [56]. 


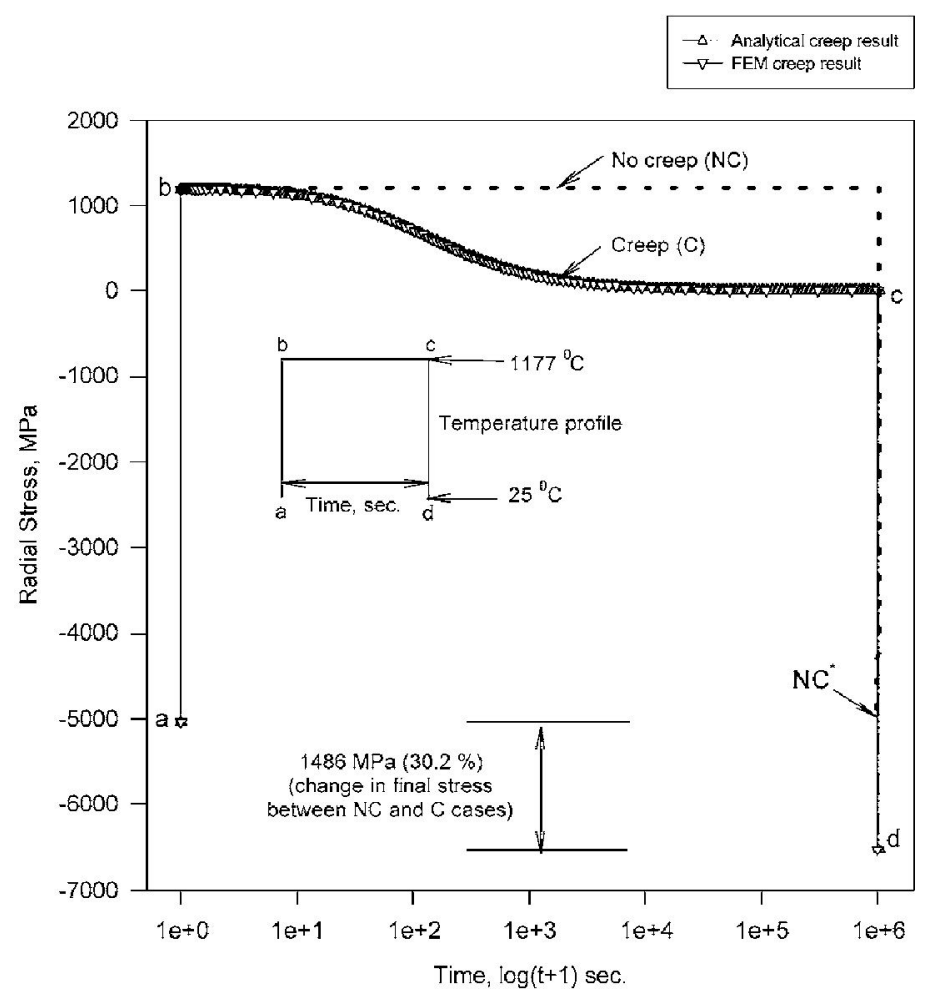

Figure 4-17 Stress vs. time in the oxide layer by thermal loading cycle [86].

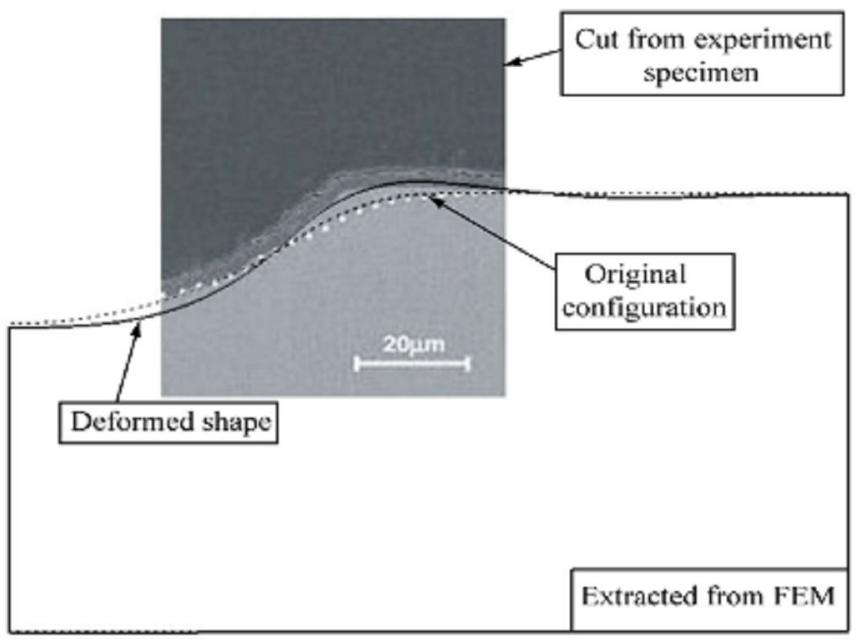

Figure 4-18 The comparison between the numerical simulation and experimental observation after 24 thermal cycles [88].

\subsection{TBC modeling}

An initial correlation between experimentally observed failure mechanism and interface stress patterns are made by assuming a sinusoidal TGO geometry. A parametric finite element analysis of a TBC system has been conducted in which the TGO is modeled using a sinusoidal wave thus accounting for any rumpling/ratcheting that may 
occur during its growth. In this manner, the residual stresses produced upon cooling may be evaluated along the TGO wave amplitude. The resulting residual stresses may then be applied to the free edge of a full TBC model for elastic modulus measurement by use of an indentation method. Through this procedure residual stress variance along the TGO growth within the TBC will be reviewed as well as any unique stress patterns that may further explain continually observed cracking and failure patterns within this structure. Finally, a correlation between unloading surface stiffness response and residual stress will be reviewed as TGO amplitude is varied. Throughout this study, the thickness of this layer will remain at a constant value of $1 \mu \mathrm{m}$ and only amplitude will be varied from 1 to $9 \mu \mathrm{m}$ with a constant wavelength of $20 \mu \mathrm{m}$. Referring to previous work by M. Y. He et al. [89] and J. Rösler et al. [80,81] in TGO modeling, $\lambda$ is defined as the TGO wave length, $A$ the amplitude and $t$ the thickness, Figure 4-20. Although this model does not recreate the exact geometrical parameters along the YSZ/TGO/BC interface, it allows stress magnitudes occurring at imperfections to be estimated. Material properties imposed on this model include the elastic modulus, Poisson's ratio, yield stress, tangent modulus and coefficient of thermal expansion for all layers, Table 4-1[69]. Simulating a TBC cooling effect, reductions in temperature are imposed on this wave and entire TBC system. Residual stress distributions developing from the coefficients of thermal expansion mismatches within the model are analyzed along the varying TGO height for correlation with experimentally observed failure patterns. Having a width of $10000 \mu \mathrm{m}$ (failure and stress analysis respectively) and a total height of $3262 \mu \mathrm{m}$, this model contains all layers; TBC: $353 \mu \mathrm{m}$, TGO: $1 \mu \mathrm{m}, \mathrm{BC}: 209 \mu \mathrm{m}$ and Substrate: $2700 \mu \mathrm{m}$, Figure 22. Defined as the axis of symmetry, the $\mathrm{x}$-axis is coupled along the edge of the model, thus ensuring similar deflections along this plane. A minimum TGO element size of $0.5 \mu \mathrm{m}$ is used thus creating a total of around 160000 elements. Producing a TBC cooling effect, a reduction in thermal load from $1100{ }^{\circ} \mathrm{C}$ to $23{ }^{\circ} \mathrm{C}$ is applied by a $\Delta \mathrm{T}$ of $-1077{ }^{\circ} \mathrm{C}$. A Plane 182 element is employed with axis symmetry and isotropic bilinear elastic-plastic material behavior.

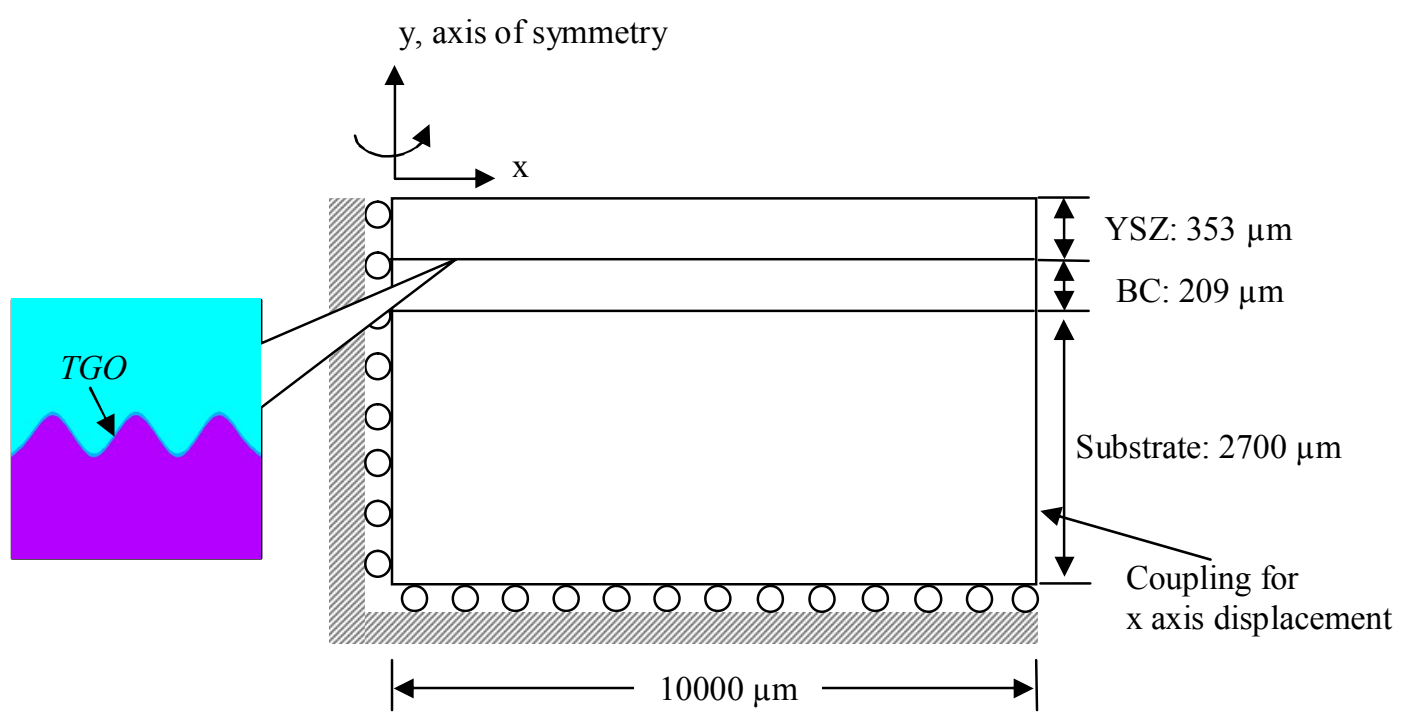

Figure 4-19 TBC model and boundary conditions. 


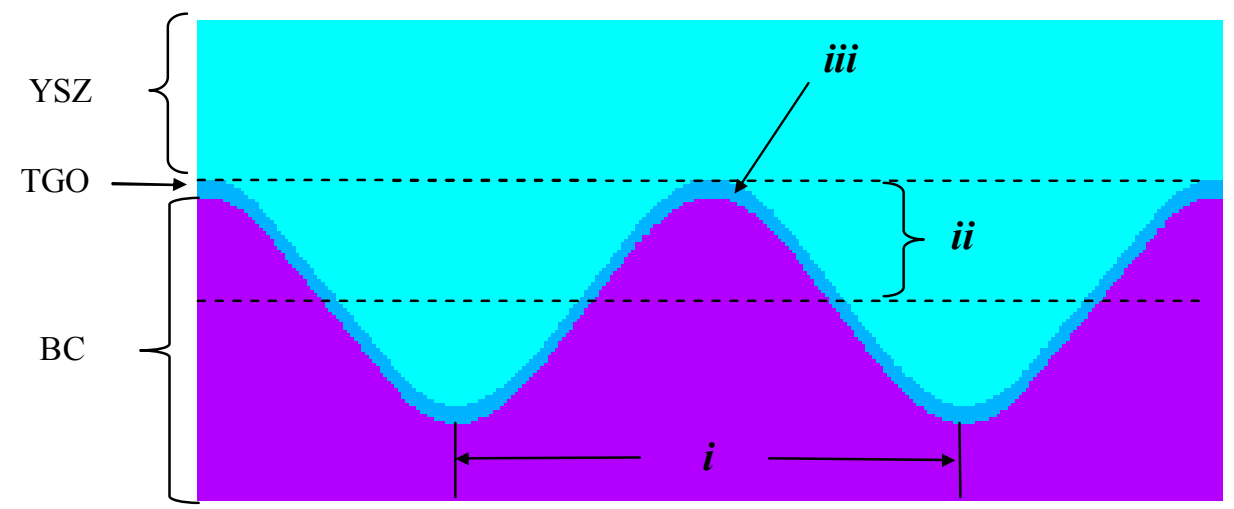

Figure 4-20 TGO rumpling shape and design parameters.

i) Wave length, $\lambda=40 \mu \mathrm{m}$ ii) Wave amplitude, $A(1 \sim 9 \mu \mathrm{m})$ iii) TGO thickness, $t=1 \mu \mathrm{m}$

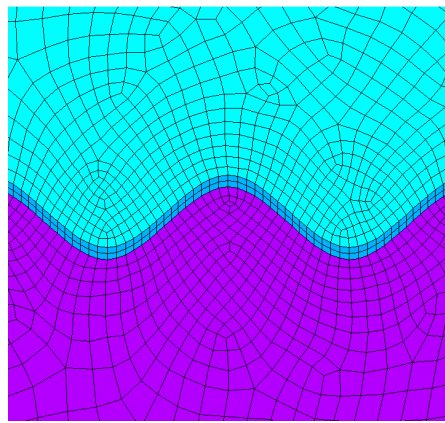

$\mathrm{A}=3 \mu \mathrm{m}$

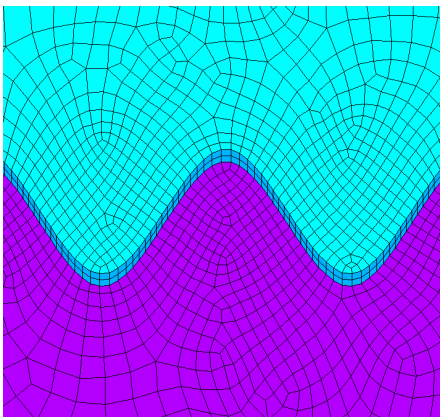

$\mathrm{A}=5 \mu \mathrm{m}$

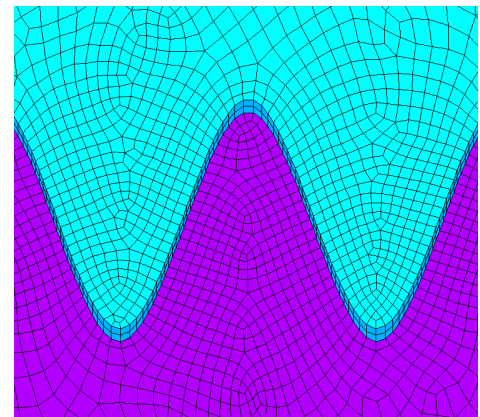

$\mathrm{A}=9 \mu \mathrm{m}$

Figure 4-21 Uniform TGO model and finite element mesh.

Table 4-1 Material Properties of TBC systems.

\begin{tabular}{|l|c|c|c|c|}
\hline \multicolumn{1}{|c|}{ Material Property } & YSZ & TGO & BC & Substrate \\
\hline Elastic Modulus (GPa) & 50 & 375 & 211 & 150 \\
\hline Poisson's Ratio & 0.1 & 0.25 & 0.3 & 0.25 \\
\hline Yield Stress (MPa) & 250 & 1000 & 422 & 841 \\
\hline Tangent Modulus (GPa) & 1 & 3.75 & 0.889 & 1.05 \\
\hline Thermal Expansion Coefficient $\left(10^{-6} /{ }^{\circ} \mathrm{C}\right)$ & 11 & 8 & 14 & 14.5 \\
\hline
\end{tabular}

\subsubsection{Residual stress in TBC}

Both in-plane $\left(\sigma_{\mathrm{x}}\right)$ and out-of-plane $\left(\sigma_{\mathrm{y}}\right)$ residual stress patterns are observed to occur in and around the YSZ/TGO/BC interfaces, Figure 4-22 and Figure 4-23. Also, the residual stress transition was calculated. Stress distribution is stable certain distance from the right end. Thus stress values are extracted from sufficiently far from the right end. Inplane stresses are not changing much at each layer. In YSZ layer in-plane stress is 
compression about $200 \mathrm{MPa}, 116 \mathrm{MPa}$ compressive stress in Bond coat and $30 \mathrm{MPa}$ tensile stress occur in the substrate. Relatively YSZ compressive stress is biggest, Figure 4-24. Out-of-plane stress is tensile stress in all layers from $10 \mathrm{KPa}$ to $1.5 \mathrm{MPa}$. This outof-plane residual stress is much smaller than in-plane compressive stress, Figure 4-25.

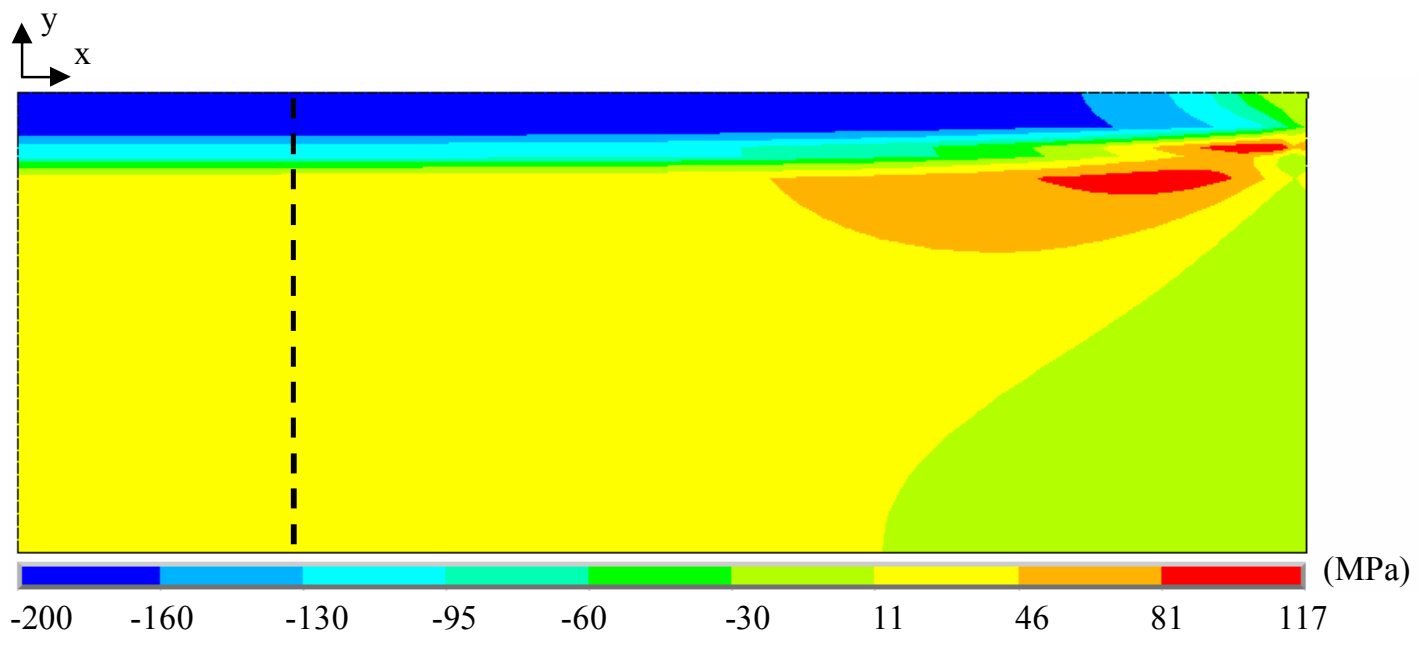

Figure 4-22 In-plane residual stress $\left(\sigma_{\mathrm{x}}\right)$ distribution in TBC.

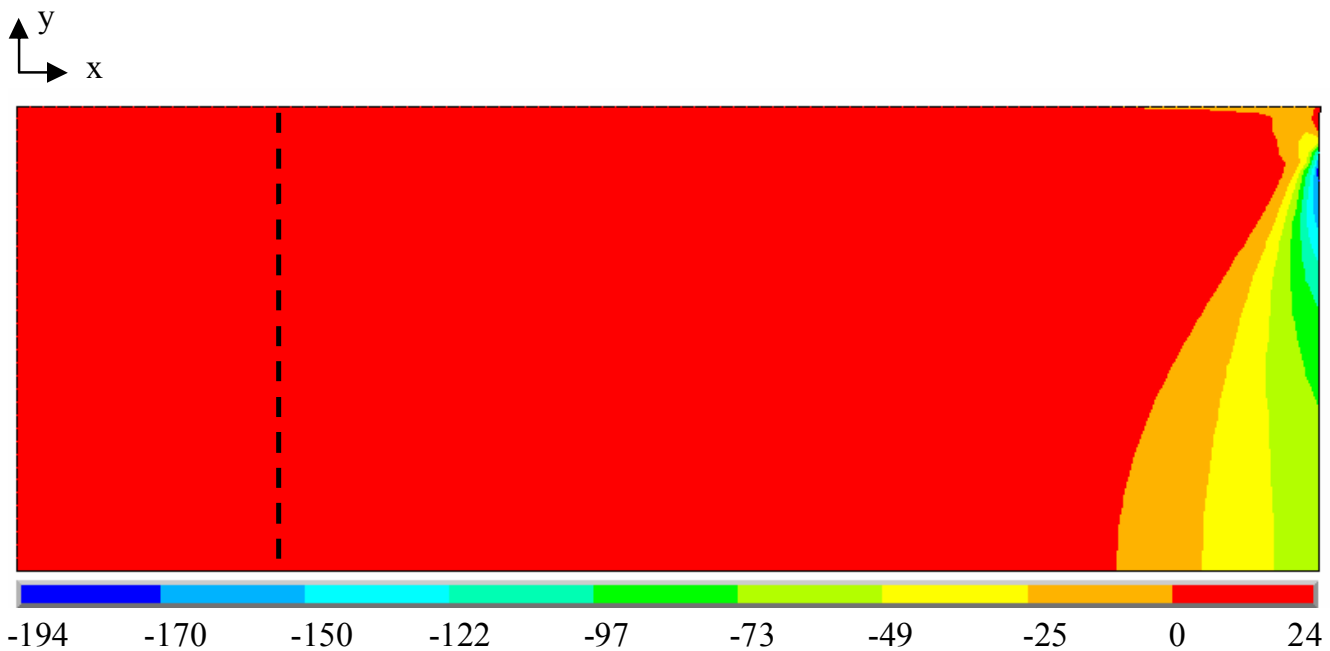

Figure 4-23 Out-of-plane residual stress $\left(\sigma_{\mathrm{y}}\right)$ distribution in TBC. 


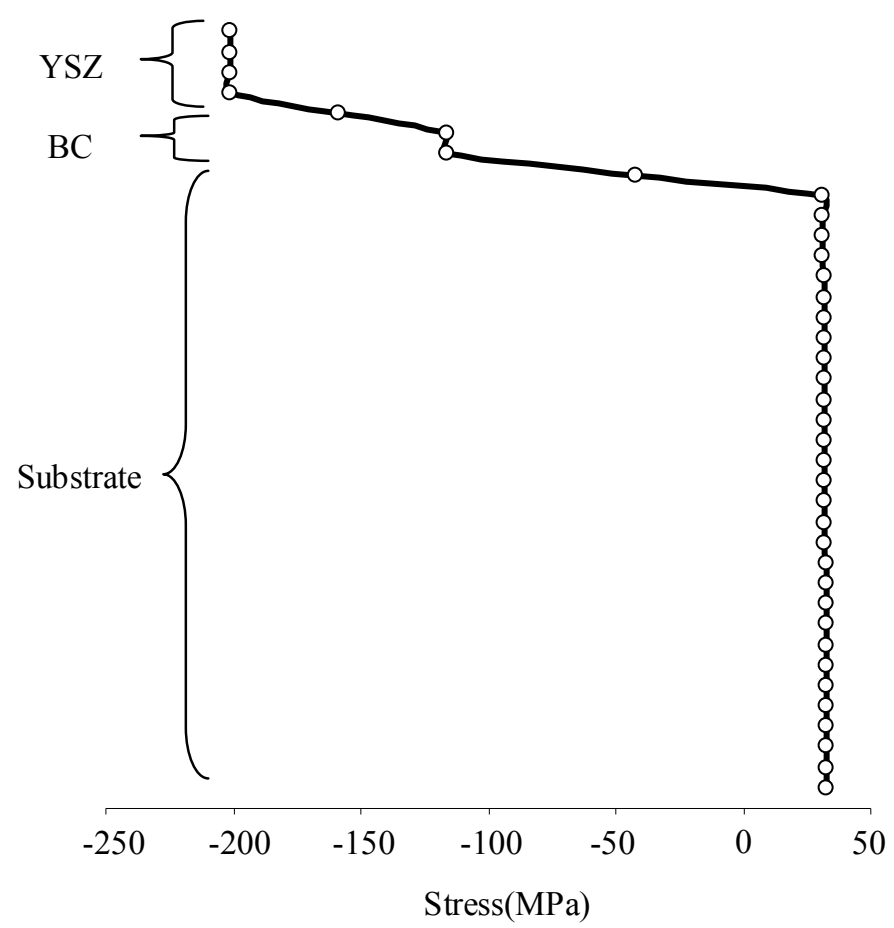

Figure 4-24 In-plane residual stress in TBC.

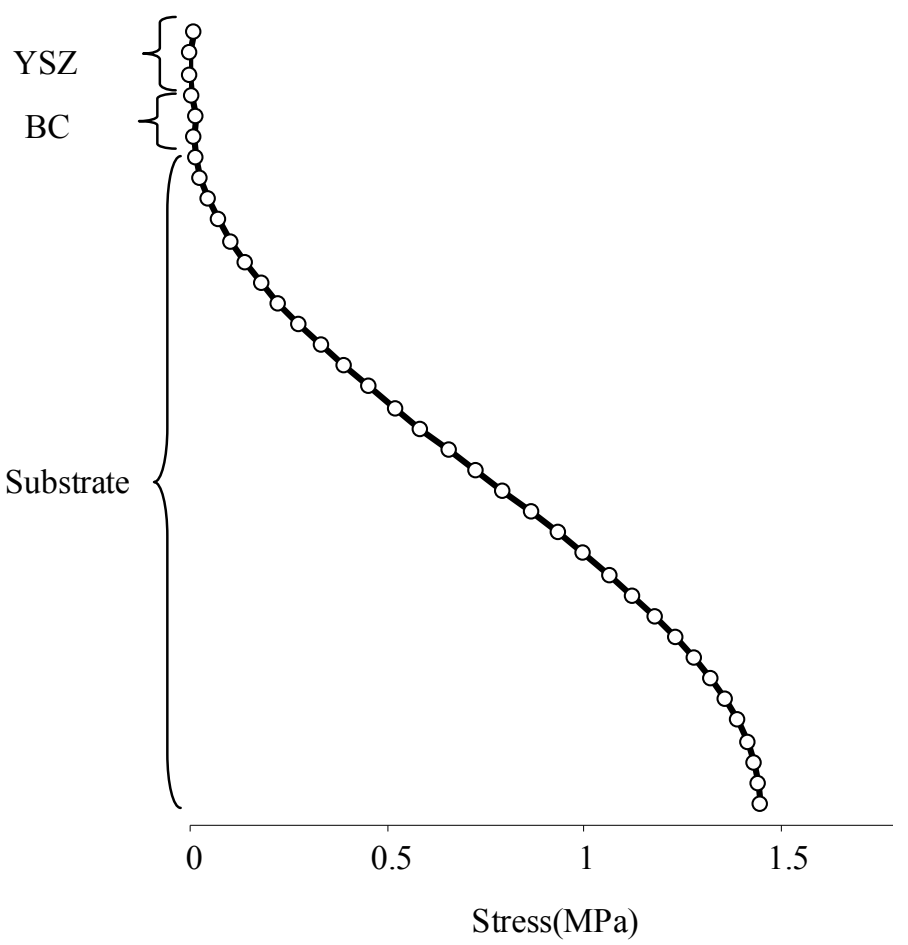

Figure 4-25 Out-of-plane residual stress in TBC. 


\subsubsection{Residual stress in and around TGO}

In this simulation only wave amplitude $(A)$ is changed and the other parameters are fixed to review stress variation along TGO wave amplitude. In the residual stress results gaps increasing between valley and peak along with TGO amplitude increasing in in-plane and out-of-plane axis are observed, Figure 4-26 and Figure 4-27. Regions subjected to tensile stresses are shown to occur within the $\mathrm{BC}$ as well. The maximum inplane tensile stress is observed to occur at the median of the wave where as the maximum compressive stress is produced along the peaks of the sine wave. The out-of-plane stress distribution, acting opposite to that of the in-plane directional stress, develops a maximum compressive stress along the median and the maximum tensile stress is concentrated at the peaks of the $\mathrm{TGO} / \mathrm{BC}$ interface. This tensile stress is found to increase along TGO rumpling and becomes and is the ultimate cause of spallation failure.
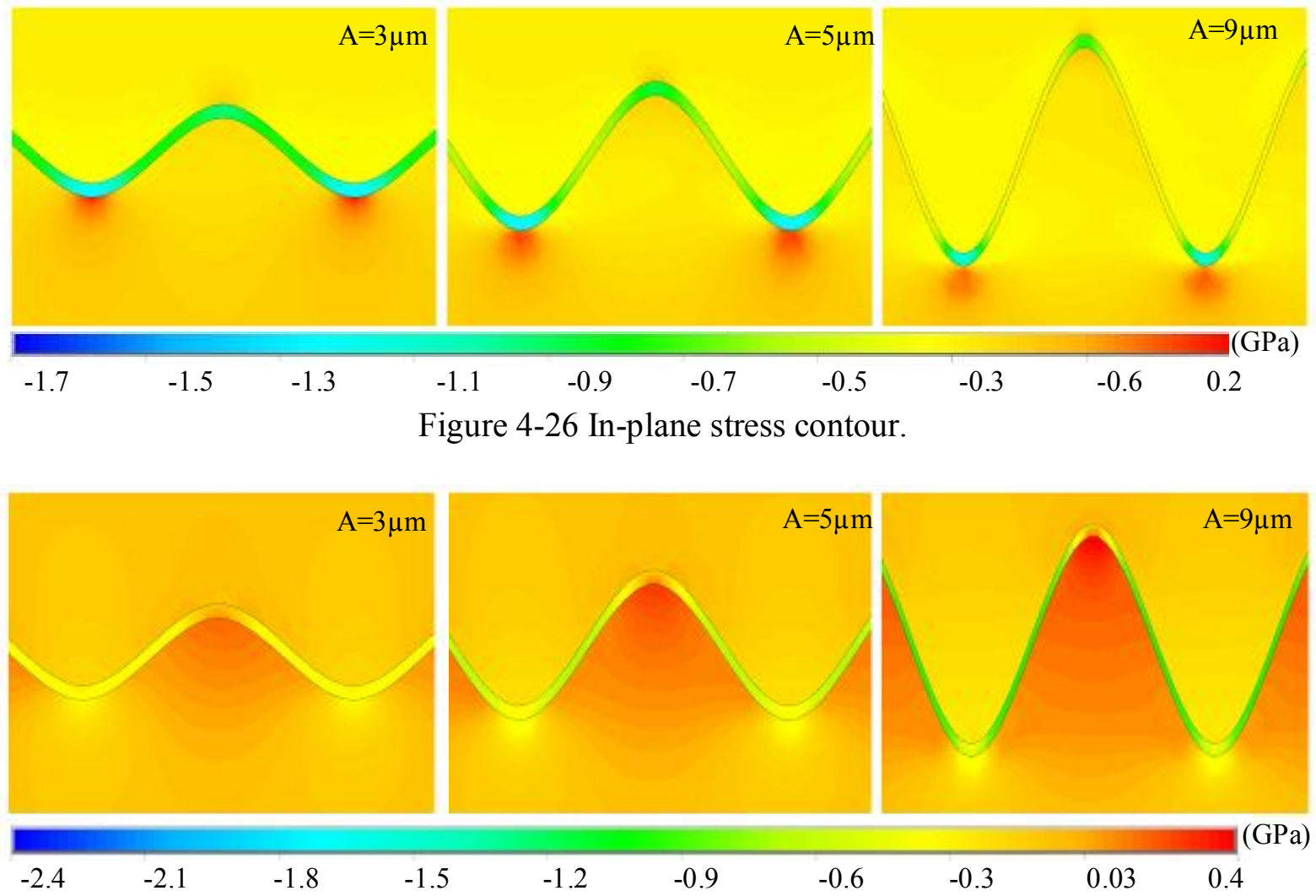

Figure 4-27 Out-of-plane stress contour.

All residual stress measurements obtained from this model are evaluated at sufficient distances from the model's boundaries. Upon applying a temperature difference of $-1077{ }^{\circ} \mathrm{C}$, both the in-plane and out-of-plane residual stresses in the aforementioned model are found to vary in all layers along the increasing wave amplitude. The in-plane compressive residual stresses occurring within the YSZ steadily increase along wave amplitude and are found to be maximum at the TBC surface in all cases, as shown in Figure 4-28. Especially residual stress in TGO layer is the biggest compression and 
decrease along with TGO rumpling because as TGO amplitude growing compressive stress is absorbed by TGO shape as like spring action. The maximum stress created in the TGO layer the maximum stress is $1 \mathrm{GPa}$ and decreases until $285 \mathrm{MPa}$. A compressive stress also develops within the YSZ and BC as well; however a tensile stress is shown to occur within the substrate. Stress variations with the YSZ and BC are found to be much smaller than those devolving within the TGO yet the trends are still clear. Also in the overall stress pattern, stresses are transiting from compression to tension in the in-plane axis and tension to compression in out-of-plane axis. This matches with the experimental prediction that spallation is caused at the edge first.

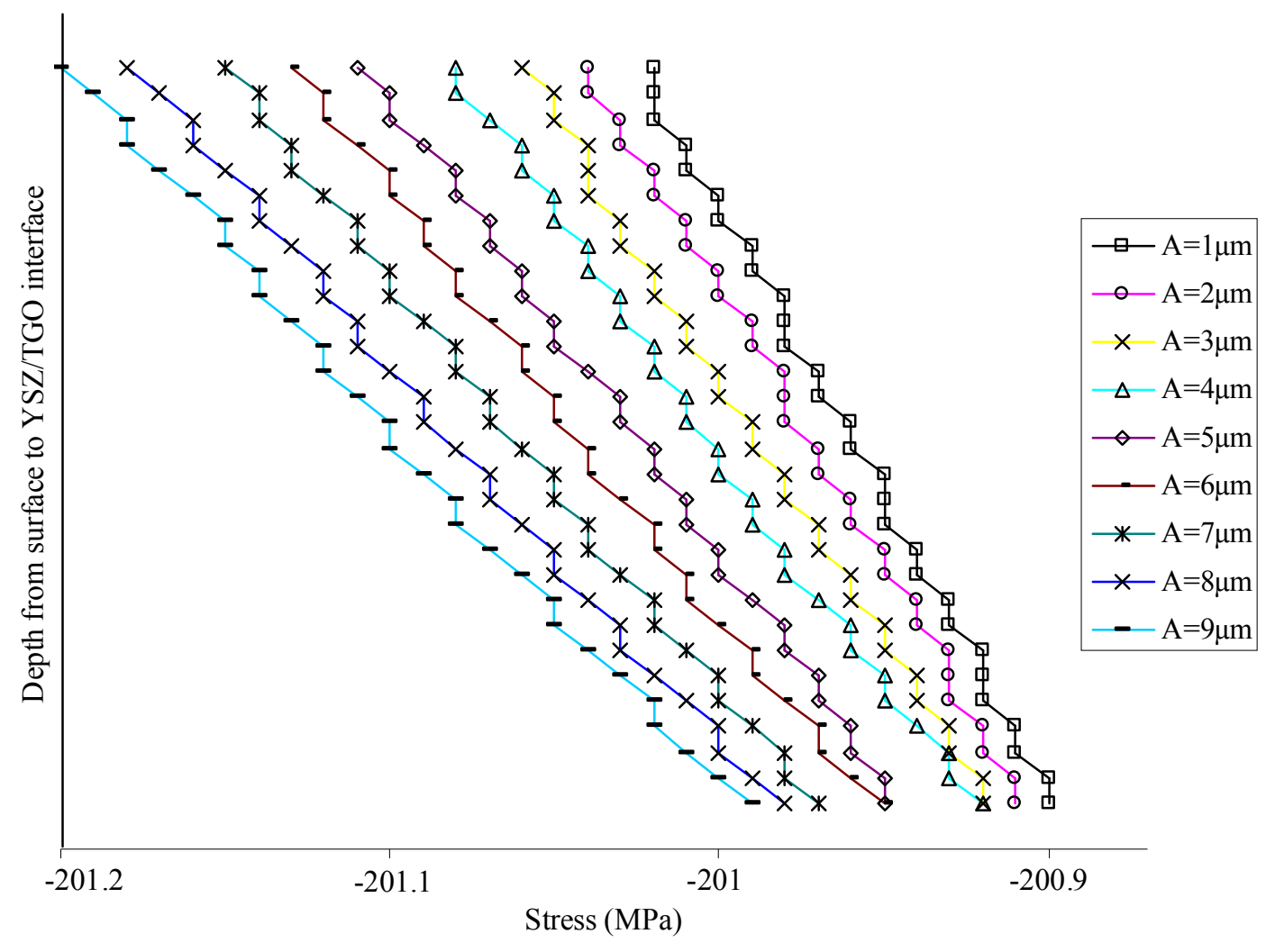

Figure 4-28 Residual stress at YSZ layer.

\subsection{Indentation on pre-stressed TBC}

Variation of mechanical properties due to residual stresses is a widely known phenomenon. Based on prior results, transition of mechanical property will be detected while varying residual stresses. Attempts to measure material properties under compressive residual stresses have been investigated by A. Bolshakov et al, where elastic modulus was measured using an indentation method along increasing compressive stress, by assuming an outer cylindrical surface pressure [90,91]. S. Suresh et al. suggested a methodology to determine the surface residual stress and residual plastic strains [92]. The 
anisotropy in the YSZ layer and long-term high temperature exposure are considered as main variables and thus trends of elastic modulus were considered by M. Ohki et al. [93]. The measurement of residual stress of copper specimens has been conducted by using indentation techniques and a method for determining material properties under the presence of residual stresses has been suggested by B. X. Xu et al. [94]. Furthermore, similar studies on the determination of residual stresses by instrumented indentation techniques have been carried out by others $[95,96]$. Residually stressed TBC systems eventually fail due to the coalescence of small cracks caused by the thermal mismatch. This crack coalescence and failure mechanics are simulated and failure scenarios are investigated [79]. Assuming residual stress as an outer surface pressure, A. Bolshakov et al. monitored the materials elastic modulus while varying the magnitude of the applied stress [90]. In this research a similar methodology is employed to investigate the variation of mechanical properties. Initially, simulation accuracy verification must be performed, thus a finite element analysis is conducted using a similar model and boundary conditions only with a spherical indenter rather than a conical indenter. An indenter radius $100 \mu \mathrm{m}$ is used with a maximum applied indenter loading and unloading displacement of 2 and $0.2 \mu \mathrm{m}$ respectively. Minimum element size beneath the indenter is $0.12 \mu \mathrm{m}$ and referenced finite element model is compared in Figure 4-29. The material property is found in Figure 4-30 [90].
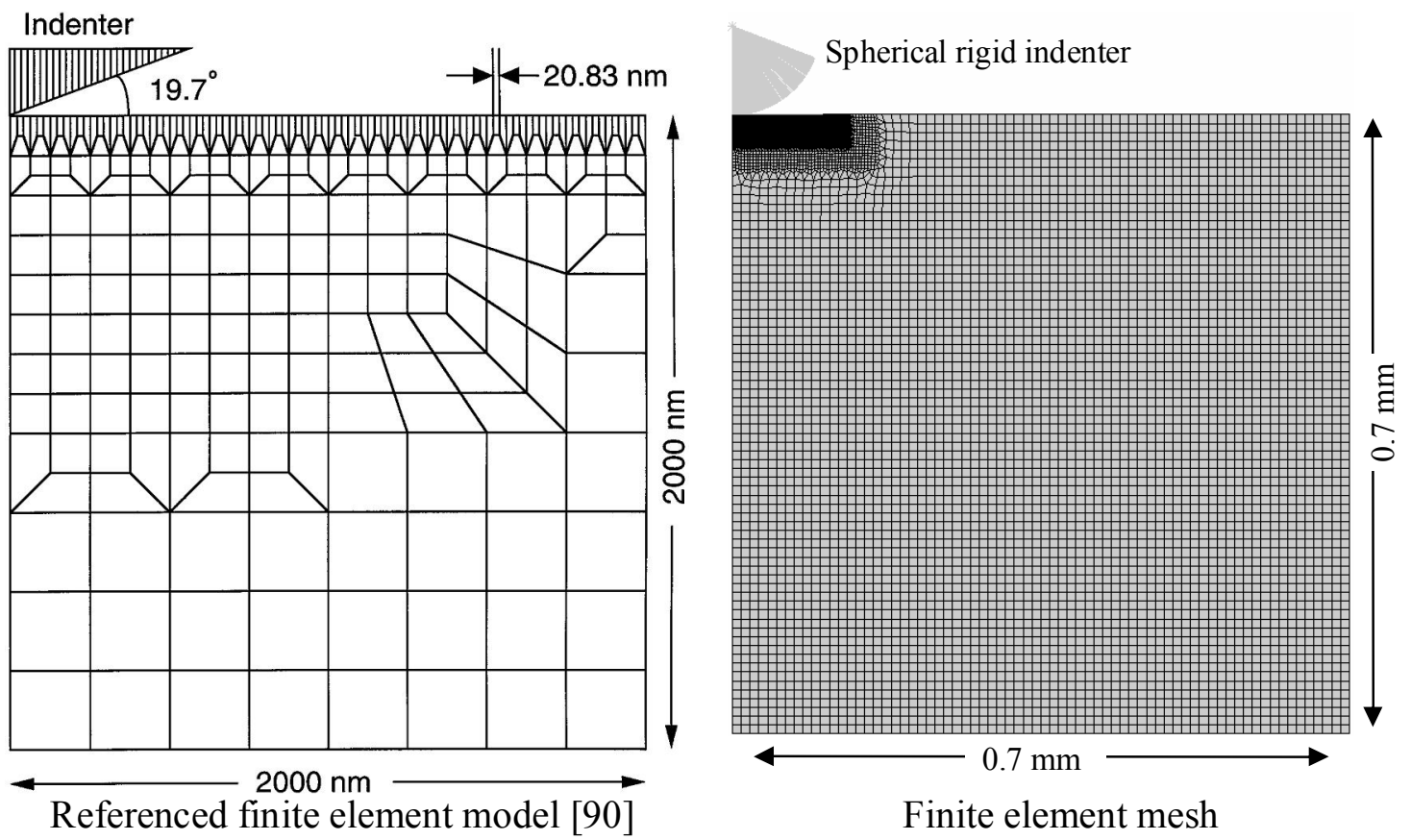

Figure 4-29 Finite element model comparison. 


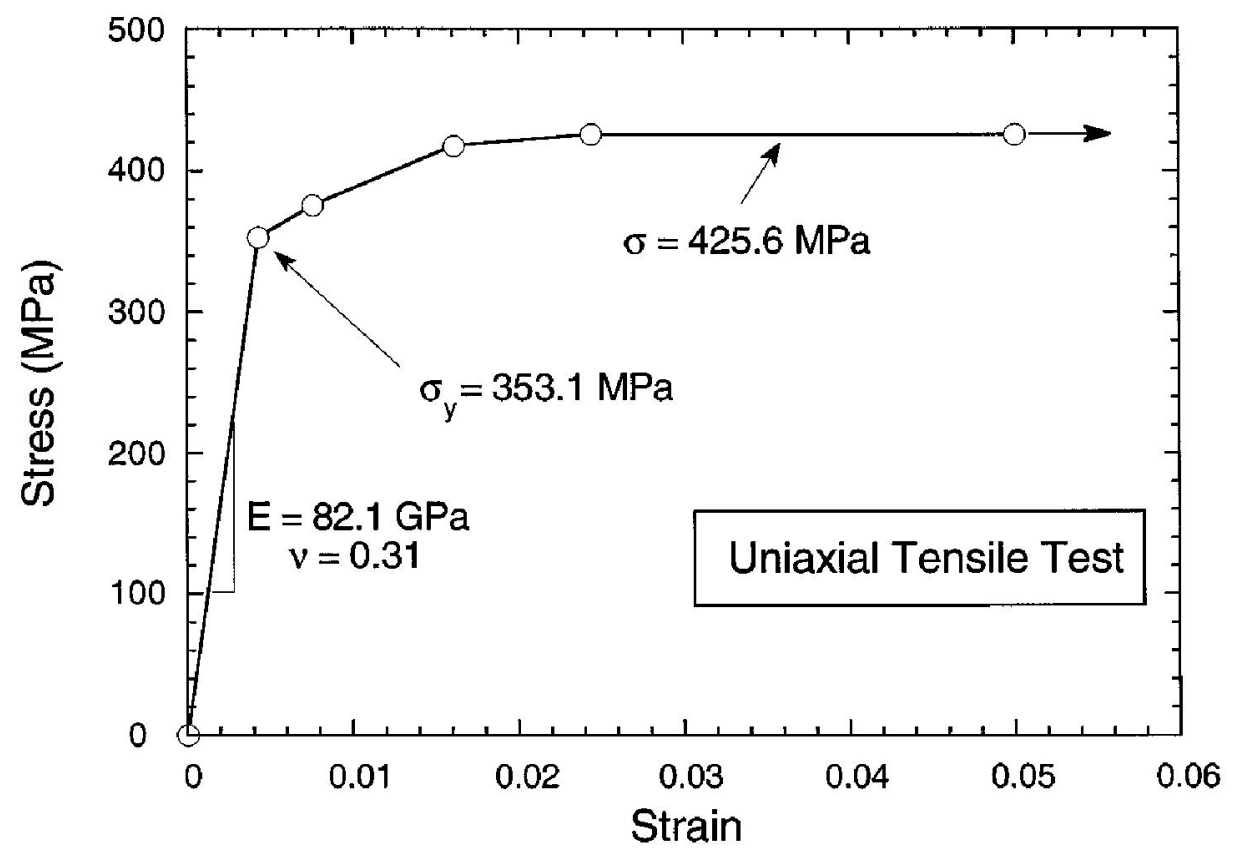

Figure 4-30 Stress-strain data used for indentation simulation [90].

The contact areas, Equation (2.18) are determined using contact depth, $h_{c}$ is plotted as a solid circle and open circle is determined by the measurement of contact area in finite element simulation, Figure 4-31. The two areas are different, the reason is the method of determining contact area from contact depth is based on an elastic analysis thus it cannot account for pileup.

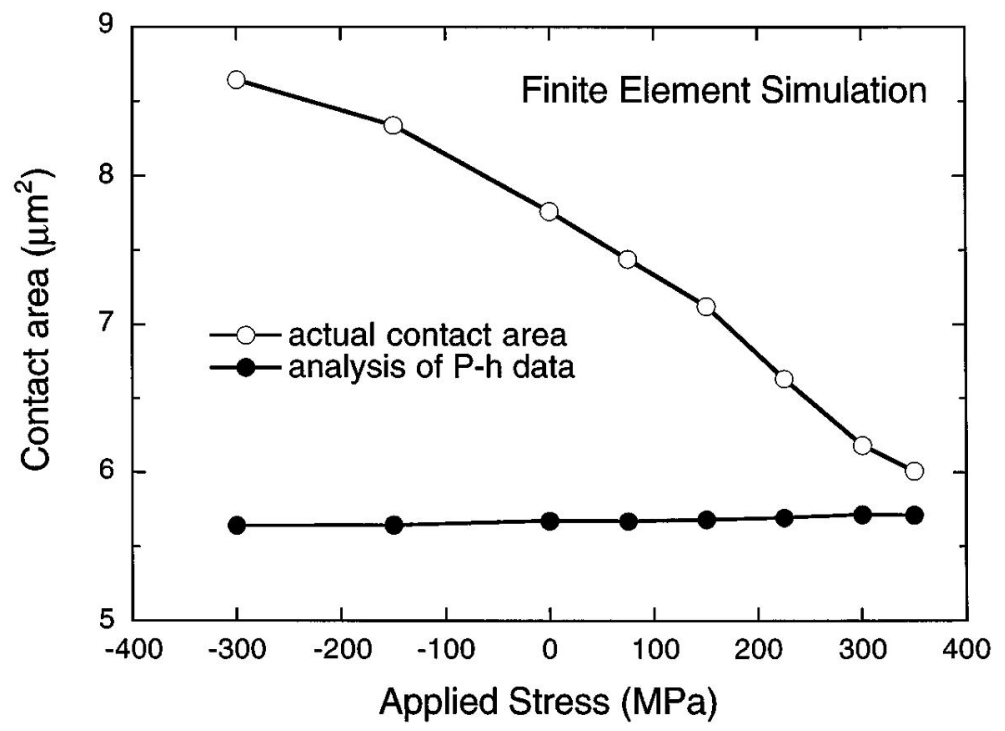

Figure 4-31 Referenced result, contact area [90].

Figure 4-32 shows the measurement of elastic modulus by the contact depth and actual measured contact radii. The elastic modulus determined by the contact depth shows sensitive variation along with applied stress. Following the same procedure detailed in 
Reference 90, elastic modulus values are obtained from this data. Finally, a similar tendency of elastic modulus and contact area are calculated with residual stress variance. These simulation results are in good agreement with contact area and elastic modulus trends found in Reference 90. Elastic modulus is found to be proportional to the materials residual stress state, where in elastic modulus increases and decreases with applied stress, Figure 4-33 and Figure 4-34.

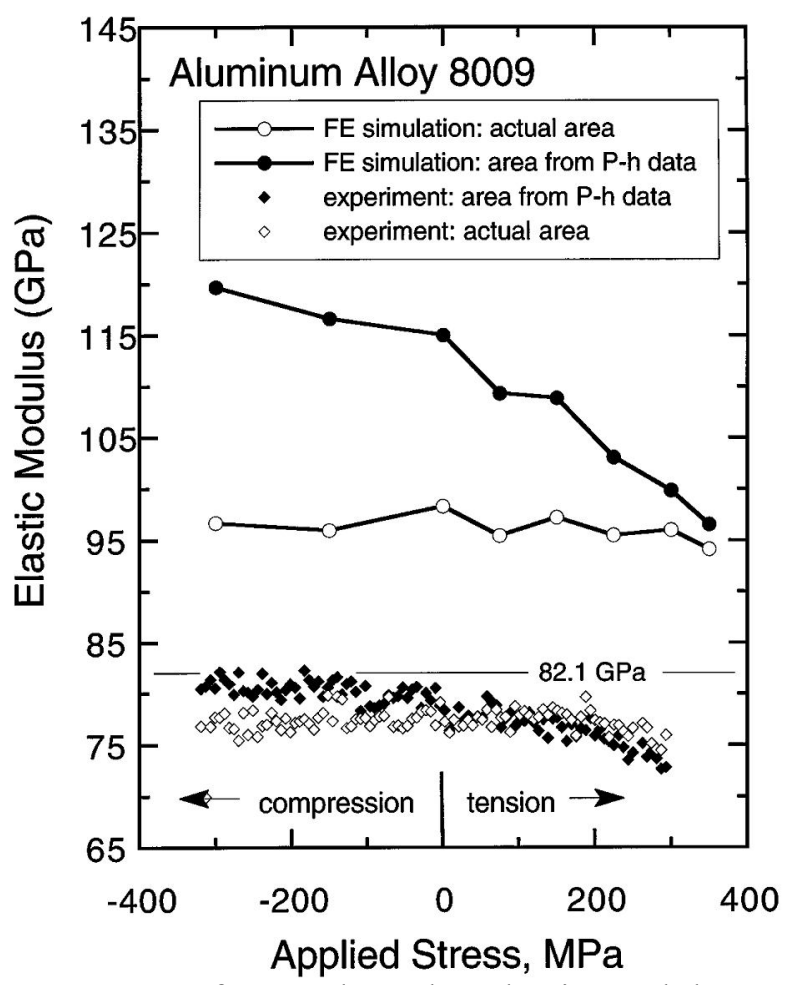

Figure 4-32 Referenced results, elastic modulus [90].

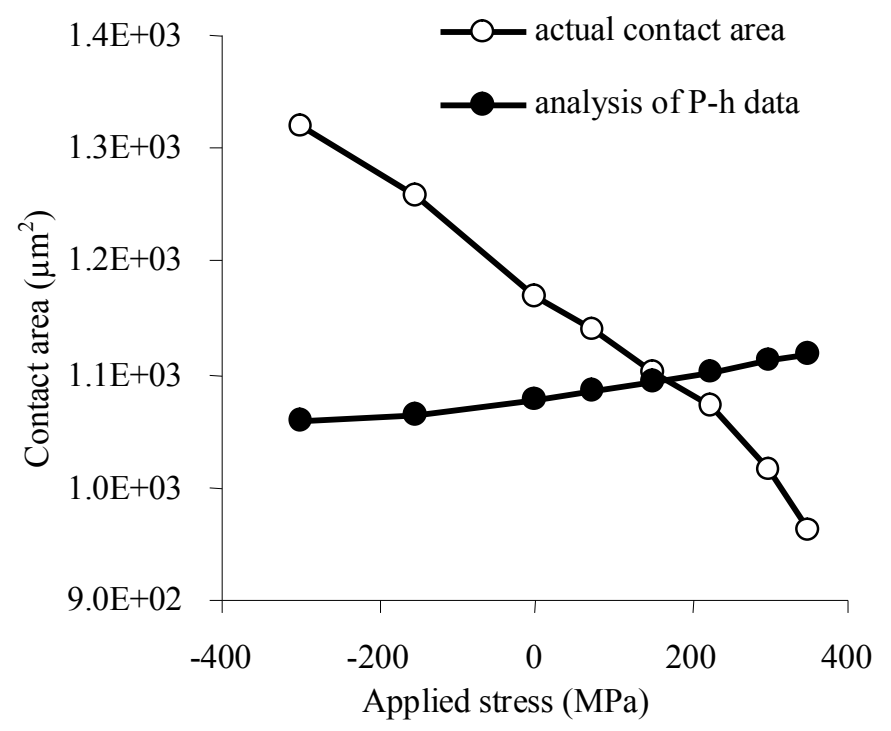

Figure 4-33 Measured contact area. 


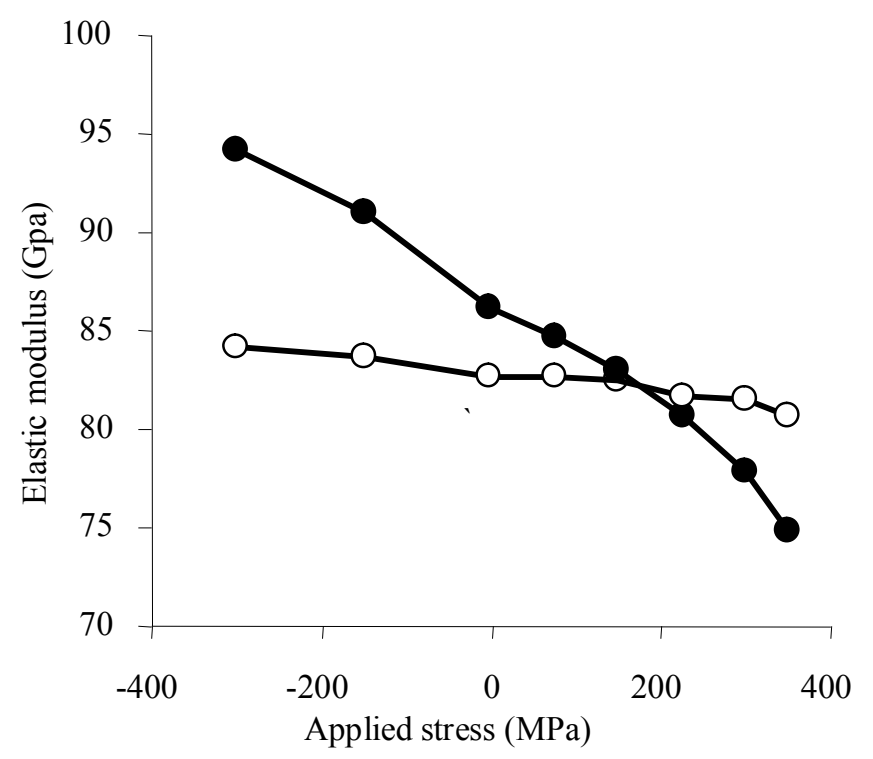

Figure 4-34 Measured elastic modulus.

Material property investigations using a traditional contact mechanics approach are conducted assuming model only incorporating only YSZ. Prior full TBC system indentation simulation efforts have shown that when using a relatively small load, indentation induced stress patterns are constrained within only YSZ. Thus, the remaining layers have no influence on the load displacement curves obtained from this model, if the applied indentation load remains small. The model is assumed to be axisymmetric where in a Plane182 element is used, Figure 4-35. Mass element (Mass21) placed in the center of the indenter and the contact surface are linked by rigid contact elements (MPC184). Contact172 and Target169 elements are used for contact. In this simulation, all friction coefficients are removed. Isotropic bilinear elastic-plastic behavior is assumed with a total of 31720 elements existing. In-plane residual stress is applied on the outer cylindrical surface of the axisymmetric model, Figure 4-36. The magnitude of the inplane stress that is applied is found from the aforementioned full scale TBC model. A 500 $\mu \mathrm{m}$ total model width, $353 \mu \mathrm{m}$ height is assumed. A minimum element size of $0.06 \mu \mathrm{m}$ is used beneath a $100 \mu \mathrm{m}$ indenter ensuring high precision contact area measurement. An applied load of $0.2 \mathrm{~N}$ and unloading of $0.18 \mathrm{~N}, 10 \%$ reduced value, are used. An A. Bolshakov et al. indentation model and data reduction methodology are used to obtain an elastic modulus measurement from the TBC systems [90]. 


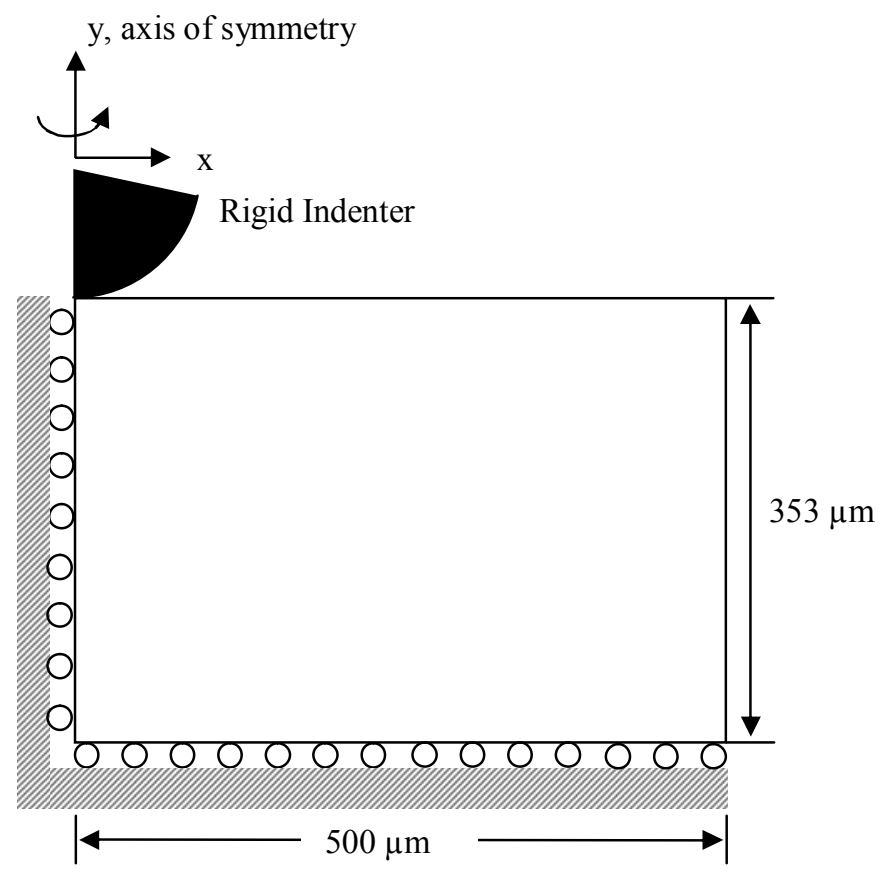

Figure 4-35 Boundary conditions.

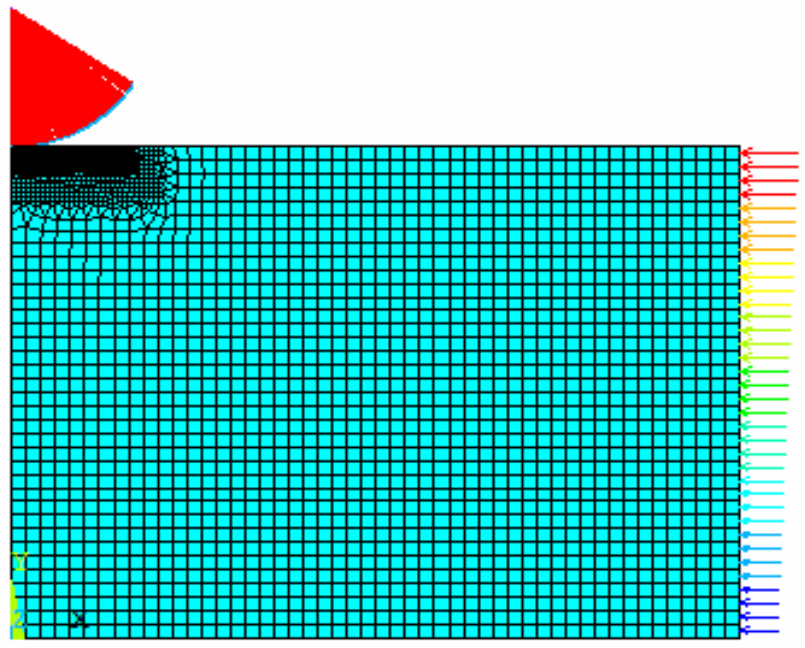

Figure 4-36 Finite element mesh for indentation.

Now, by applying only the in-plane YSZ residual compressive stresses to the outer surface of the YSZ only model, it is shown that indentation unloading slope increases with TGO wave amplitude, Figure 4-37 and measured elastic modulus is increasing as well, Figure 4-38. Thus, these findings are consistent with the experimental expectations that localized unloading surface stiffness response will increase as compressive stress strengthens due to TGO growth with the associated interfacial ratcheting/rumpling morphology, making these regions more prone to spallation failure. 


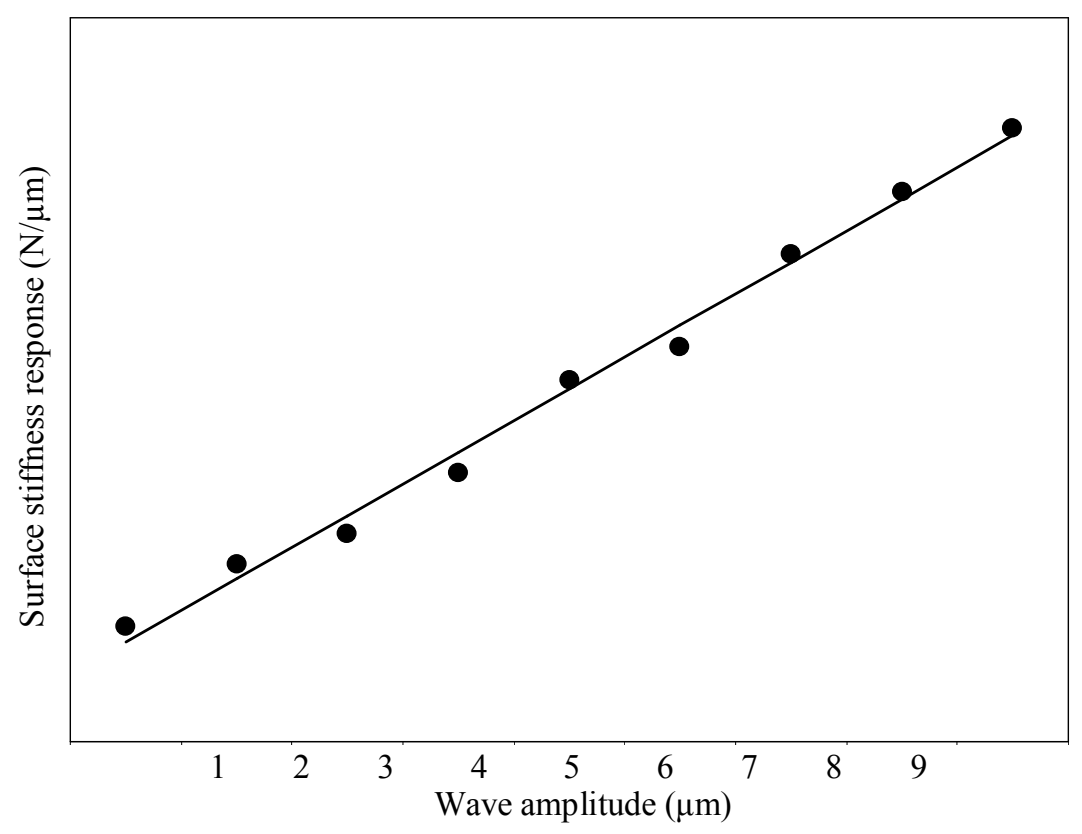

Figure 4-37 Surface stiffness responses to increase residual stress.

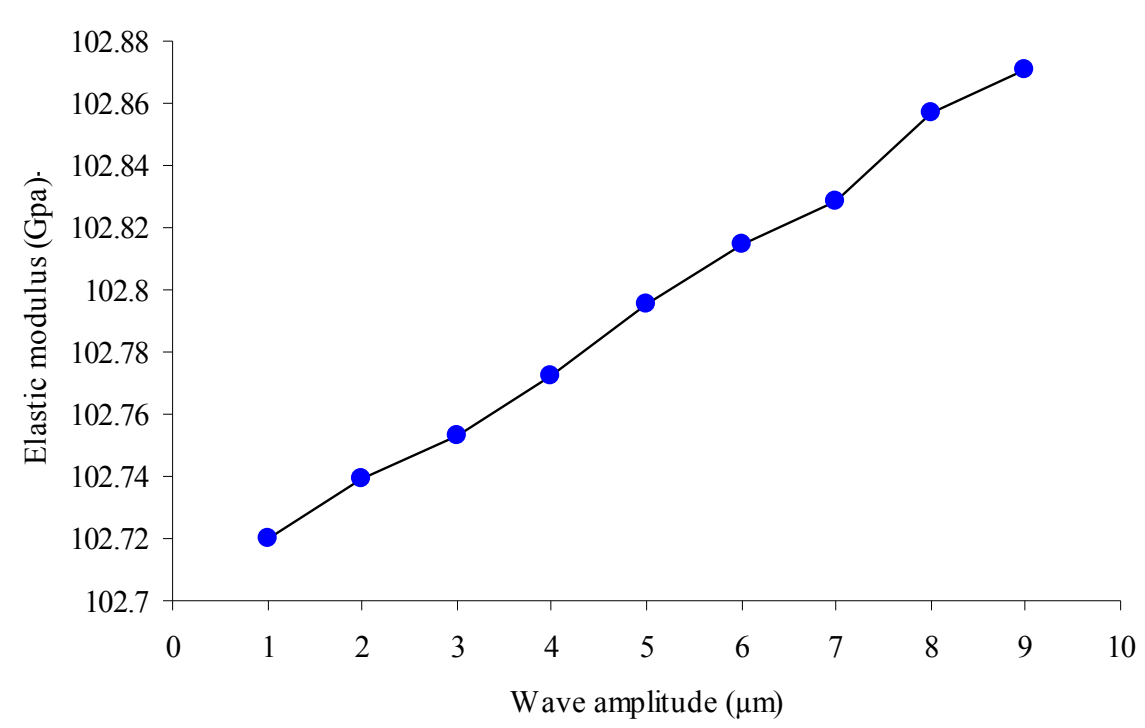

Figure 4-38 Measured elastic modulus with increase residual stress.

\subsubsection{Indentation on residually stressed TBC}

As previously shown indentation based elastic modulus calculations of a residually stressed body display a higher stiffness response along TGO wave amplitude increasing. From this, it is predicted that stiffness response will change along location in TBC as well. The highest residual stresses occurring in the most rumbled TGO model are applied as an initial condition in the finite element model. Following this indentation is simulated on two different locations, both the center and edge. To accomplish this 
axisymmetric indentation is performed both at the center and the edge of the simulated TBC full model with residual stress initiation on the model, Figure 4-39 and Figure 4-40.

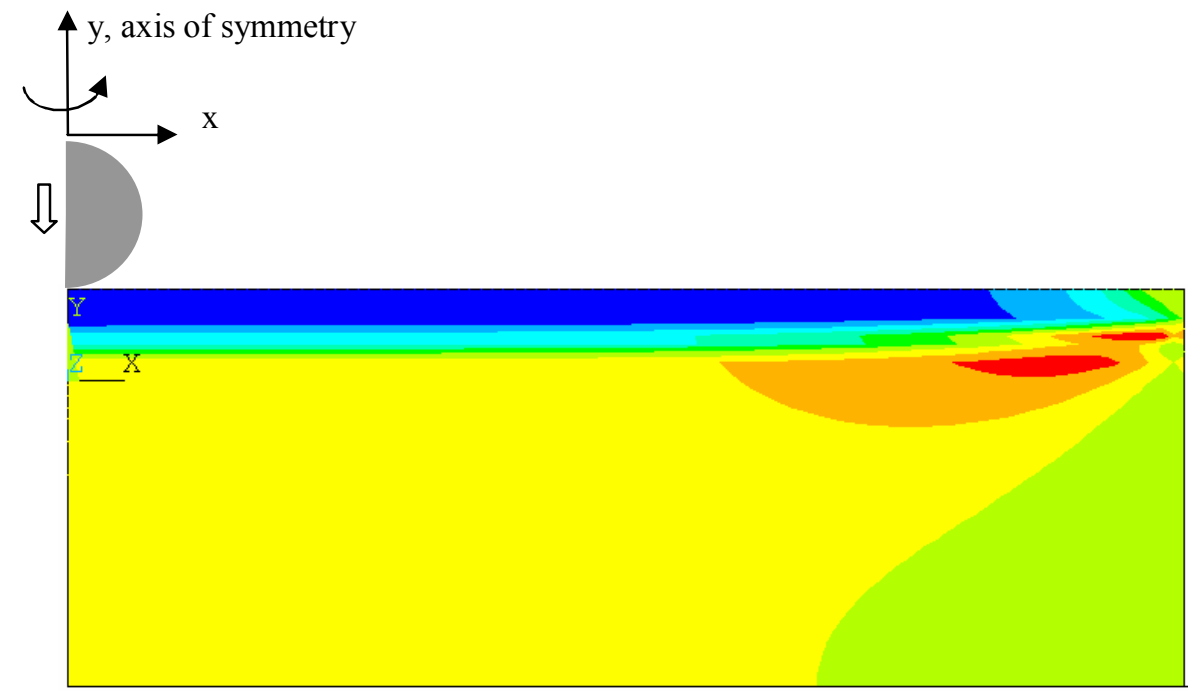

Figure 4-39 Schematic of indentation at the center on residual stressed TBC.

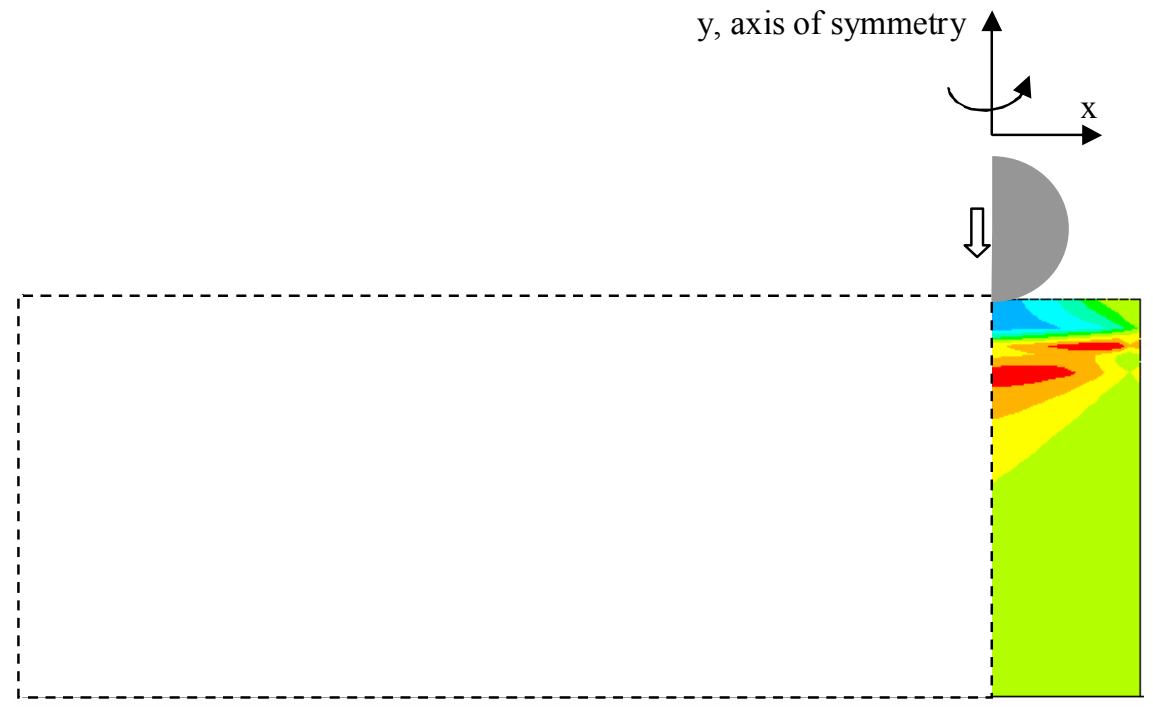

Figure 4-40 Schematic of indentation at the edge on residual stressed TBC.

The indentation results show clear trends, where measurements on the highly stressed locations display an increased elastic modulus, Table 4-2. This trend is consistent with previous study.

Table 4-2 Result of indentation on residually stressed model.

\begin{tabular}{|c|c|c|}
\cline { 2 - 3 } \multicolumn{1}{c|}{} & Indentation for center position & Indentation for edge position \\
\hline Elastic modulus (Gpa) & 57.33 & 66.32 \\
\hline
\end{tabular}




\section{Chapter 5 NON-UNIFORM TGO GROWTH}

The thermal expansion mismatch occurrence by cooling to ambient temperature drives significant interfacial crack and coalescence. The current premature and spallation failure of TBC systems are dominated by residual stress occurrence by thermal expansion mismatches and unstable thermally grown oxides. Although nearly all researches agree on the significance of bond coat oxidation as a parameter for determining TBC life, the exact failure mechanisms for the various coatings types are not completely clarified $[64,97]$. Complicating matters further, time to failure is largely dependent upon the cycle frequency and temperature, whereby considerable scatter is observed for even a single coating system [98]. However, TGO growth is generally believed to be one of the major degradation mechanisms controlling the lifetime of TBC systems, yet no successful failure criteria using only oxidation rate has been developed. For more than a decade, the influence of bond coat oxidation behavior on TBC lifetime has been described simply by TGO thickness $[99,100]$, however it has recently been shown clearly that the adherence of the $\mathrm{YSZ} / \mathrm{TGO} / \mathrm{BC}$ interface is the most important parameter governing the durability of these systems. As a result, lifetimes of these systems are determined by the microstructural evolution taking place at material interfaces when exposed to thermal loads [107]. Furthermore, once thought to provide additional adherence, the bond coats used in APS TBCs typically have high surface roughness or height asperity along their interfaces, however upon cooling, these non-uniform interfaces develop both in-plane and out-ofplane residual stresses [82]. Moreover, additional roughing or rumpling of this interface as a result of non-uniform TGO growth leads to the development of additional geometrical imperfections [59,60]. At these locations stresses become amplified and ultimately induce micro-cracking in and around the YSZ, TGO, BC and their interfaces [101]. These micro-cracks often occur only at the peaks of the TGO/BC interface, yet do not propagate beyond this point due to compressive residual stress states elsewhere $[102,83]$. In this research several finite element models are developed via experimentally obtained cross sectional scanning electron micrographs. Through a detailed analysis of the out-of-plane tensile stresses produced upon cooling, a complete spallation failure prediction path has been developed in addition to causes for such delaminations occurring prior to a sufficiently thick TGO scale developing.

\subsection{Experimental Observations}

The investigated thermal barrier coating systems consisted of the single crystal Ni-base superalloy RenéN5 substrate, NiCoCrAlY bond coat and a 7wt\% yttria partially stabilized zirconia top coat applied by an air plasma-spray process. Atop the $1 / 8$ " thick by 
1 " square substrate, bond coats and top coats were applied with thicknesses of 300 and $350 \mu \mathrm{m}$, respectively. Coupons were thermally cycled at temperatures of $1100{ }^{\circ} \mathrm{C}$ in ambient air environments. Each thermal cycle consisted of heating with a rate of $1.2{ }^{\circ} \mathrm{C} / \mathrm{s}$ followed by a dwell time at a maximum temperature of $1100^{\circ} \mathrm{C}$ for 40 hours, followed by a subsequent $1.2{ }^{\circ} \mathrm{C} / \mathrm{s}$ cooling to room temperature. Thermally exposures were conducted in a horizontal, resistance coil tube furnace able to maintain a set temperature of $\pm 3{ }^{\circ} \mathrm{C}$. The coupons were metallographically prepared by cold mounting the samples in epoxy resin to avoid additional damage that may occur during this process. Coupon section was performed with precision diamond wafer blades where after the initial grinding with the $\mathrm{SiC}$ lapping film was followed by a final polishing being performed with colloidal silica suspension liquid down to $1 \mu \mathrm{m}$ grain size. The colloidal silica provided both a chemomechanical polishing (CMP) action and reduced subsurface damage. Micro-structural investigations were carried out with a JEOL 7600F scanning electron microscope. All coupon cross-sections were sputter coated (AuPd) prior to viewing, this procedure was required to reduce the amount sample charging throughout imaging. All TBC coupons were supplied by the National Energy Technology Laboratory (NETL) a subsidiary of the United States Department of Energy (DOE). Large scale spallation failure of all thermally cycled TBC systems initiated from the coupons edges, however prior to this event several micro-structural TGO interface observations were made and are as follows:

a) Although a majority of the numerical models developed to evaluate residual stresses and failure mechanisms of APS TBC systems enlist uniform TGO thickness, these geometrical assumptions are rarely experimentally observed, Figure 5-1.

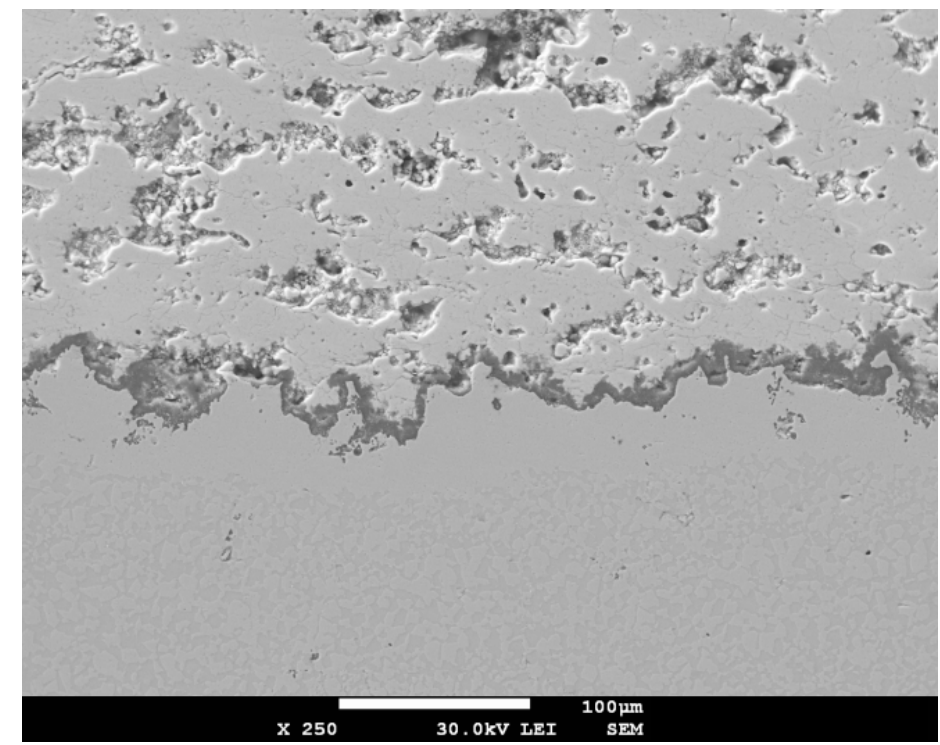

Figure 5-1 Non-uniform TGO thickness.

b) A result of bond coat roughness, $\mathrm{YSZ} / \mathrm{TGO} / \mathrm{BC}$ interface geometry resembles that of a sinusoidal wave and would be applicable to model in this manor, Figure 5-2. 


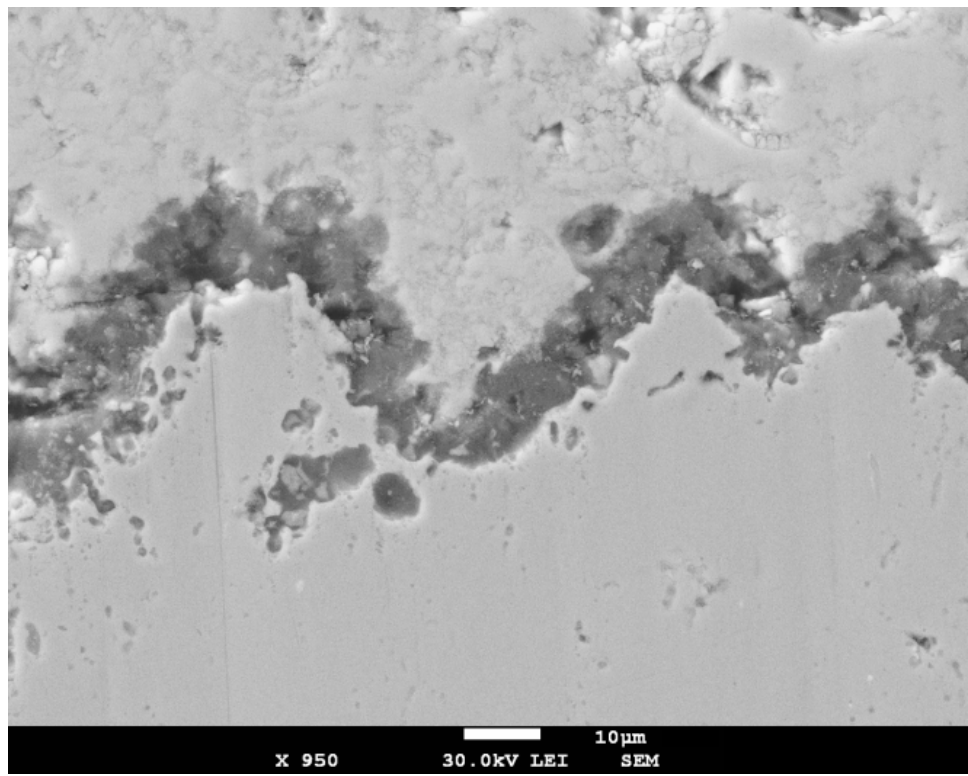

Figure 5-2 Sinusoidal wave pattern.

c) Within the TGO wave several thickness variation trends were observed, however may be separated into three categories:

i. Uniform thickness across the wave.

ii. Greater TGO thickness at the apex, Figure 5-3.

iii. Greater TGO thickness at the base.

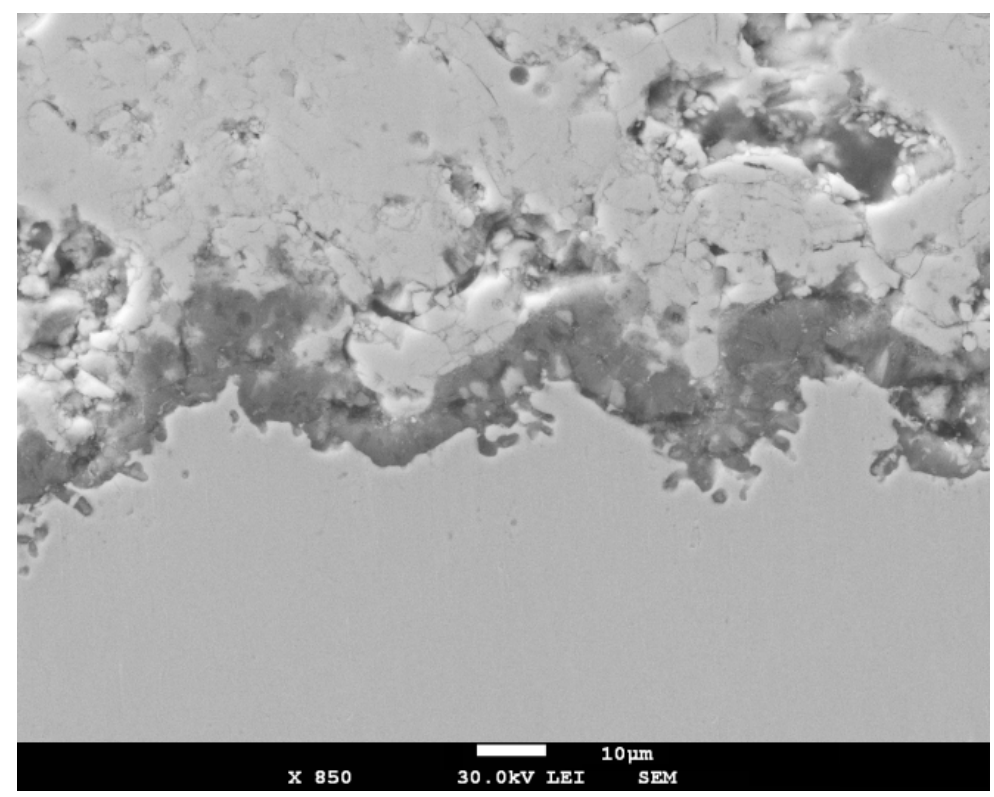

Figure 5-3 Wave thickness variability.

d) Although micro-cracks were observed in several locations, those taking place within the TGO and not its interfaces occurred at the TGO wave's midline, Figure $5-4$. 


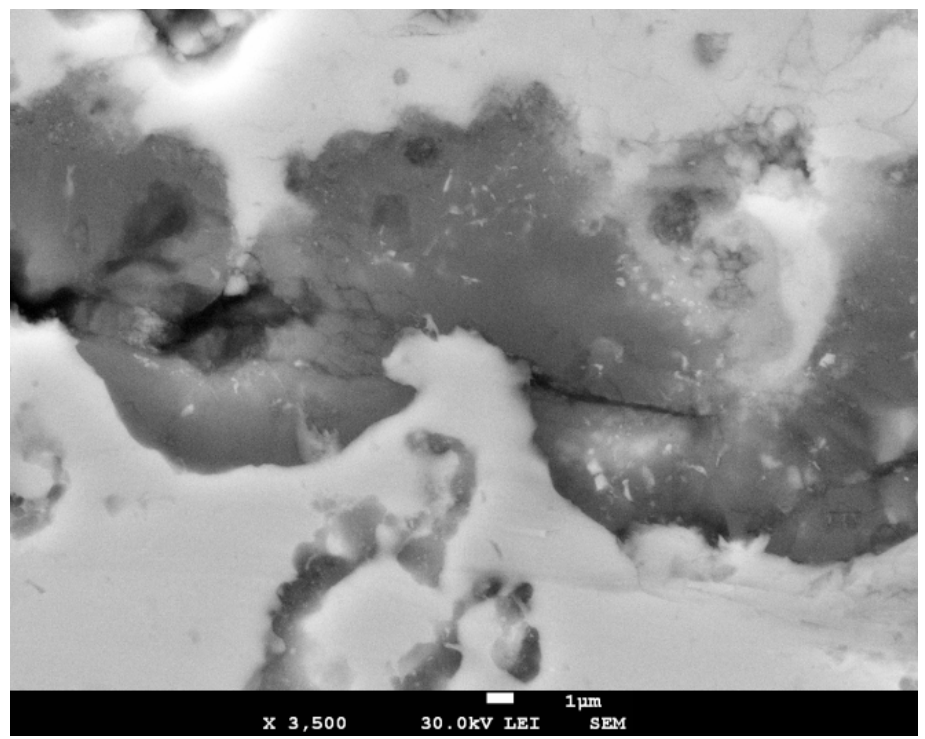

Figure 5-4 Observed TGO thickness variability.

e) Interface crack coalesce generally followed a similar failure progression to that previously established by various researches [52] where:

i. Micro cracks develop at the apex TGO/BC interface wave.

ii. These cracks then propagate and extended through the TGO at the wave mid line.

iii. Emerging on the opposite side of the TGO, these micro-cracks then lengthen and extend to the YSZ just above the TGO wave's base, Figure 5-5.

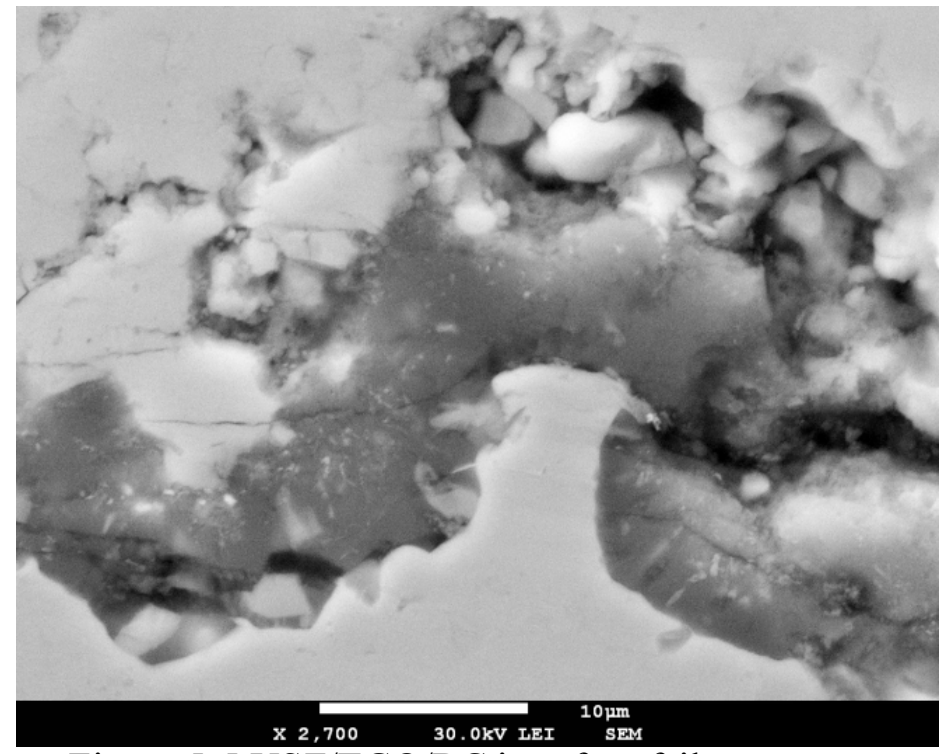

Figure 5-5 YSZ/TGO/BC interface failure pattern.

With these observations a parametric numerical model has been developed to explain the more commonly observed failure patterns. Specifically, detail the micro-cracking 
progression described in item (e) using a variable TGO thickness model. Also, establish a relative residual stress state at the YSZ/BC/TGO interface using the various non-uniform TGO thickness geometries presented in item (c). Moreover, as several uniform TGO thickening models have been developed researchers [103-106], a final objective of this research is the determine the relationship variable TGO geometries have on interface residual stress states.

\subsection{Parametric design}

Residual stress trends at each interface are reviewed with TGO geometrical rumpling effect. Actual TGO rumpling is a combination of both additional rumbling and thickening [54-56]. This TGO is generated in the early stages of TBC life and thicken along thermal cycling and eventually rumple due to thermal expansion mismatches within the system. TBC failure mechanisms are complex processes including TGO thickening, rumpling, crack initiation and crack propagation. Failure modes are closely linked to thermal loading conditions and early initiated micro cracks do not propagate along the YSZ/TGO/BC interface due to the presence of out-of-plane compressive stresses that exists in the $\mathrm{YSZ} / \mathrm{TGO} / \mathrm{BC}$ interface troughs. Yet once a sufficiently thick TGO layer with increased rumpling aspect ratio is formed, the tensile out-of-plane stresses at the TGO rumpling peaks develop and eventually cause micro spallation [103108]. Variable TGO modeling is suggested in this research in order to consider this TGO thickening and rumpling in the simulation.

\subsubsection{Finite element model for uniform and non-uniform TGO growth}

In this parametric modeling design, a sinusoidal $\mathrm{YSZ} / \mathrm{TGO} / \mathrm{BC}$ interface was assumed. As previously stated, this geometry was implemented to more precisely simulate the experimentally observed $\mathrm{YSZ} / \mathrm{TGO} / \mathrm{BC}$ interfacial microstructure. To accomplish this, sine wave functions were implemented for both the TGO/BC as well as the YSZ/TGO interface, Figure 5-6. Defined by amplitude $\left(A_{i}\right)$, wave length $(\lambda)$ and offset $(k)$, functions for both lines are developed using Equation (5.1) and Equation (5.2). From these it can be seen that if both the TGO/BC interface amplitude $\left(A_{1}\right)$ and YSZ/TGO amplitude $\left(A_{2}\right)$ are equal, a uniform TGO model is generated with a thickness of offset $(k)$.

$$
\begin{gathered}
y_{T G O / B C}=A_{1} \sin \left(\frac{2 \pi}{\lambda} x\right) \\
y_{Y S Z / T G O}=A_{2} \sin \left(\frac{2 \pi}{\lambda} x\right)+k
\end{gathered}
$$




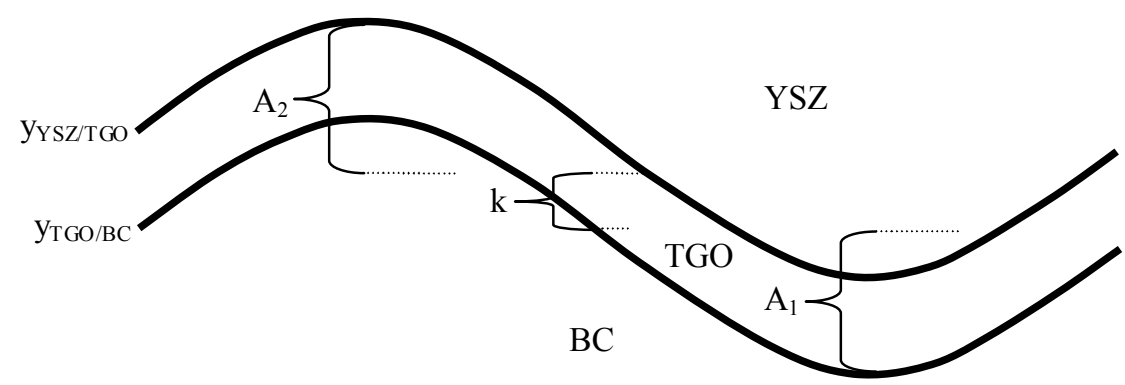

Figure 5-6 Thermally grown oxide modeling parameters.

Prior to evaluating the effects of variable thickness TGO scale growth, numerical models were generated to evaluate stresses occurring at the $\mathrm{YSZ} / \mathrm{TGO} / \mathrm{BC}$ as uniform thickness TGO scales develop, Table 5-1.

Table 5-1 Numerical uniform TGO model design parameters.

\begin{tabular}{|c|c|c|c|c|}
\hline Model Number & $\lambda(\mu \mathrm{m})$ & $A_{1}(\mu \mathrm{m})$ & $A_{2}(\mu \mathrm{m})$ & $k(\mu \mathrm{m})$ \\
\hline 1 & 80 & 5 & 5 & 2.0 \\
\hline 2 & 80 & 5 & 5 & 3.5 \\
\hline 3 & 80 & 5 & 5 & 5.0 \\
\hline 4 & 80 & 5 & 5 & 6.5 \\
\hline 5 & 80 & 5 & 5 & 8.0 \\
\hline
\end{tabular}

Although models having a uniform TGO thickness have been found capable of reasonably predicting TBC spallation patterns [108] rarely are homogeneous TGO layers found in APS TBC systems. As previously presented, modeling this layer with a variable thickness is more practical and will ultimately lead to a more detailed failure analysis. To accomplish this, the amplitude of both interfaces, TGO/BC and YSZ/TGO, may not be equal. Furthermore, although it may be simple to vary interfacial geometry when modeling, the $\mathrm{TGO} / \mathrm{BC}$ interface roughness is the result of several manufacturing parameters [109] and largely influenced by oxygen ingress, thermal cyclic temperature and surface morphology among others [107]. As a result, oxidation rates across even a single TBC coating may vary, leading to the development of non-uniform TGO scales. To simulate this effect a constant $\mathrm{TGO} / \mathrm{BC}$ interface amplitude of $5 \mu \mathrm{m}$ was chosen, and only YSZ/TGO amplitude $\left(A_{2}\right)$ is varied. Additionally, although composed of several parameters $\left(A_{1}, A_{2}\right.$ and $k$ ), variations in TGO geometry may defined as the ratio between thicknesses at the apex and the base of the sinusoidal wave, Equation (5.3), thus combining all geometric parameters into one quantifiable value, defined as the TGO aspect ratio.

$$
\beta=\frac{\left.t_{T G O}\right|_{\lambda / 4}}{\left.t_{T G O}\right|_{3 \lambda / 4}}=\frac{A_{2}-A_{1}+k}{A_{1}-A_{2}+k}
$$


Conducting a parametric numerical analysis along $\beta$ has been designed to establish any correlation that may exist between variable TGO growth geometry and residual stress state at the YSZ/TGO/BC interface, where the YSZ/TGO wave amplitude wave $\left(A_{2}\right)$ was increased from $3 \mu \mathrm{m}$ to $7.0 \mu \mathrm{m}$ in increments of $0.5 \mu \mathrm{m}$ Table 5-2.

Table 5-2 Numerical TGO model design parameters.

\begin{tabular}{|c|c|c|c|c|c|}
\hline Model Number & $\lambda(\mu \mathrm{m})$ & $A_{1}(\mu \mathrm{m})$ & $A_{2}(\mu \mathrm{m})$ & $k(\mu \mathrm{m})$ & $\beta(\mu \mathrm{m} / \mu \mathrm{m})$ \\
\hline 1 & 80 & 5 & 3.0 & 8.0 & $3 / 5$ \\
\hline 2 & 80 & 5 & 3.5 & 6.5 & $5 / 8$ \\
\hline 3 & 80 & 5 & 4.0 & 5.0 & $2 / 3$ \\
\hline 4 & 80 & 5 & 4.5 & 3.5 & $3 / 4$ \\
\hline 5 & 80 & 5 & 5.0 & 2.0 & $1 / 1$ \\
\hline 6 & 80 & 5 & 5.5 & 3.5 & $4 / 3$ \\
\hline 7 & 80 & 5 & 6.0 & 5.0 & $3 / 2$ \\
\hline 8 & 80 & 5 & 6.5 & 6.5 & $8 / 5$ \\
\hline 9 & 80 & 5 & 7.0 & 8.0 & $5 / 3$ \\
\hline
\end{tabular}

From this a more detailed TBC failure progression may be established and also provide an explanation for the experimentally observed spallation patterns detailed in the previous section. By assuming $\beta$, the ratio of the thickness between the peaks and valleys changes thus three types of non-uniform TGO thickening models can be defined, Figure 5-7. The reverse TGO model, wherein TGO thickness is thicker at the valley than that of the peak, the uniform TGO model has uniform thickness through the wave and the variable TGO model is realistic to experimental observations, TGO thickness at the peak is greater than that the valley.

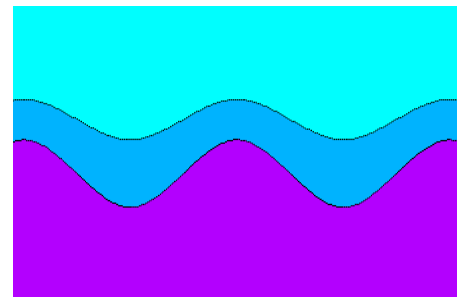

Reverse TGO, Model \# 1

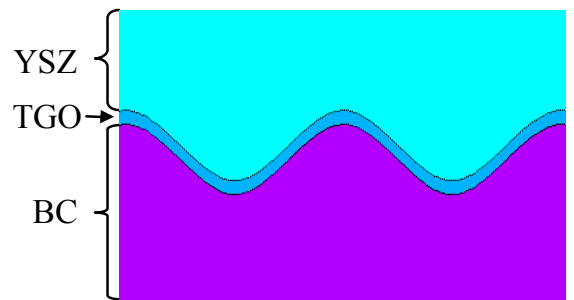

Uniform TGO, Model \# 5

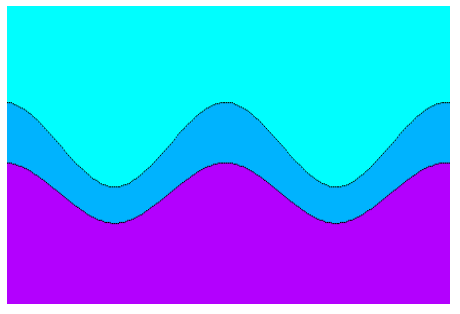

Variable TGO, Model \# 9

Figure 5-7 Three types of TGO thickening models.

Finite element simulations were carried out using an axisymmetric TBC model in ANSYS $^{\mathrm{TM}}$ v11.0 containing all layers with thicknesses of each being $353 \mu \mathrm{m}, 209 \mu \mathrm{m}$ and $2700 \mu \mathrm{m}$ for the YSZ, BC and Substrate, respectively [80,81]. To avoid singularity and obtain a semi-infinite domain a width of $500 \mu \mathrm{m}$ is used with nodes along the axis of symmetry and those along the base constrained to allow movement the length of these 
axes only, Figure 5-8. Enhancing resolution of the resultant stress distribution, minimum element sizes of $0.7 \mu \mathrm{m}$ were implemented within the TGO and increased to a value of 3 $\mu \mathrm{m}$ when entering the YSZ and BC, Figure 5-9. Required to induce residual stress, a reduction in thermal load from $1100{ }^{\circ} \mathrm{C}$ to $23{ }^{\circ} \mathrm{C}$ is applied to the TBC system with a $\Delta \mathrm{T}$ of $-1077{ }^{\circ} \mathrm{C}$. These temperatures were chosen due to the condition of which the experimental coupons were thermally cycled. Finally, a bilinear isotropic hardening material model has been employed, as a result elastic-plastic behavior material behavior is considered, Table 4-1[69].

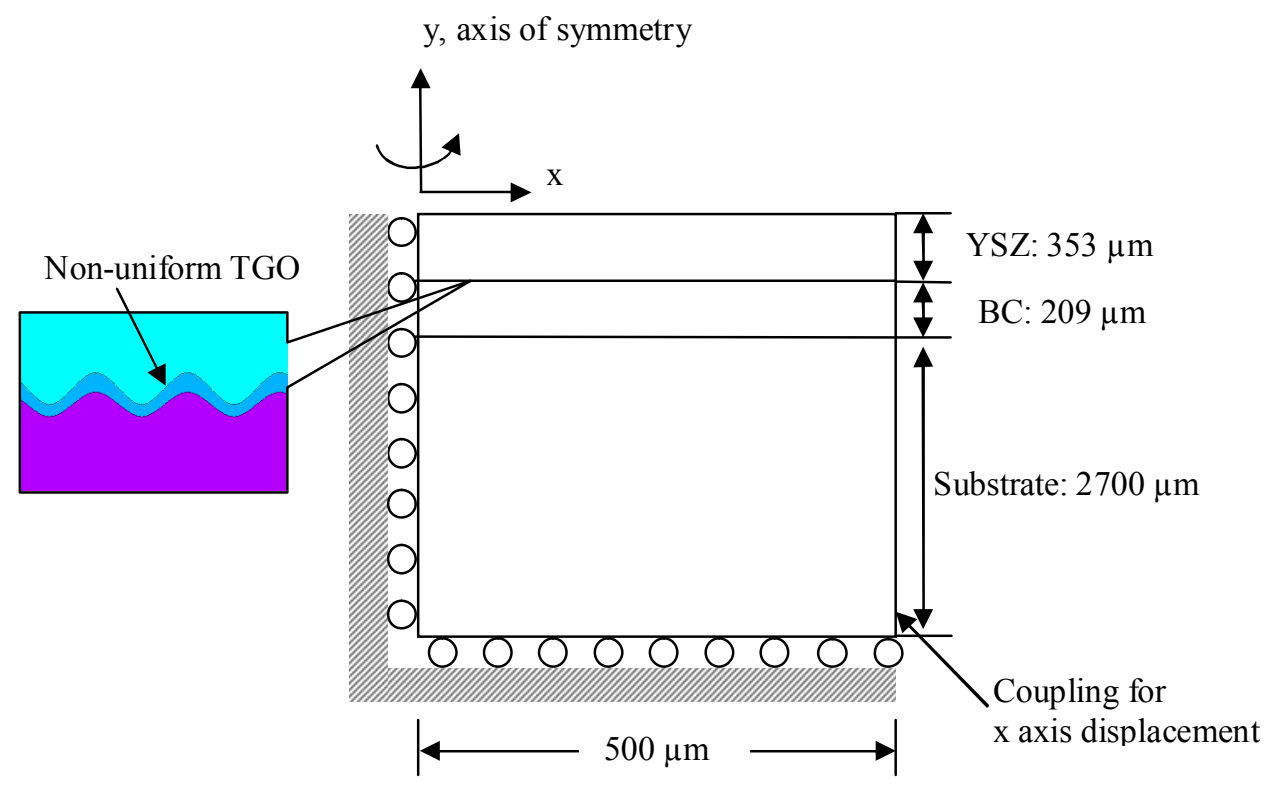

Figure 5-8 Boundary conditions applied to the numerical TBC model.

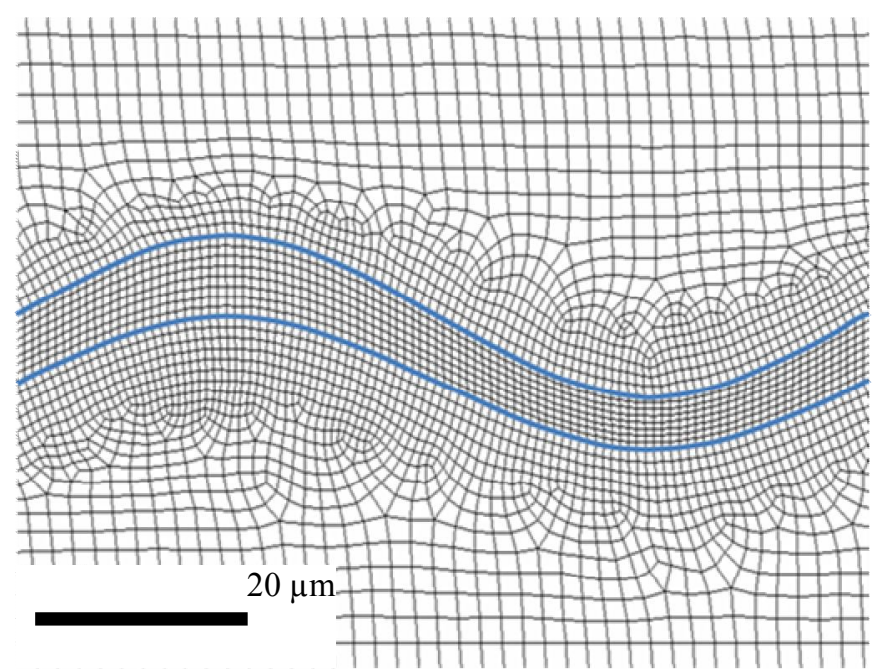

Figure 5-9 Finite element mesh resolution around YSZ/TGO/BC interface. 


\subsection{Analytic result review}

Due to the complexity of TBC interface overall residual stress states along $\beta$, only the five locations where micro-cracking was consistently observed are presented, Figure 5-10. Of these five locations, four reside at the apex and the base of the YSZ/TGO (nodes 1 and 2) and TGO/BC (nodes 3 and 4) interfaces, in addition to one at the TGO wave's midline (node 5). Although in-plane residual stress states have been reviewed, their overall magnitude was found to be well bellow that needed to cause compressive failure. Furthermore, recent studies indicate that it is not the in-plane but rather that out-of-plane tensile stresses that are directly responsible for micro-cracking and spallation failure patterns in TBC systems [52]. Due to this only the out-of-plane tensile stresses at interface nodes 1,2, 3 and 4, as well as shear stress at node 5 are presented.

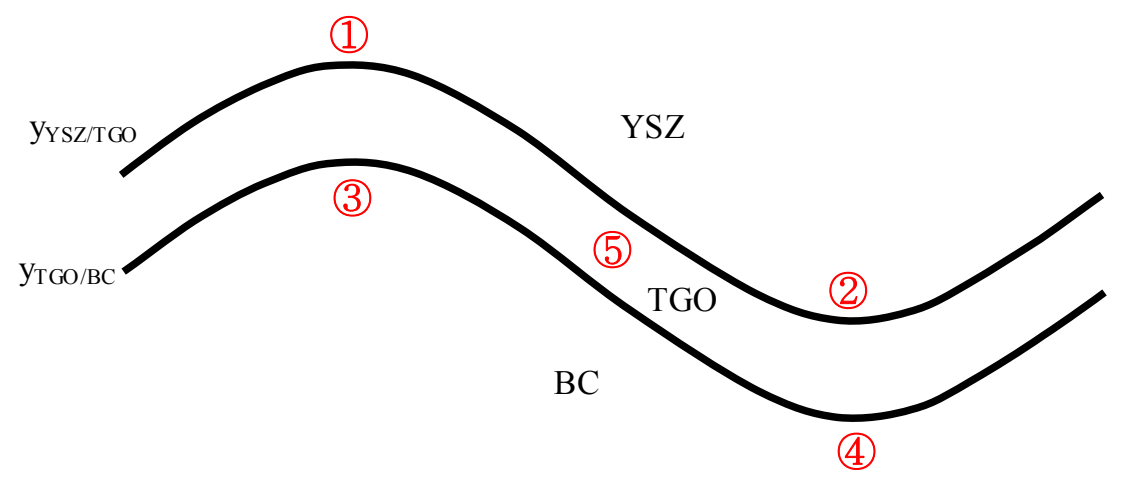

Figure 5-10 Selected locations for result review.

\subsubsection{Uniform TGO growth}

Only the effects of uniform TGO scale thicken are considered in this section, where residual stresses acting at locations $1,2,3,4$, and 5 are evaluated along offset $(k)$, Figure 5-11, Figure 5-12. In this graph it is shown that no path for crack propagation or coalescence is evident as TGO scale thickness increases. Although tension at node 1 exists as TGO thickness is minimum $(k=2 \mu \mathrm{m})$, these cracks will not propagate as only a compressive out-of-plane stress state exists at location 2. Furthermore, as oxidation persist, the out-of-plane stresses at locations 1 and 4 become increasingly compressive as $(k)$ approaches $8 \mu \mathrm{m}$, Figure 5-11. However, at location 3 (apex of the TGO/BC interface) out-of-plane tensile stresses are found to increase with uniform TGO scale thickness. Due to this, micro-cracks are found to develop early in the TBC system's life cycle at the apex of the TGO/BC interface [67]. Additionally, the shear stresses acting at node 5 are found to decrease as $k$ approaches a maximum, Figure 5-12. However, according to the Rankine criterion for brittle materials, failure takes place when the maximum principal stress at any point inside the material reaches a value equal to the tensile strength $\left(\sigma_{y}\right)$ as found in a simple tension test [110]. Thus according to this criterion, the principle stresses acting at node $5(-9.23 \mathrm{MPa},-1.05 \mathrm{GPa}$ and $-1.06 \mathrm{GPa})$ as $k$ approaches a maximum $(k=8 \mu \mathrm{m})$ exceed that of the TGO's yield stress (1 GPa [111]) and initiate failure. However, as cracks develop within the TGO they are unable to propagate across the TGO scale wave as compressive stresses still exist in locations 1,2 , and 4 as $k$ increases. Thus as thin 
uniform TGO scales develop, cracks developing at the TGO wave midline are able to propagate to the apex of the TGO/BC interface (node 3 ) yet may not extend further as the stresses acting at locations $(1,2$, and 4$)$ are in a compressive state.

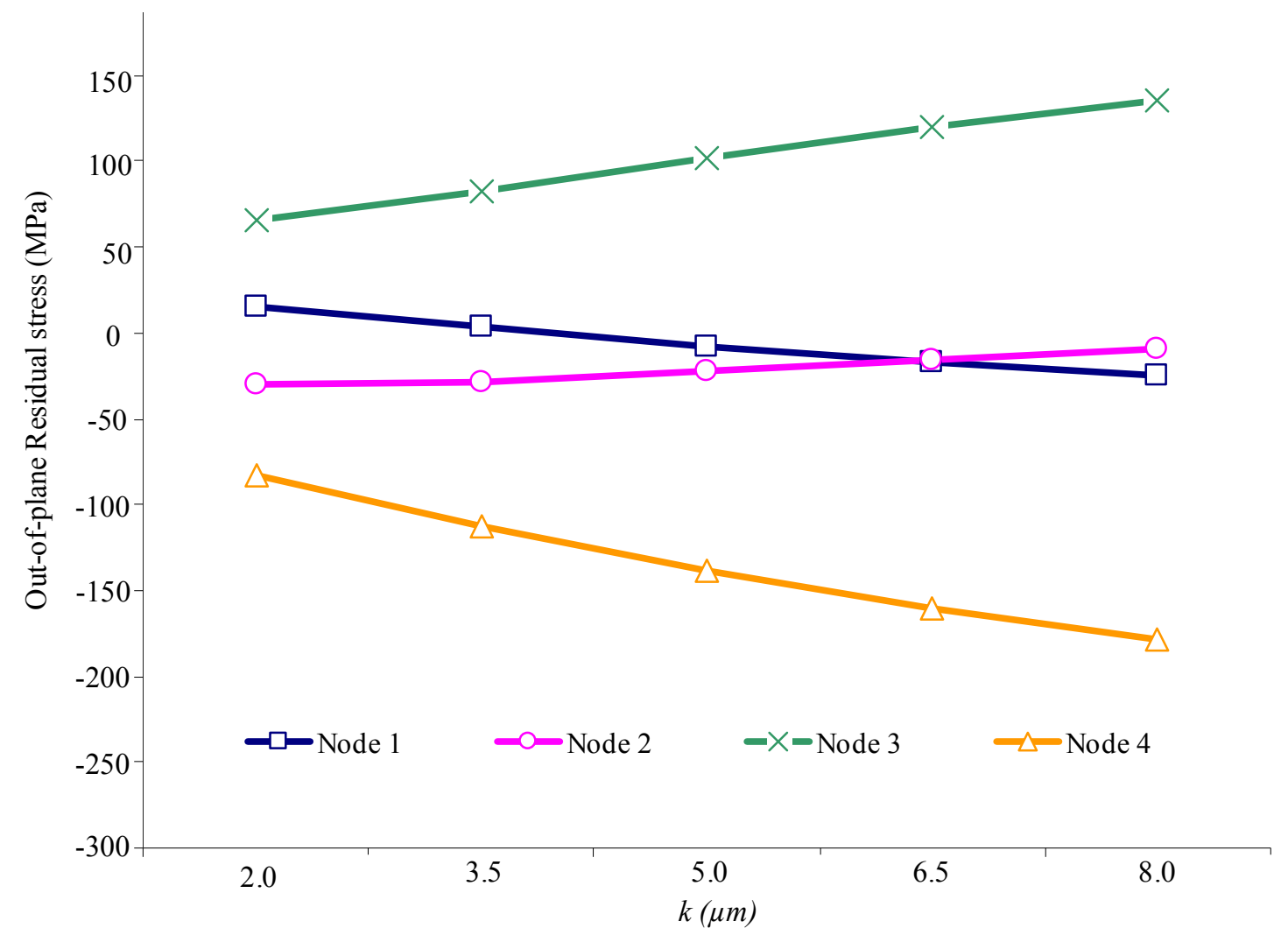

Figure 5-11 Out-of-plane residual stress along k.

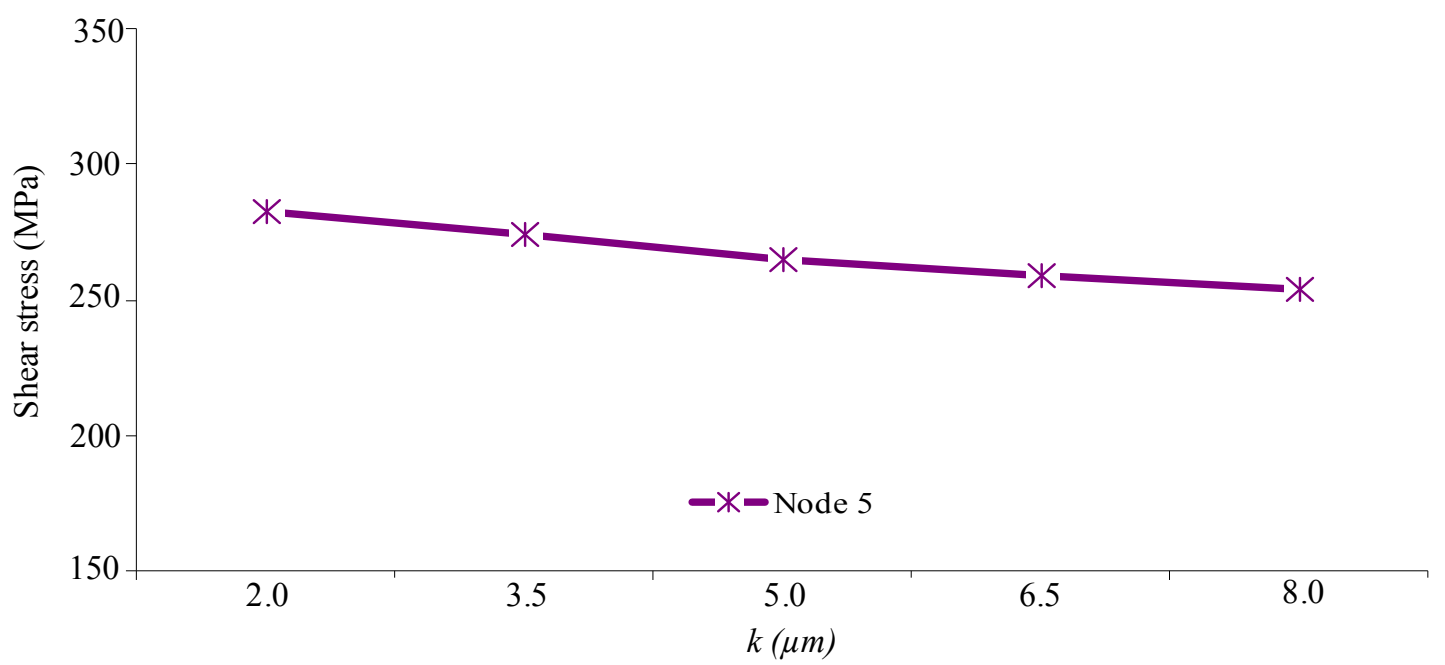

Figure 5-12 Shear stress state along k. 


\subsubsection{Non-uniform TGO growth}

Whereas only the effects of uniform TGO scale thickening were investigated in the previous section, here those attributed with non-uniform TGO scale thicken are considered in this section, where the residual stresses acting at locations $1,2,3,4$, and 5 are evaluated along TGO aspect ratio $(\beta)$, Figure 5-13. In this graph it is shown that a path for crack propagation is evident as the TGO geometries of large $\beta$ develop. The outof-plane stresses developing at the YSZ/TGO interface's apex (node 1) are found to be tensile as $\beta$ approaches zero, however transitions to compression as it exceeds 1 . Conversely, stresses developing at the interface's base (node 2 ) are inversely proportional to those at the apex, where the tensile stresses at this location exist only as $\beta$ exceeds 1 , Figure 5-13. These contrasting states of stress at nodes 1 and 2 acts to prevent localized cracking that may develop at either location from propagating beyond these points. As a result, it is not surprising that large scale spallation failures along this interface are rarely observed. Furthermore, this contrast in the residual stress state exists between locations 3 and 4 as well, where the out-of-plane stresses at node 3 increase symmetrically about $\beta=1$, yet residual stress states at location 4 are found to be uniformly compressive along all $\beta$, Figure 5-13.

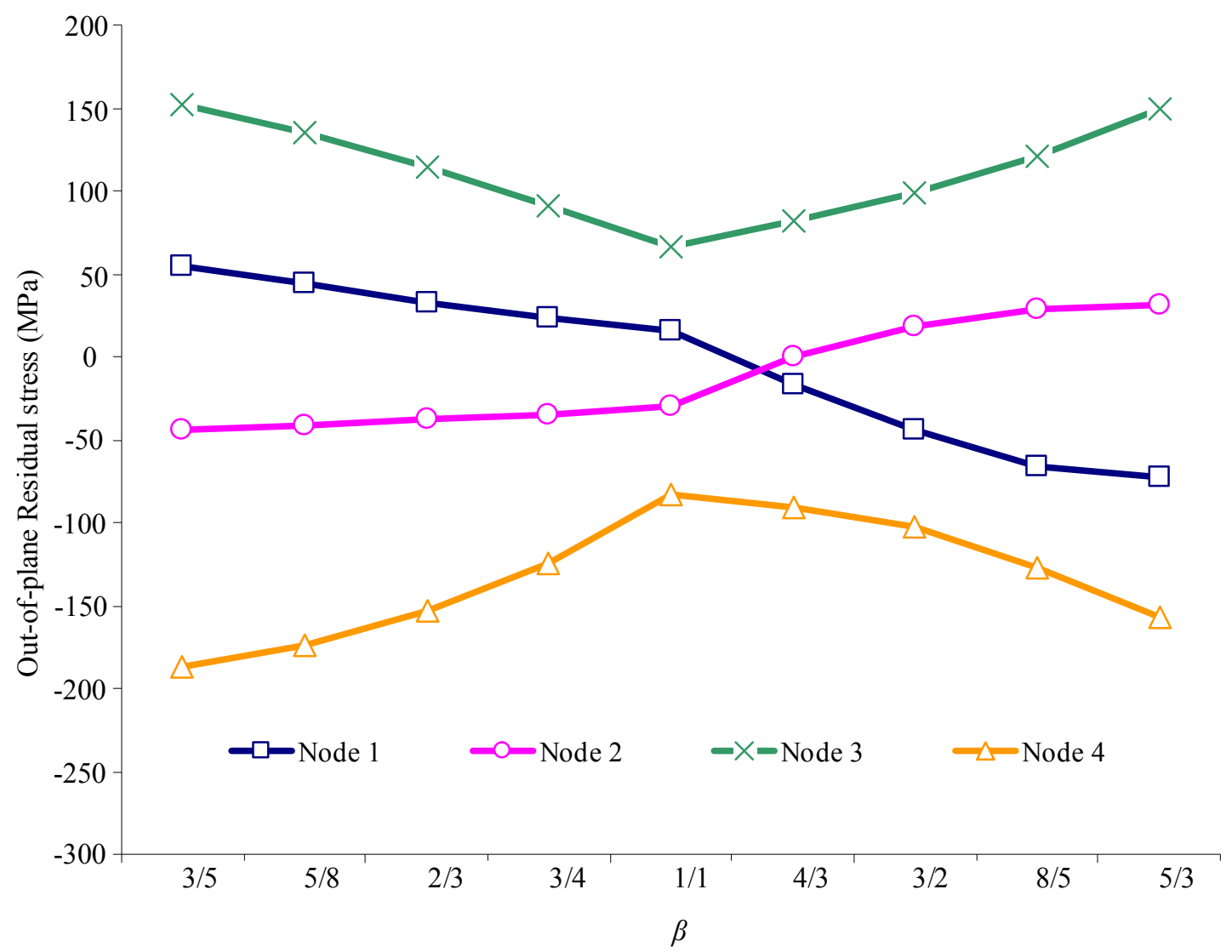

Figure 5-13 Residual stress state along $\beta$. 
These compressive stresses produced at node 4 are not conducive to micro-crack development and thus those developing at the location 3 typically do to propagate along the $\mathrm{TGO} / \mathrm{BC}$ interface and result in large scale spallation failure either. Unlike that of nodes 1,2 and 3, cracks developing at location 5 are not easily explained through review of the out-of-plane residual stresses acting in this region as a compressive stress state exists along all $\beta$. However, the cause of localized cracking in this region becomes evident upon review of the system's maximum shear stress magnitude and location (node 5), Figure 5-14 and Figure 5-15. Furthermore, again citing the Rankine failure criterion for brittle materials, the principle stresses acting at node $5(-50.8 \mathrm{MPa},-1.10 \mathrm{GPa}$ and $1.13 \mathrm{GPa}$ ) as $\beta$ approaches a maximum exceed that of the TGO's yield stress ( $1 \mathrm{GPa})$ and initiate failure.

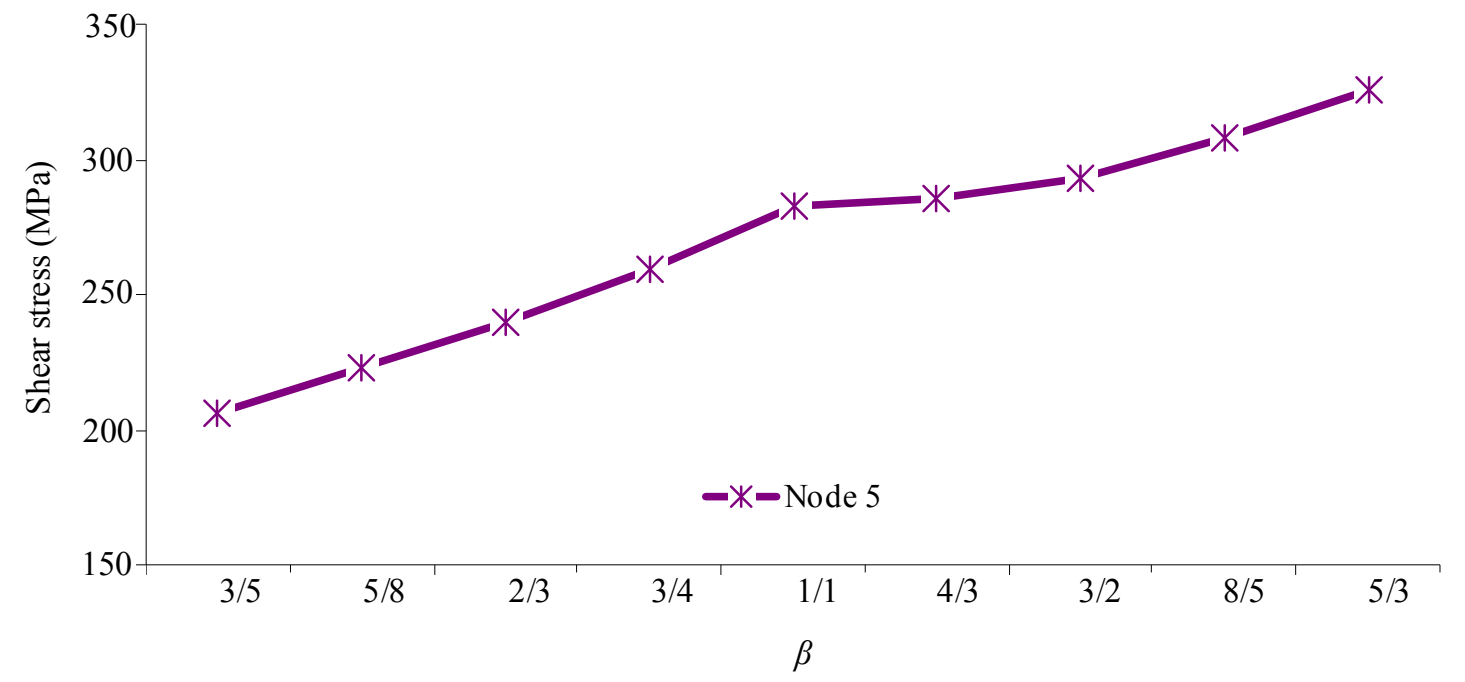

Figure 5-14 Shear stress state along $\beta$.

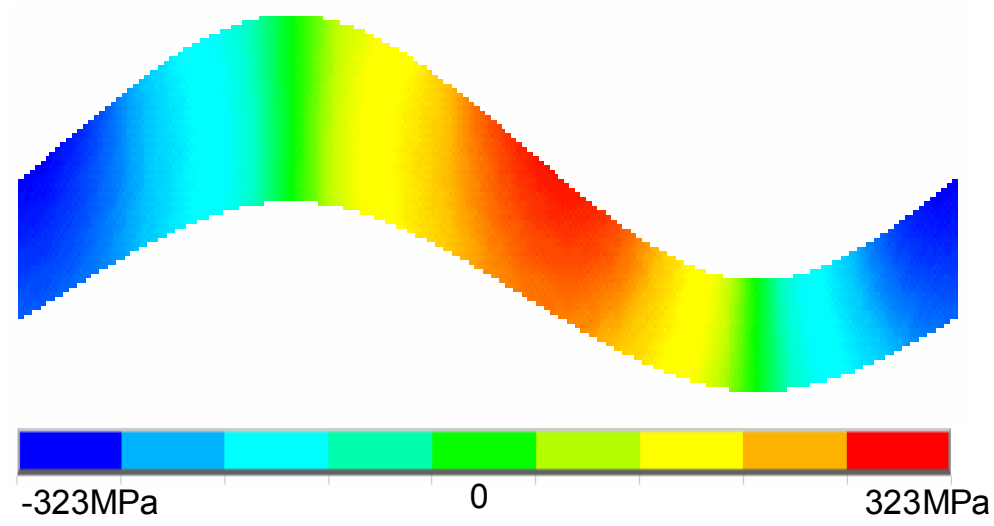

Figure 5-15 Shear stress contour in TGO layer at $\beta=5 / 3$.

From this, a now complete spallation failure pattern becomes evident as $\beta$ exceeds 1. More specifically, as the out-of-plane tensile residual stress at node 2 and 3 increase simultaneously with shear and $\beta$ a crack path of least resistance is generated. Inversely, as $\beta$ approaches zero out-of-plane tensile stresses only occur at locations above and bellow 
the TGO wave apex (nodes 1 and 3 ), and thus are not advantageous for micro-crack propagation. Finally, although micro-cracks at nodes 1, 2 and 3 may exist due to tensile stresses are developing in these regions at various $\beta$, it is not astonishing that large scale spallation failure patterns along either interface are seldom found. The contrasting out-ofplane residual stresses acting at these locations prevent the propagation and coalescence of micro-cracks. As a result, large scale micro-spallation is more likely to follow a failure pattern in which cracks developing at the peak of the TGO/BC interface wave (node 3) extend not along this interface but rather through the TGO wave midline (node 5) followed by an extension into the top coat just above the YSZ/TGO interface wave's base (node 2). The stress states are indicated by schematic drawing about $\beta=5 / 3$, Figure 5-16. This analytic result is comparable to experimental observation, Figure 5-17 [102].

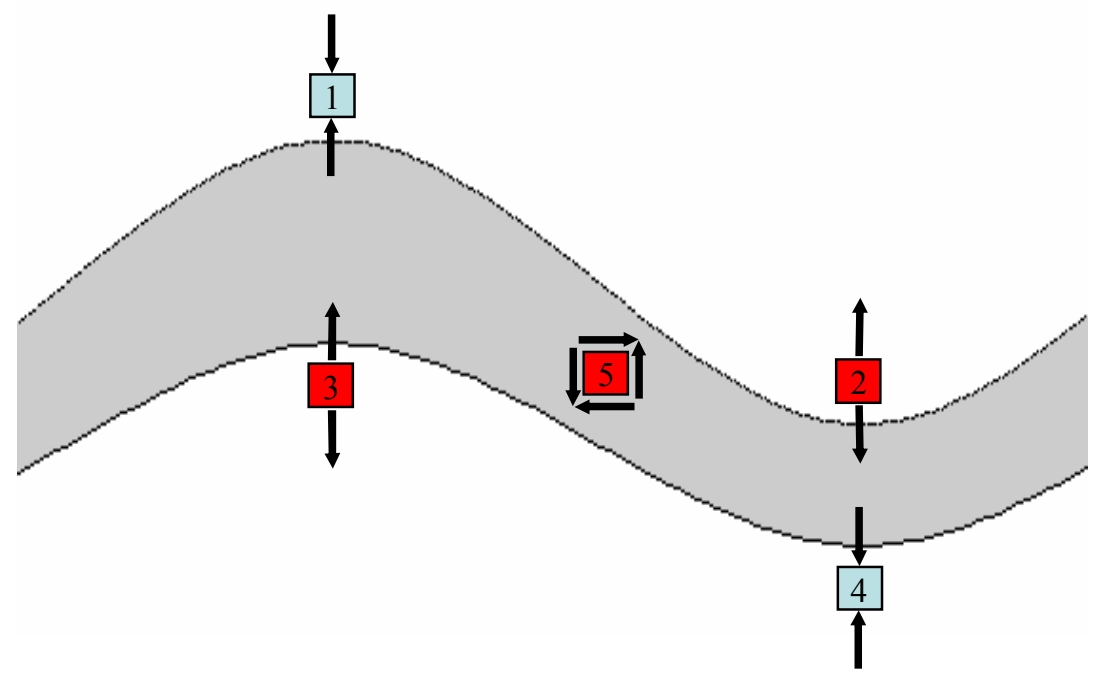

Figure 5-16 Residual stress states in and around TGO at $\beta=5 / 3$.

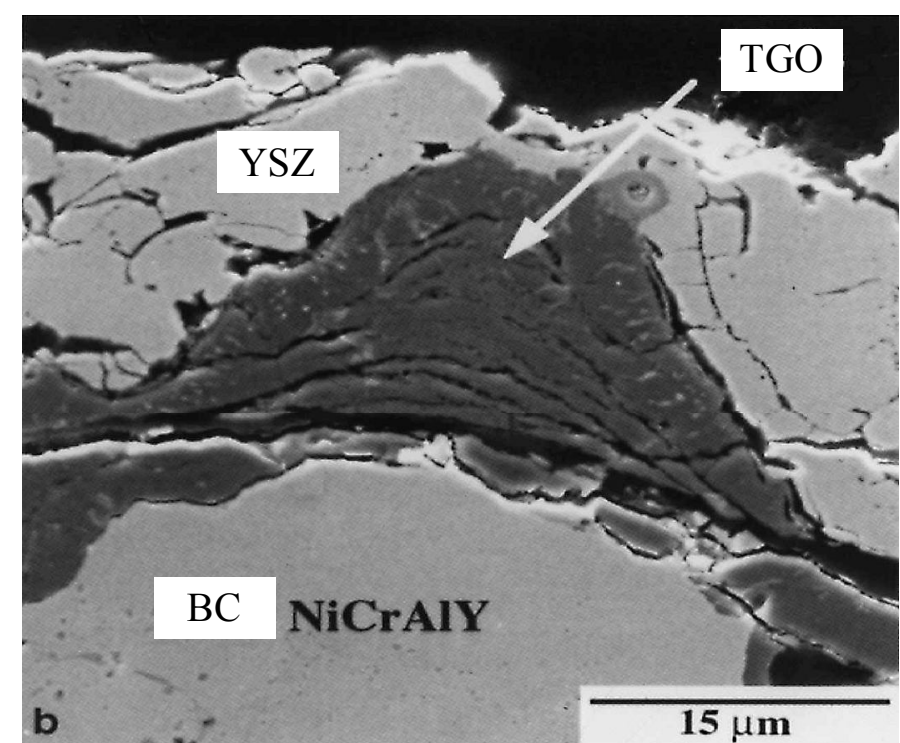

Figure 5-17 Non-uniform TGO growth and interfacial crack path [102]. 
Consequently large scale spallation failure pattern is expected to follow the path node 3 to node 5 and node 2, Figure 5-18. Although this failure pattern has been continually observed, its cause has been attributed to simply TGO thickness; however these results indicate that not only is it a function of TGO thickness but uniformity/geometry as well. In the event that TGO scales with a large $\beta$ develop, the out-of-plane residual stresses responsible for these failure patterns will become present much earlier in the TBC's life cycle and ultimately lead to premature debonding. Experimentally observed micro-cracking and delamination patterns have been analyzed numerically along the variable TGO aspect ratio, $\beta$. The results of this study indicate that the tensile out-of-plane residual stresses acting within the YSZ/TGO/BC interface and responsible for large scale spallation failure emerge prior to the development of sufficiently thick TGO scales as previously thought but rather as $\beta$ exceeds 1 . Crosssectional scanning electron micrographs of thermally cycled APS/MCrAlY/RenéN5 TBC coupons displaying TGO morphologies resembling that of a variable thickness sinusoidal wave were enlisted to develop a finite element TGO model. The interfacial residual stress states at five locations within this model were evaluated as possible crack initiation sites along $\beta$, from this it was determined that large shears stress developing at the TGO wave midline allow cracks generated at the apex of the TGO/BC interface to extend to the YSZ above the sinusoidal wave's base. Although TGO thickness has been shown capable of producing the out-of-plane tensile stresses required to initiate these failure patterns, variable thickness TGO scale geometries will produce such stresses significantly earlier in the TBC system's life cycle.

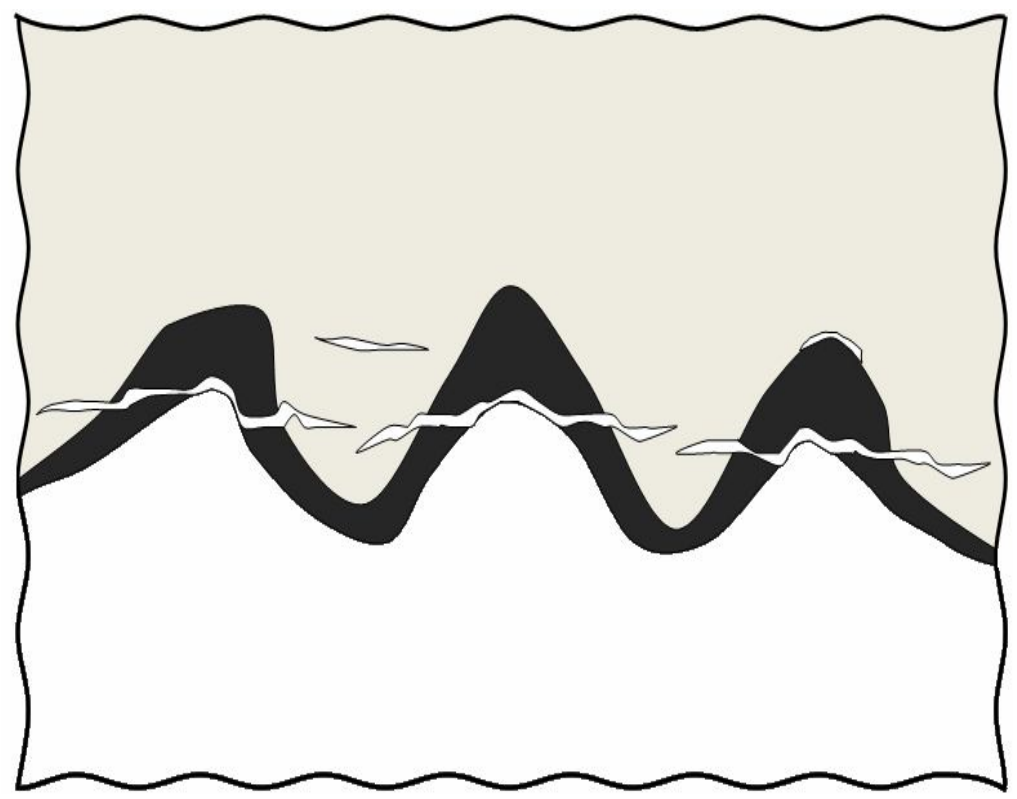

Figure 5-18 Cracking sequence by the stresses due to variable TGO growth. 


\section{Chapter 6 SURFACE STIFFNESS RESPONSE FOR THE PROGRESSION OF FAILURE}

Due to cyclic thermal exposure and TGO scale development, TBCs develop high residual stresses upon cooling. Once a sufficiently thick TGO is formed interface crack growth and is thus considered a two phase failure mechanism, including both incubation (Phase I) and propagation (Phase II) phases. In this research, The variation of indentation unloading surface stiffness response is monitored and reviewed along the progression of TBC failure. The variation of indentation unloading surface stiffness responses is measured by finite element analysis and a load-based multiple partial unloading microindentation procedure is employed. The result shows the possibility that this technique can be used for TBC failure prediction tool.

\subsection{Unloading indentation surface stiffness responses for TBC failure}

In the previous chapter, variable thickness TGO scale is proved to produce significant residual stress directly responsible for the spallation failure. Utilizing experimentally observed micro structural images and numerical results, geometrical spallation failure path is defined. Based on the failure pattern within the TBC system, the progression of failure is defined as a two phase process to represent failure modes. Phase I is the process of the TGO thickening and rumpling. A sufficiently thick TGO with nonuniform aspect ratio is grown, out-of-plane tensile stresses around at the TGO peaks are increased and this tensile stress is the ultimate cause of spallation failure. According to $\mathrm{N}$. P. Padture et al. these common cracking patterns are comparable [67]. Thus at the end of Phase I, micro-cracks located at the peaks of the TGO/BC interface are initiated. Microcrack modeling is introduced in the final developed variable TGO model of phase I. In this manner, phase II is defined as cracking and its propagation. From this, a two phase TBC spallation failure mechanism is proposed. For validation purpose, finite element modeling simulations have been conducted with the inclusion of Phase I and Phase II micro-structural characteristics at $\mathrm{YSZ} / \mathrm{TGO} / \mathrm{BC}$ interfacial region. By simulating a TBC cooling from $1100{ }^{\circ} \mathrm{C}$ to room temperature, this temperature difference is imposed on the model and surface stiffness responses are evaluated along phase I and phase II. Surface stiffness responses are evaluated along with variable TGO evolution and micro-crack propagation. The variation of surface stiffness responses allows experimentally observed failure patterns to be explained analytically. 


\subsubsection{Finite element model for the progression of TBC failure}

In FE modeling, a five FE models which variable TGO thickening and rumpling for phase I are prepared, Figure 6-1 and design parameters are shown in Table 6-1. This variable TGO shape and design parameters are determined by observation of experimental micro structural images, Figure 6-2 [102]. The five FE models mimic the variable TGO thickening evolution subjected to thermal exposure cycles, these finite element models are created in which $\mathrm{TGO}$ amplitudes of $\mathrm{TGO} / \mathrm{BC}$ interface and YSZ/TGO interface are varied and offset as well in FE model. The phase II crack model is inserted at the end of the TGO model in the phase I. Five crack models are made with five cracking steps according to the failure pattern. This crack initiation and propagation path are determined through observation of experimental micro structural images, Figure 6-3 and Figure 6-4 [69,49]. In this numerical analysis, a plane182 element type is used with axisymmetric option in ANSYS ${ }^{\mathrm{TM}} \mathrm{v} 11.0$ and the other boundary conditions and material properties are same with previous analyses. A total of ten FE models were produced, the first five encompassing only TGO rumbling and thickness increases (Phase I) and the second five used to analyze the effects of interface cracking (Phase II). As shown in Figure 6-1, the models developed for this analysis include a more realistic TGO geometry, wherein TGO thicknesses at the peaks of the wave are greater than that of the troughs. Utilizing experimentally observed micro-structural images, this type of interface geometry was developed to more accurately reproduce the true conditions. In Phase I stage, an increasing TGO thickness results in amplification of the indentation based unloading surface stiffness response $(d P / d h)$. Furthermore, the magnitude of such an increase is a function of TGO geometry, thickness and amplitude. At phase II, using the most extreme TGO evolution model developed for Phase I, crack propagation models were created to evaluate the effects of micro-structural cracking on indentation unloading slope with five steps, as shown in Figure 6-5. The progression of cracking is as follows:

a) Debonding at the $\mathrm{TGO} / \mathrm{BC}$ interface peaks.

b) Crack extension along the $\mathrm{TGO} / \mathrm{BC}$ interface approaching the $\mathrm{TGO}$ wave midline.

c) Crack propagation through the TGO at wave midline.

d) Initiation of cracks within the YSZ.

This crack propagation path is consistent through experimentally observed fracture patterns, as shown in Figure 6-4 [49]. Micro crack modeling is created by node overlapping to derive element separation. By simulating TBC cooling, material surface stiffness responses are evaluated using the micro-indentation testing methodology. Insertion of an increasing YSZ modulus function within the finite element analysis is expected to increase variation in surface stiffness response along Phase I. 


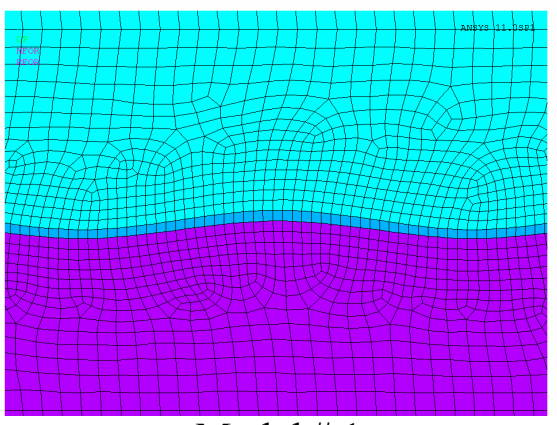

Model \# 1

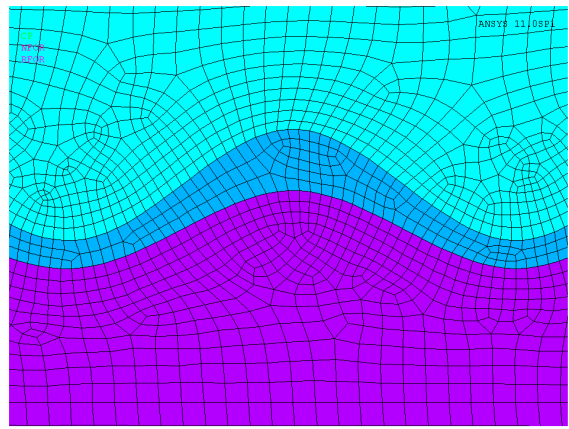

Model \# 3

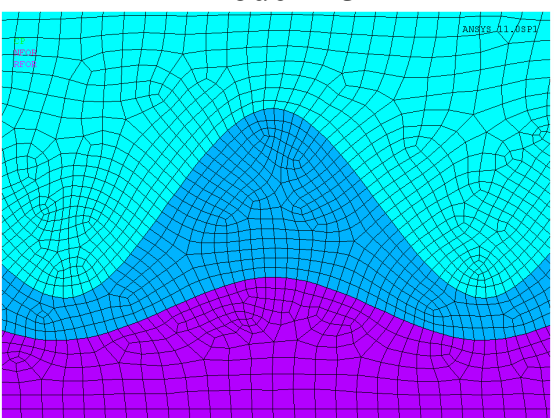

Model \# 5

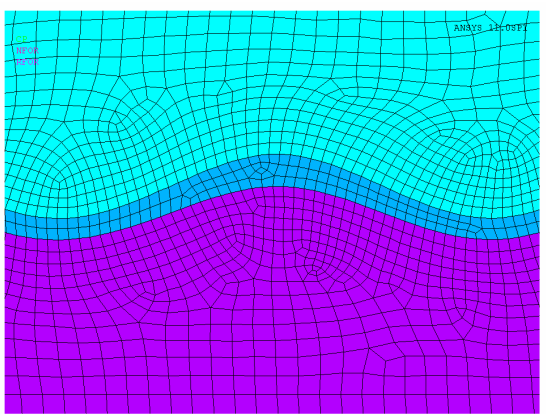

Model \# 2

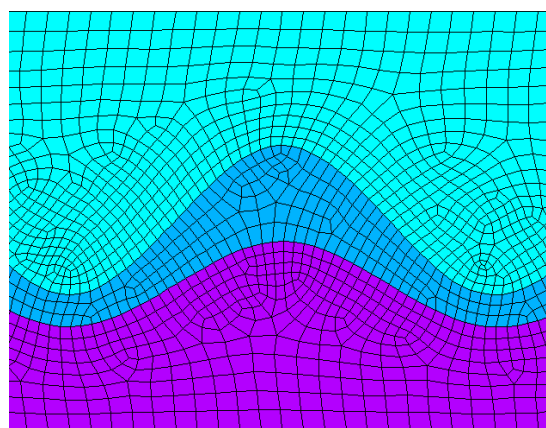

Model \# 4

Figure 6-1 Variable TGO model of phase I and finite element mesh.

Table 6-1 Design parameters for variable TGO evolution.

\begin{tabular}{|c|c|c|c|c|c|}
\hline $\begin{array}{c}\text { Model } \\
\text { Number }\end{array}$ & $\lambda(\mu \mathrm{m})$ & $A_{1}(\mu \mathrm{m})$ & $A_{2}(\mu \mathrm{m})$ & $k(\mu \mathrm{m})$ & $\beta(\mu \mathrm{m} / \mu \mathrm{m})$ \\
\hline 1 & 80 & 0.9 & 1 & 1 & $1.1 / 0.9$ \\
\hline 2 & 80 & 2.5 & 3 & 2.5 & $3 / 2$ \\
\hline 3 & 80 & 3.5 & 5 & 4 & $5.5 / 2.5$ \\
\hline 4 & 80 & 4 & 7 & 6 & $9 / 3$ \\
\hline 5 & 80 & 4 & 9 & 9 & $14 / 4$ \\
\hline
\end{tabular}




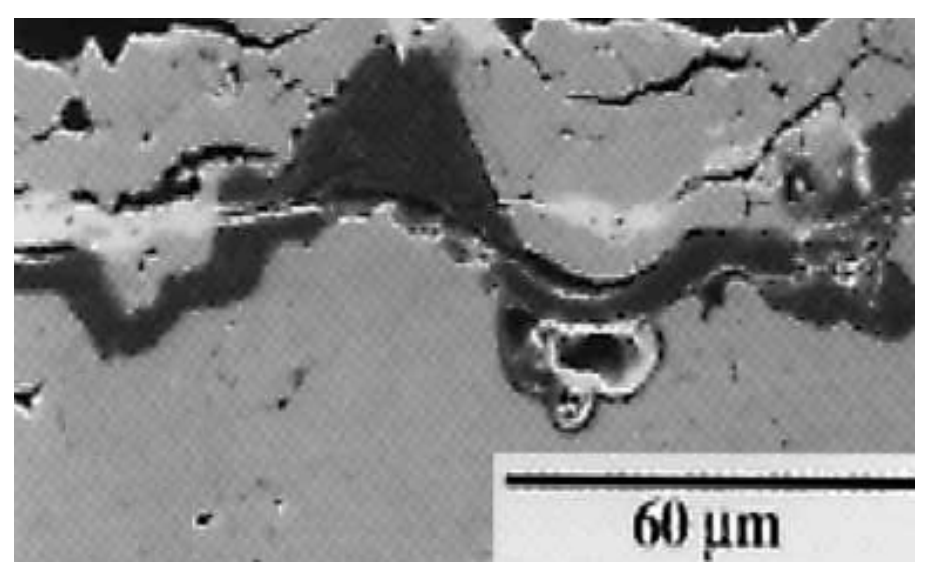

Figure 6-2 TGO micro-structural evolution and micro-cracking pattern [102].

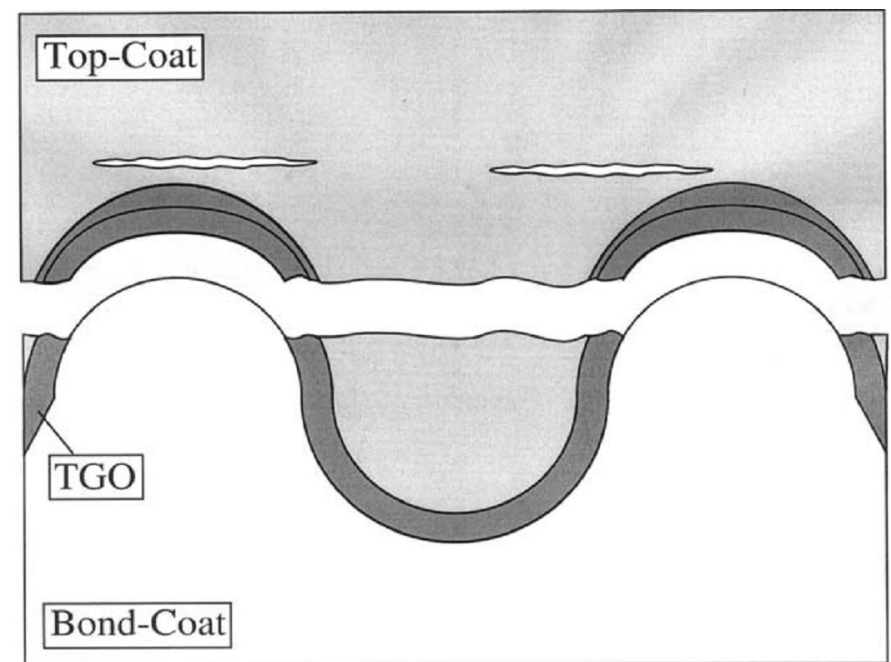

Figure 6-3 Schematic failure modes in TBC [69].

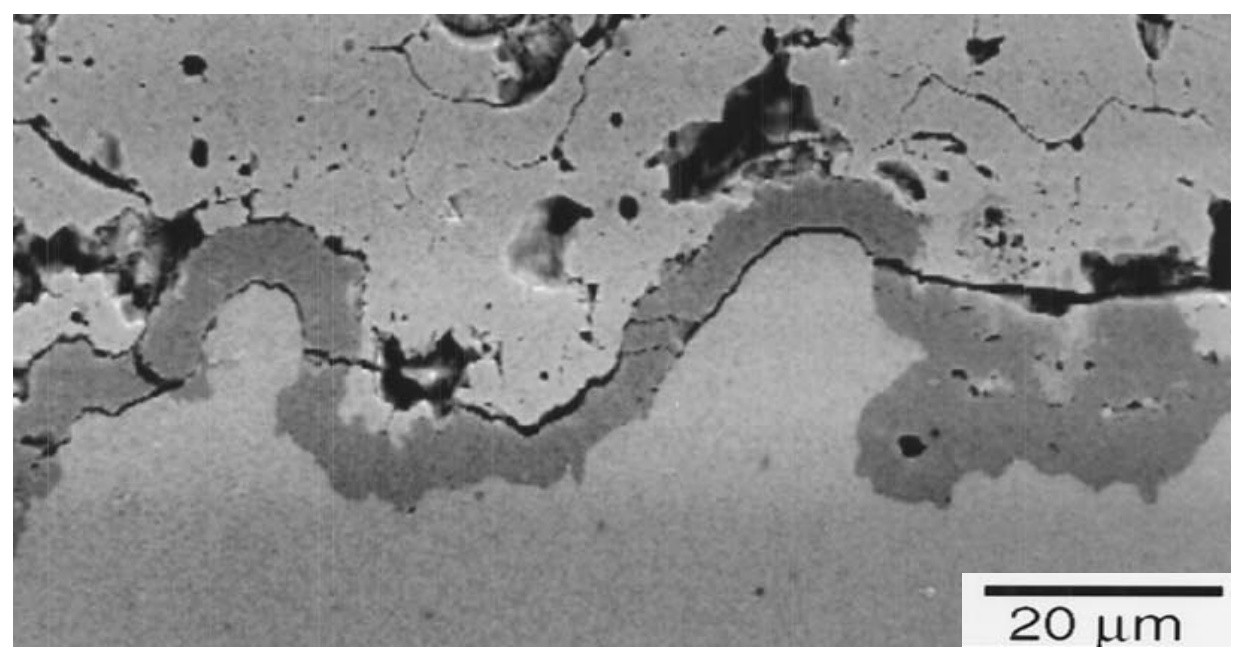

Figure 6-4 APS TBC crack propagation path [49]. 


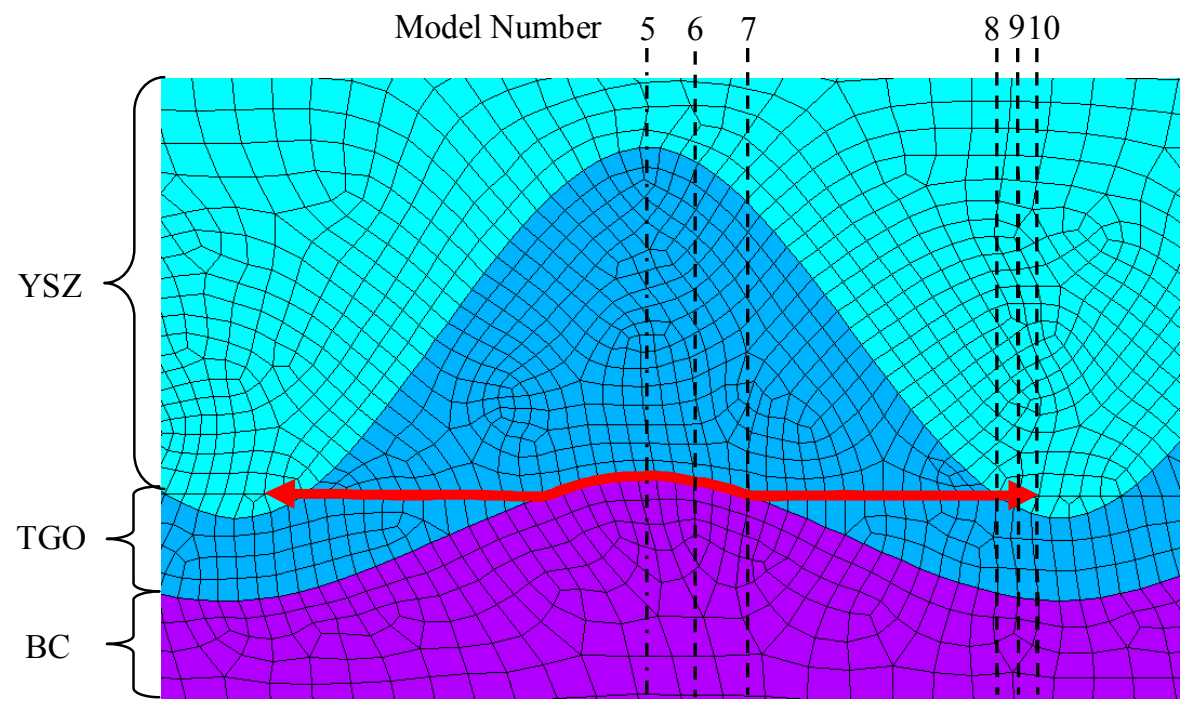

Figure 6-5 Micro-cracking path in FE model.

\subsubsection{Surface stiffness responses for the progression of TBC failure}

As shown in Figure 6-6, the surface stiffness response measurement along TGO variation is shown to little bit increase prior to the initiation of micro-crack and decrease by micro-crack insertion. The accumulation of cracking within the interface is observed to have a profound effect on surface stiffness response. This large reduction in slope is also expected to occur within the experimentally obtained data. In the experiment, surface stiffness response will increase at the early thermal cycle due to the YSZ sintering effects, yet these are not considered in the finite element numerical analysis. However, it is apparent that micro-cracking, TGO rumpling and thickening can clearly be correlated with the measured micro-indentation surface stiffness responses.

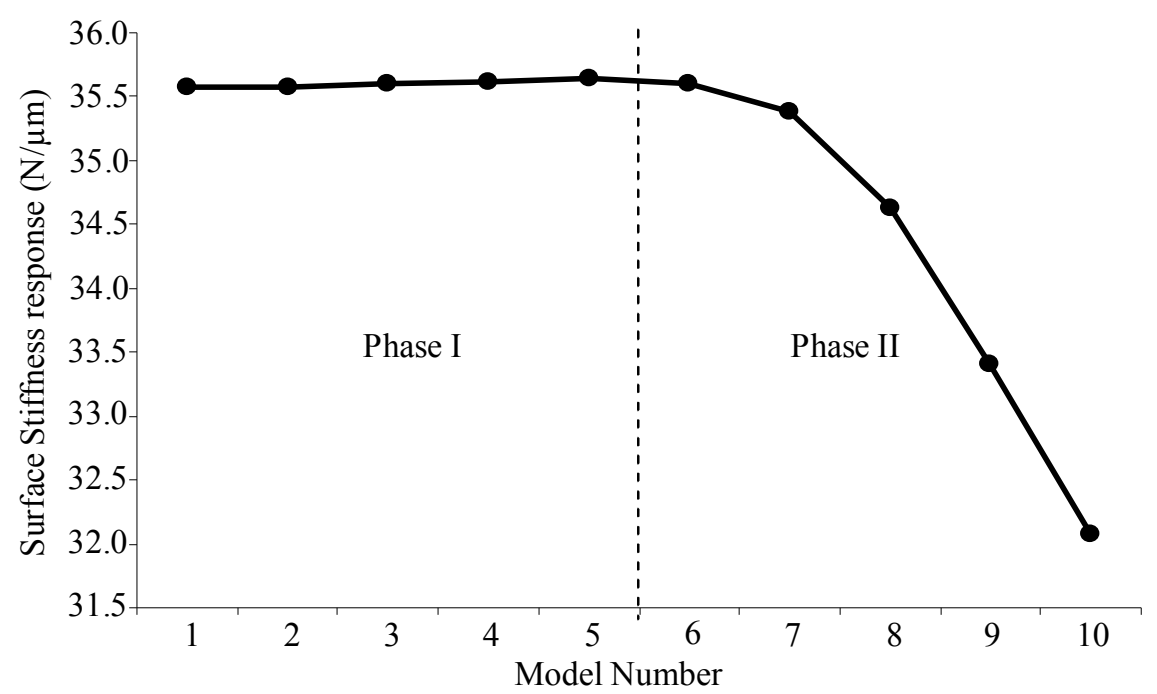

Figure 6-6 Indentation stiffness responses along with spallation failure. 


\section{Chapter 7 CONCLUSION AND FURTHER RESEARCH}

\subsection{Conclusions}

All the presented previous research results have shown that a load-based multiple partial unloading micro-indentation methodology for measurement of surface stiffness response is applied successfully in the TBC systems.

In the micro-indentation technique, a new analytical approach for determining the elastic modulus, yield stress and strain hardening exponent is successfully established through the numerical finite element analyses and experimental validations. This newly developed indentation method is applied to TBC systems. On the other hand, simulating a cooling effect on TBC systems, both the in-plane and out-of-plane residual stresses are found to vary in all layers along the increasing wave amplitude. The in-plane compressive residual stresses occurring within the YSZ steadily increase along wave amplitude and are found to be maximum at the TBC surface in all cases. By applying only the in-plane compressive stresses to the outer surface of the YSZ, the indentation surface stiffness responses increase with TGO wave amplitude. Thus, these findings are stating that a load-based micro-indentation technique is able to measure the variation of residual stresses in TBC systems.

The thermal expansion mismatch occurrence by cooling to ambient temperature drives significant interfacial crack and coalescence spallation failure of TBC systems. The spallation failure is dominated by residual stress and TGO rumpling is related to the development of micro-cracking. By detailed analyses using variety non-uniform TGO growth scales, a complete spallation failure prediction path has been developed. The failure pattern is more likely to follow in which a sufficiently thick TGO layer with increasing rumpling aspect ratio is formed, cracks develop at the peak of the TGO/BC interface wave extend through the TGO midline due to maximum shear stress and link to the just above the YSZ/TGO interface base. This finding leads to a more realistic progression of $\mathrm{TBC}$ spallation failure and also provides an explanation for the experimentally observed spallation patterns. These results indicate that TBC spallation failure is not only a function of TGO thickness but uniformity/geometry as well. The variable TGO scale geometries produce such significant stress formations in and around TGO layer earlier in the TBC system's life cycle.

Finally the surface stiffness responses are evaluated along with variable TGO evolution and micro-crack propagation. The variation of surface stiffness responses allows experimentally observed failure patterns to be explained analytically. The result is found to have a clear trend between the surface stiffness responses and the progression of the spallation failure. The reduction in surface stiffness response is the result of an extension of micro-cracking. The simulated surface stiffness responses have proven that a 
load-base micro-indentation technique is able to be a viable analysis tool for the determination of spallation failure progression.

\subsection{Further research}

Further studies focus on TBS system microstructure analysis along thermal exposure for both isothermally and cyclically exposed. For the studies, the remaining tasks should be considered :

- Verification of the variation of micro-structural stresses along with the thermal cycles.

- Definition of the correlated TBC model through the micro-structural FE analysis.

- Validation of the relationship between the surface stiffness response and the microstructural stress.

\subsubsection{Micro-structural stress analysis}

An idealized numerical model is simulated and used to predict the TBC failure mode. Real residual stress pattern along isothermal cycles is helpful to build a complete theoretical model for the TBC failure mechanism. Modeling of micro structural imaging for the FE analysis has also been utilized by other researchers. This analysis method is known as an object-oriented finite element analysis (OOF). The advantageous point of OOF is that it can be used directly on micro-structural images, Figure 7-1 [53]. OOF is conducted on the actual micro-structure thus actual residual stress of a full field can be reviewed.

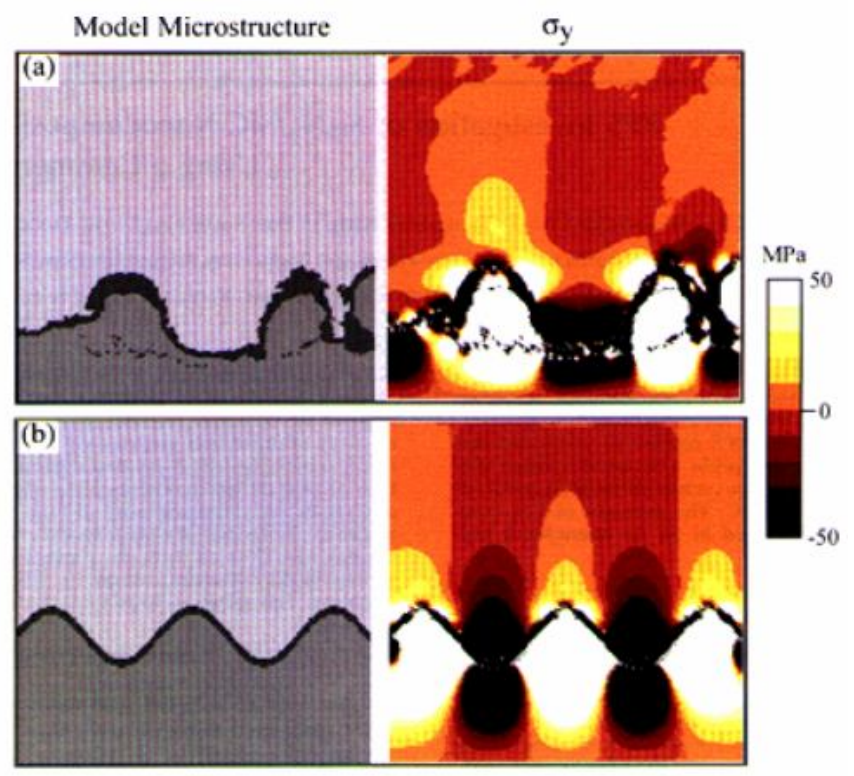

Figure 7-1 Micro-structural model and the calculated residual stress [53]. 
The micro-structural images can be converted to finite element meshes using the object oriented finite element technique, Figure 7-2 and Figure 7-3. The results from microstructural FEA is a real residual stress state in and around TGO layer, Figure 7-4. These results can be used for correlation with the mathematical model.

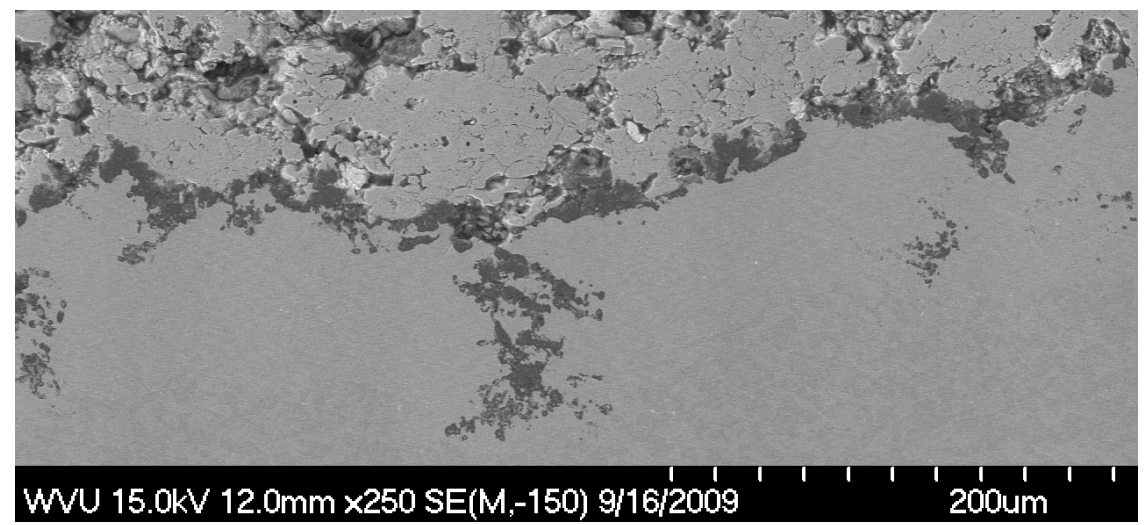

Figure 7-2 Micro-structural image.

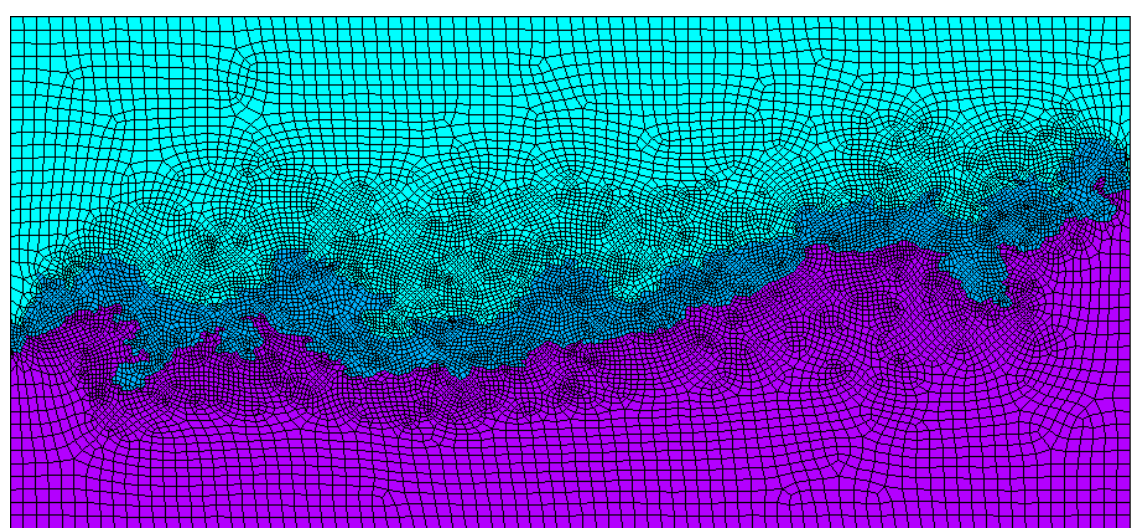

Figure 7-3 Finite element mesh of micro-structure.

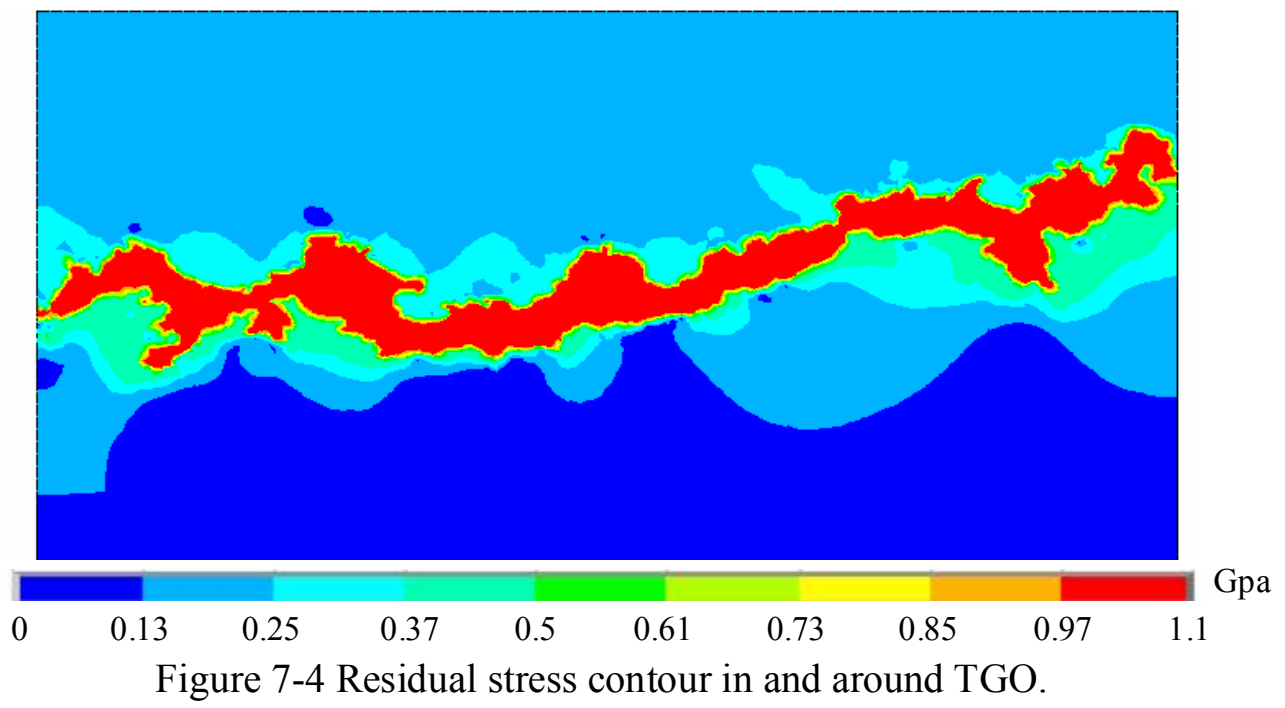




\section{REFERENCES}

1. J. P. Singh, B. Nair, D. Renusch, M. Sutaria and M. Grimsditch, Damage Evolution and Residual Stresses in Plasma-Sprayed Zirconia Thermal Barrier Coatings, Ceramic Engineering and Science, 20, 3 (1999).

2. J. P. Singh, B. G. Nair, D P. Renusch, M. P. Sutaria and M. H. Grimsditch, Damage Evolution and Stress Analysis in Zirconia Thermal Barrier Coatings during Cyclic and Isothermal Oxidation, Journal of the American Ceramic Society, 84, 10 (2001).

3. C. Feng, J.M. Tannenbaum, B.S. Kang, M.A. Alvin, A Load-Based Multiple-Partial Unloading Micro-Indentation Technique for Mechanical Property Evaluation, Society for Experimental Mechanics, Springer Boston (2009).

4. Jared M. Tannenbaum, Non-Destructive Thermal Barrier Coating Spallation Detection by Use of a Spherical Micro-indentation Method, Dissertation, West Virginia University, (2011).

5. H. Hertz, On the contact of elastic solids, J. Reine Angew. Math. 92, 1881, translated and reprinted in English in Hertz's Miscellaneous Papers, Macmillan \& Co., London (1896).

6. Jack A. Collins, Hengy R. Busby and George H. Staab, Mechanical design of machine elements and machines 2 nd ed., John wiley \& sons, (2009)

7. A. C. Fischer-cripps, A review of analysis methods for sub-micron indentation testing, Vacuum, 58, 4 (2000).

8. Brain R. Lawn, Indentation of ceramics with spheres: A century after Herz, J. Am. Ceram. Soc., 81, 1977 (1998).

9. J. S. Field and M.V. Swain, A simple predictive model for spherical indentation, J. Mater. Res., 8, 2 (1993).

10. M. F. Doerner and W.D. Nix, A method for interpreting the data from depth-sensing indentation measurements, J. Mater. Res., 1, 4 (1986).

11. I. N. Sneddon, The relation between load and penetration in the axisymmetric boussinesq problem for a punch of arbitrary profile, Int. J. Eng. Sci. V3, 47, (1965).

12. S. B. Liu, A. Peyronnel, Q.J. Wang and L.M. Keer, An extension of the Hertz theory for three-dimensional coated bodies, Tribology Letters, 18, 3, March (2005).

13. D. N. Jarrett and P.W. McMillan, Hertzian strength measurements of opaque brittle materials, J. Phys. E: Sci. Instrum., 7, 913 (1974).

14. G. M. Pharr, W.C. Oliver and F.R. Brotzen, On the generality of the relationship among contact stiffness, contact area, and elastic modulus during indentation, J. Mater. Res., 7, No. 3, (1992). 
15. W. C. Oliver and G.M. Pharr, An improved technique for determining hardness and elastic modulus using load and displacement sensing indentation experiments, J. Mater. Res., 7, 1564, (1992).

16. F. M. Borodich and L. M. Keer, Evaluation of elastic modulus of materials by adhesive (no-slip) nano-indentation, Proc. R. Soc. Lond. A 460, 507, (2004).

17. J. C. Hay, G.M. Pharr, Experimental investigations of the sneddon solution and an improved solution for the analysis of nanoindentation data, Mater. Res. Soc. Spr. Mtg., 522, 39, (1998)

18. Fischer-Cripps, Nanoindentation 2nd ed., Springer, (2002).

19. Fischer-Cripps, Introduction to contact mechanics 2 nd ed., Springer, (2007).

20. D. J. Strange and A.K. Varshneya, Finite element simulation of microindentation on aluminum, J. Mater. Sci., 36, 1943 (2001).

21. I. S. Choi, M. Dao and S. Suresh, Mechanics of indentation of plastically graded materials - I: Analysis, J. Mech. Phys. Solids, 56, 157 (2008).

22. X. Deng, N. Chawla, K.K. Chawla and M. Koopman, Deformation behavior of $(\mathrm{Cu}$, Ag)-Sn intermetallics by nanoindentation, Acta Mater., 52, 4291 (2004).

23. D. Tabor, The Hardness of Metals, Clarendon Press, Oxford, (1951).

24. B. Taljat, T. Zacharia, New analytical procedure to determine stress-strain curve from spherical indentation data, Int. J. Solids structures, V35, 33, 4411, (1998)

25. H. Bei, Z.P. Lu, E.P. George, Theoretical strength and the onset of plasticity in bulk metallic glasses investigated by nanoindentation with a spherical indenter, Phys. Rev. Lett. 93, 125504 (2004).

26. H. Lee, J.H. Lee, G.M. Pharr, A numerical approach to spherical indentation techniques for material property evaluation, J. Mech. Phys. Solids, 53, 2037 (2005).

27. M. Zhao, N. Ogasawara, N. Chiba, X. Chen, A new approach to measure the elasticplastic properties of bulk materials using spherical indentation, Acta Mater. 54, 23 (2006).

28. S. Basu, A. Moseson, M.W. Barsoum, On the determination of spherical nanoindentation stress-strain curves, J. Mater. Res., V21, 10 (2006)

29. Y. C. Lu, S. Kurapati, F. Yang, Finite element analysis of deep indentation by a spherical indenter, J. Mater. Sci. 43, 6331 (2008)

30. Bharat Bhushan, Contact mechanics of rough surface in tribology: multiple asperity contact, Tribology Letters, 4, 1 (1998).

31. A. Kim and K. Tunvir, Study of Al-alloy foam compressive behavior based on instrumented sharp indentation technology, J. Mech. Sci. Tech. (KSME int. J.), 20, 6 (2006).

32. S. Kucharski, Z. Mroz, Identification of hardening parameters of metals from spherical indentation test, J. Eng. Mater. Tech. 123, 245 (2001).

33. S. Kucharski, Z. Mroz, Identification of material parameters by means of compliance moduli in spherical indentation test, Mater. Sci. Eng., A 379, 448 (2004).

34. Y. J. Park, G.M. Pharr, Nanoindentation with spherical indenters: finite element studies of deformation in the elastic-plastic transition regime, Thin solid films 447-448, 246-250 (2004).

35. Sinisa Dj, Mesarovic, N.A. Fleck, Spherical indentation of elastic-plastic solids, Proc. R. Soc. Lond., A 455, 2707 (1999). 
36. S. Kucharski, Z. Mroz, Identification of yield stress and plastic hardening parameters from a spherical indentation test, Int. J. Mech. Sci. 49, 1238 (2007).

37. D. C. Hurley, K. Shen, N.M. Jennett and J.A. Turner, Atomic force acoustic microscopy methods to determine thin-film elastic properties, J. Appl. Phys. 94.4 (2003).

38. A. Caron, U. Rabe, M. Reinstadtler, J.A. Turner and W. Arnold, Imaging using lateral bending modes of atomic force microscope cantilevers, Appl. Phys. Lett., 85,26 (2004).

39. Shen Xiaojun, Yi sung, Lallit Anand and Zeng Kaiyang, Studies on nano-indentation of polymeric thin film using finite element methods, AMMNS, (2002).

40. B. N. Lucas, J.C. Hay and W.C. Oliver, Using multi-dimensional contact mechanics experiments to measure poisson's ratio of porous low-k films, Mat. Res. Soc. Symp. Proc. Vol. 766, (2003).

41. Michelle L. Oyen, Robert F. Cook, John A. Emerson and Neville R. Moody, Indentation responses of time-dependent films on stiff substrates, J. Mater. Res., Vol. 19, No. 8 (2004).

42. P. L. Gould, Introduction to Linear Elasticity, Second Edition, Springer-Verlag, New York (1994).

43. T. Y. Tsui, W. C. Oliver and G. M. Pharr, Influences of Stress on the Measurement of Mechanical Properties Using Nanoindentation: Part I. Experimental in an Aluminum Alloy, Journal of Materials Research, 11, 3 (1996).

44. J. M. Tannenbaum, B.J. Conklin, B.S.-J. Kang, and M.A. Alvin, Development of a High-temperature Micro-indentation Technique for Material Mechanical Property Evaluation up to $1200^{\circ} \mathrm{C}$, TMS 2010 Annual Meeting \& Exhibition, Seattle, WA (2010).

45. G. W. Goward, Progress in Coatings for Gas Turbine Airfoils, Surface and Coatings Technology, 108-109, 1-3 (1998).

46. S. M. Meier and D.K. Gupta, The Evolution of Thermal Barrier Coatings in Gas Turbine Engine Applications, Journal of Engineering for Gas Turbines and Power, 116, 1 (1994).

47. J. P. Singh, B. Nair, D. Renusch, M. Sutaria and M. Grimsditch, Damage Evolution and Residual Stresses in Plasma-Sprayed Zirconia Thermal Barrier Coatings, Ceramic Engineering and Science Proceedings, 20, 3 (1999).

48. J. P. Singh, B.G. Nair, D.P. Renusch, M.P. Sutaria and M.H. Grimsditch, Damage Evolution and Stress Analysis in Zirconia Thermal Barrier Coatings during Cyclic and Isothermal Oxidation, Journal of the American Ceramic Society, 84, 10 (2001).

49. A. Radiei and A.G. Evans, Failure Mechanisms Associated with the Theramally Grown Oxide in Plasma-Sprayed Thermal Barrier Coatings, Acta Materialia, 48, 15 (2000).

50. L. Lelait, S. Alpérine, R. Mévrel, Alumina Scale Growth at Zirconia-MCrAlY Interfaces: A Microstructural Study, Journal of Materials Science, 27, 1 (1992).

51. A. G. Evans, D. R. Clarke and C. G. Levi, The Influence of Oxides on the Performance of Advanced Gas Turbine, Journal of the European Ceramic Society, 28, 7 (2008). 
52. A. G. Evans, D. R. Mumm, J. W. Hutchinson, G. H. Meier and F. S. Pettit, Mechanisms Controlling the Durability of Thermal Barrier Coatings, Progress in Materials Science, 46, 5 (2001).

53. H. Hsueh, J. A. Haynes, M. J. Lance, P. F. Becher, M. K. Ferber, E. R. Fuller, S. A. Langer, W. C. Carter and W. R. Cannon, Effects of Interface Roughness on Residual Stresses in Thermal Barrier Coatings, Journal of the American Ceramic Society, 82, 4 (1999).

54. V. K. Tolpygo and D. R. Clarke, On the Rumpling Mechanism in Nickel-Aluminide Coatings Part I: An Experimental Assessment, Acta Materialia, 52, 17 (2004).

55. V. K. Tolpygo and D. R. Clarke, On the Rumpling Mechanism in Nickel-Aluminide Coatings Part II: Characterization of Surface Undulations and Bond Coat Swelling, Acta Materialia, 52, 17 (2004).

56. V. K. Tolpygo and D. R. Clarke, Rumpling Induced by Thermal Cycling of an Overlay Coating: The Effect of Coating Thickness, Acta Materialia, 52,3 (2004).

57. D. S. Balint and J. W. Hutchinson, An Analytical Model of Rumpling in Thermal Barrier Coatings, Journal of the Mechanics and Physics of Solids, 53, 4 (2005).

58. D. S. Balint, T. Xu, J. W. Hutchinson and A. G. Evans, Influence of bond coat thickness on the cyclic rumpling of thermally grown oxides, Acta Mater. 54, 1815 (2006).

59. J. A. Nychka, T. Xu, D. R. Clarke and A. G. Evans, The Stresses and Distortions Caused by Formation of a Thermally Grown Alumina: Comparison Between Measurements and Simulations, Acta Materialia, 52, 9 (2004).

60. W. Davis and A. G. Evans, Some Effects of Imperfection Geometry on the Cyclic Distortion of Thermally Grown Oxides, Oxidation of Metals, 65, 1-2 (2006).

61. A. M. Karlsson and A. G. Evans, A numerical model for the cyclic instability of thermally grown oxides in thermal barrier systems, Acta Mater., 49, 1793 (2001).

62. A. M. Karlsson, T. Xu and A.G. Evans, The effect of the thermal barrier coating on the displacement instability in thermal barrier systems, Acta Mater., 50, 1211 (2002).

63. A. M. Karlsson, J. W. Hutchinson and A. G. Evans, A fundamental model of cyclic instabilities in thermal barrier systems, J. Mech. Phys. Solids, 50, 1565 (2002).

64. P. K. Wright and A. G. Evans, Mechanisms Governing the Performance of Thermal Barrier Coatings, Current Opinion in Solid State and Materials Science, 4, 3 (1999).

65. S. R. Choi, J. W. Hutchinson and A.G. Evans, Delamination of Multilayer Thermal Barrier Coatings, Mechanics of Materials, 31, 7 (1999).

66. E. Tzimas, H. Mullejans, S. D. Peteves, J. Bressers and W. Stamm, Failure of Thermal Barrier Coating Systems Under Cyclic Thermomechanical Loading, Acta Materialia, 48, 18-19 (2000).

67. N. P. Padture, M. Gell and E. H. Jordan, Thermal Barrier Coatings for Gas-Turbine Engine Applications, Science, 296, 5566 (2002).

68. K. W. Schlichting, K. Vaidyanathan, Y. H. Sohn, E. H. Jordan, M. Gell and N. P. Padture, Application of $\mathrm{Cr}^{3+}$ Photoluminescence Piezo-Spectroscopy to PlasmaSprayed Thermal Barrier Coatings for Residual Stress Measurement, Materials Science and Engineering: A, 291, 1-2 (2000). 
69. K. W. Schlichting, N. P. Padture, E. H. Jordan and M. Gell, Failure Modes in Plasma-Sprayed Thermal Barrier Coatings, Materials Science and Engineering: A, 342, 1-2 (2003).

70. Y. H. Sohn, K. Vaidyanathan, M. Ronski, E. H. Jordan and M. Gell, Thermal Cycling of EB-PVD/MCrAlY Thermal Barrier Coatings: II. Evolution of Photo-Stimulated Luminescence, Surface and Coatings Technology, 146-147 (2001).

71. Y. H. Sohn, E. Y. Lee, B. A. Nagaraj, R. R. Biederman and R. D. Sisson, Microstructural Characterization of Thermal Barrier Coatings on High Pressure Turbine Blades, Surface and Coatings Technology, 146-147 (2001).

72. A. Portinha, V. Teixeria, J. Carneiro, M. G. Beghi, C. E. Bottani, N. Franco, R. Vassen, D. Stoever and A. D. Sequeira, Residual Stresses and Elastic Modulus of Thermal Barrier Coatings Graded in Porosity, Surface and Coatings Technology, 188-189 (2004).

73. D. W. Jordan and K. T. Faber, X-Ray Residual Stress Analysis of a Ceramic Thermal Barrier Coating Undergoing Thermal Cycling, Thin Film Solids, 235, 1-2 (1993).

74. T. S. Hille, A. S. J. Suiker and S. Turteltaub, Microcrack nucleation in thermal barrier coating systems, Eng. Fract. Mech., 76, 813 (2009).

75. T. S. Hille, T. J. Nijdam, A. S. J. Suiker, S. Turteltaub and W. G. Sloof, Damage growth triggered by interface irregularities in thermal barrier coatings, Acta Mater., 57, 2624 (2009).

76. Aditad Vasinonta and Jack L. Beuth, Measurement of interfacial toughness in thermal barrier coating systems by indentation, Eng. Fract. Mech., 68, 843 (2001).

77. M. J. Stinger, G. H. Meier, F. S. Pettit, Q. Ma, J. L. Beuth and M. J. Lance, Accelerated cyclic oxidation testing protocols for thermal barrier coatings and alumina-forming alloys and coatings, Mater. Corrosion, 57, No. 1, (2006).

78. T. W. Clyne and S. C. Gill, Residual Stresses in Thermal Spray Coatings and Their Effect on Interfacial Adhesion: A Review of Recent Work, Journal of Thermal Spray Technology, 5, 4 (1996).

79. X. Chen, J. W. Hutchinson, M. Y. He and A. G. Evans, On the Propagation and Coalescence of Delamination Cracks in Compressed Coatings: With Application to Thermal Barrier Systems, Acta Materialia, 51, 7 (2003).

80. J. Rösler, M. Bäker and K. Aufzug, A Parametric Study of the Stress State of Thermal Barrier Coatings, Part I: Creep Relaxation, Acta Materialia, 52, 16 (2004).

81. J. Rösler, M. Bäker and M. Volgmann, Stress State and Failure Mechanisms of Thermal Barrier Coatings: Role of Creep in Thermally Grown Oxide, Acta Materialia, 49, 18 (2001).

82. M. Martena, D. Botto, P. Fino, S. Sabbadini, M. M. Gola and C. Badini, Modeling of TBC System Failure: Stress Distribution as a Function of TGO Thickness and Thermal Expansion Mismatch, Engineering Failure Analysis, 13, 3 (2006).

83. F. Tang and J. M. Schoenung, Local Accumulation of Thermally Grown Oxide in Plasma-Sprayed Thermal Barrier Coatings with Rough Top-Coat/Bond-Coat Interfaces, Scripta Materialia, 52, 9 (2005).

84. Himanshu Bhatnagar, somnath Ghosh and Mark E. Walter, Parametric studies of failure mechanisms in elastic EB-PVD thermal barrier coatings using FEM, Int. J. sol. and struc. 43 (2006). 
85. M.Y. Ali, S. Q. Nusier and G. M. Newaz, Mechanics of damage initiation and growth in a TBC/superalloy system, Int. J. Sol. Str., 38, 3329 (2001).

86. M.Y. Ali, X. Chen and G. M. Newaz, Oxide layer development under thermal cycling and its role on damage evolution and spallation in TBC system, J. Mater. Sci., 36, 4535 (2001).

87. M.Y. Ali, S. Q. Nusier and G. M. Newaz, Creep effects on early damage initiation in a TBC system, J. Mater. Sci., 39, 3383 (2004).

88. Jun Ding, Feng-Xun Li and Ki-Ju Kang, Numerical simulation of displacement instabilities of surface grooves on an alumina forming alloy during thermal cylcling oxidation, J. Mech. Sci. Tech., 23, 2308 (2009).

89. M. Y. He, J. W. Hutchinson and A. G. Evans, Large deformation simulations of cyclic displacement instabilities in thermal barrier systems, Acta Mater., 50 (2002).

90. A. Bolshakov, W. C. Oliver and G.M. Pharr, Influence of stress on the measurement of mechanical properties using nanoindentation: part II. Finite element simulations, J. of Mater. Res., Vol. 11, No. 3, Mar 1996.

91. A. Bolshakov, W. C. Oliver, Influence of pileup on the measurement of mechanical properties by load and depth sensing indentation technique, J. Mater. Res., Vol. 13, No. 4, Apr (1998).

92. S. Suresh and A. E. Giannakopoulos, A new method for estimating residual stresses by instrumented sharp indentation, Acta Mater. Vol. 46, No. 16, (1998).

93. M. Ohki, T. Ishibashi, J. Kinoshita and H. Uchiyama, Application of indentation test to the evaluation of TBC young's modulus, HARDMEKO 2007, Rec. Adv. Theor. Prac. Hard. Meas., 19, (2007).

94. B. X. Xu, B. Zhao and Z. F. Yue, Investigation of residual stress by the indentation method with the flat cylindrical indenter, J. Mater. Eng. Perfor., 15(3), (2006).

95. S. Carlsson and P. -L. Larsson, On the determination of residual stress and strain fields by sharp indentation testing. Part I: Theoretical and numerical analysis, Acta Mater. 49, 2179 (2001).

96. S. Carlsson and P. -L. Larsson, On the determination of residual stress and strain fields by sharp indentation testing. Part II: Experimental investigation, Acta Mater. 49, 2193 (2001).

97. P. Niranatlumpong, C. B. Ponton and H. E. Evans, The Failure of Protective Oxides on Plasma-Sprayed NiCrAlY Overlay Coatings, Oxidation of Metals, 53, 3-4 (2000).

98. E. P. Busso, L. Wright, H. E. Evans, L. N. McCartney, S. R. J. Saunders, S. Osgerby and J. Nunn, A Physics-Based Life Prediction Methodology for Thermal Barrier Coating Systems, Acta Materialia, 55, 5 (2007).

99. J. T. DeMasi, K. D. Sheffler and M. Ortiz, Thermal Barrier Coating Life Predication Model Development: Phase I-Final Report, National Aeronautics and Space Administration, Contractor Report, 182230 (1989).

100. S. M. Meier, D. M. Nissley and K. D. Sheffler, Thermal Barrier Coating Life Predication Model Development: Phase II-Final Report, National Aeronautics and Space Administration, Contractor Report, 189111 (1991).

101. A. G. Evans, G. B. Crumley and R. E. Demaray, On the Mechanical Behavior of Brittle Coatings and Layers, Oxidation of Metals, 20, 5-6 (1983). 
102. J. A. Haynes, M. K. Ferber, W. D. Porter and E. D. Rigney, Characterization of Alumina Scales Formed During Isothermal and Cyclic Oxidation of PlasmaSprayed TBC Systems at $1150^{\circ} \mathrm{C}$, Oxidation of Metals, 52, 1-2 (1999).

103. P. Bednarz, R. Herzog, E. Trunova, R. W. Steinbrech, H. Eschler, W. J. Quaddakers, F. Schubert and L. Singheiser, Stress Distribution in APS-TBCs Under Thermal Cycling Loading Conditions, 29th International Conference on Advanced Ceramics and Composites, January 23-28, Cocoa Beach, Florida (2005).

104. D. Naumenko, V. Shemet, L. Singheiser and W. J. Quadakkers, Failure Mechanisms of Thermal Barrier Coatings on MCrAlY-Type Bondcoats Associated with the Formation of the Thermally Grown Oxide, Journal of Materials Science, 44, 7 (2009).

105. O. Trunova, T. Beck. R. Herzog, R. W. Steinbrech and L. Singheiser, Damage Mechanisms and Lifetime Behavior of Plasma Sprayed Thermal Barrier Coating Systems for Gas Turbines - Part I: Experiments, Surface Coatings and Technology, 202, 20 (2008).

106. T. Beck. R. Herzog, O. Trunova, M. Offermann, R. W. Steinbrech and L. Singheiser, Damage Mechanisms and Lifetime Behavior of Plasma Sprayed Thermal Barrier Coating Systems for Gas Turbines - Part II: Modeling, Surface Coatings and Technology, 202, 24 (2008).

107. H. Echsler, D. Renusch and M. Schütze, Bond Coat Oxidation and its Significance to for Life Expectancy of Thermal barrier Coating Systems, Materials Science and Technology, 20, 3 (2004).

108. P. Bednarz, Finite Element Simulation of Stress Evolution in Thermal Barrier Coating Systems, Dissertation, Schriften des Forschungszentrums Jülich, Energy Technology (2007).

109. R. Vaßen, G. Kerkhoff and D. Stöver, Development of a Micromechanical Life Prediction Model for Plasma Sprayed Thermal Barrier Coatings, Material Science and Engineering: A, 303, 1-2 (2001).

110. W. -F. Chen and D. -J. Han, Plasticity for Structural Engineers, Springer-Verlag, New York, New York (1988).

111. A. M. Karlsson, J. W. Hutchinson and A. G. Evans, A Fundamental Model of Cyclic Instabilities in Thermal Barrier Systems, Journal of the Mechanics and Physics of Solids, 50, 8 (2002). 